\title{
Reactions of an Arylrhodium Complex with Aldehydes, Imines, Ketones and Alkynones. New Classes of Insertion Reactions
}

Christopher Krug and John F. Hartwig*

Department of Chemistry, Yale University, PO Box 208107, New Haven, CT 06520-8107

\section{Supporting Information}

\section{Table of Contents}

Table S1. Crystal Data and Crystallographic Data Collection Parameters for 2a, 4, 6, 9 and 26.

Experimental Procedure for the X-ray Diffraction of 2a

Table S2. Crystal data and structure refinement for $\mathbf{2 a}$.

Table S3. Atomic coordinates ( $\mathrm{x} 10^{4}$ ) and equivalent isotropic displacement parameters $\left(\AA^{2} \times 10^{3}\right)$ for $\mathbf{2 a}$.

Table S4. Bond lengths $[\AA]$ and angles $\left[{ }^{\circ}\right]$ for $2 \mathbf{2 a}$.

S7

Table S5. Anisotropic displacement parameters $\left(\AA^{2} \times 10^{3}\right)$ for $\mathbf{2 a}$.

Table S6. Hydrogen coordinates (x $10^{4}$ ) and isotropic displacement parameters $\left(\AA^{2} \times 10^{3}\right)$ for $\mathbf{2 a}$.

Experimental Procedure for the X-ray Diffraction of 4.

Table S7. Crystal data and structure refinement for 4.

Table S8. Atomic coordinates ( $\mathrm{x} 10^{4}$ ) and equivalent isotropic displacement parameters $\left(\AA^{2} \times 10^{3}\right)$ for 4 .

Table S9. Bond lengths $[\AA]$ and angles $\left[{ }^{\circ}\right]$ for 4.

Table S10. Anisotropic displacement parameters $\left(\AA^{2} \times 10^{3}\right)$ for 4 .

Table S11. Hydrogen coordinates $\left(\mathrm{x}_{10^{4}}\right.$ ) and isotropic displacement parameters $\left(\AA^{2} \times 10^{3}\right)$ for 4.

Experimental Procedure for the X-ray Diffraction of $\mathbf{6}$.

Table S12. Crystal data and structure refinement for 6 .

Table S13. Atomic coordinates ( $\mathrm{x} 10^{4}$ ) and equivalent isotropic displacement parameters $\left(\AA^{2} \times 10^{3}\right)$ for 6 .

Table S14. Bond lengths $[\AA]$ and angles $\left[{ }^{\circ}\right]$ for 6 .

Table S15. Anisotropic displacement parameters $\left(\AA^{2} \times 10^{3}\right)$ for 6 .

Table S16. Hydrogen coordinates $\left(x 0^{4}\right)$ and isotropic displacement parameters $\left(\AA^{2} \times 10^{3}\right)$ for 6.

Experimental Procedure for the X-ray Diffraction of 9.

Table S17. Crystal data and structure refinement for 9.

Table S18. Atomic coordinates ( $\mathrm{x} 10^{4}$ ) and equivalent isotropic displacement parameters $\left(\AA^{2} \times 10^{3}\right)$ for 9 .

Table S19. Bond lengths $[\AA]$ and angles $\left[{ }^{\circ}\right]$ for 9 . 
Table S20. Anisotropic displacement parameters $\left(\AA^{2} \times 10^{3}\right)$ for $9 . \quad$ S52

Table S21. Hydrogen coordinates (x 104) and isotropic displacement parameters S54 $\left(\AA^{2} \times 10^{3}\right)$ for 9 .

Experimental Procedure for the X-ray Diffraction of $\mathbf{2 6 .}$

Table S22. Crystal data and structure refinement for 26.

Table S23. Atomic coordinates ( $\mathrm{x} 10^{4}$ ) and equivalent isotropic displacement parameters $\left(\AA^{2} \times 10^{3}\right)$ for $\mathbf{2 6}$.

Table S24. Bond lengths $[\AA]$ and angles $\left[{ }^{\circ}\right]$ for 26.

S61

Table S25. Anisotropic displacement parameters $\left(\AA^{2} \times 10^{3}\right)$ for 26.

Table S26. Hydrogen coordinates (x 104) and isotropic displacement parameters $\left(\AA^{2} \times 10^{3}\right)$ for 26. 


\begin{tabular}{|c|c|c|c|c|c|}
\hline $\begin{array}{l}\text { Empirical } \\
\text { formula }\end{array}$ & $\begin{array}{l}\mathrm{C}_{38} \mathrm{H}_{36} \mathrm{~N} \mathrm{P}_{2} \mathrm{Rh} \\
(\mathbf{2 a})\end{array}$ & $\begin{array}{l}\mathrm{C}_{61} \mathrm{H}_{59} \mathrm{~N}_{2} \mathrm{O}_{2} \mathrm{P}_{2} \\
\mathrm{Rh}(\mathbf{4})\end{array}$ & $\begin{array}{l}\mathrm{C}_{60} \mathrm{H}_{74} \mathrm{~N} \mathrm{O}_{3.50} \\
\mathrm{P}_{3} \mathrm{Rh}(\mathbf{6})\end{array}$ & $\begin{array}{l}\mathrm{C}_{48} \mathrm{H}_{44} \mathrm{~N} \mathrm{O} \mathrm{P}_{2} \\
\mathrm{Rh}(\mathbf{9})\end{array}$ & $\begin{array}{l}\mathrm{C}_{50} \mathrm{H}_{53} \mathrm{O}_{2} \mathrm{P}_{2} \mathrm{Rh} \\
\text { (26) }\end{array}$ \\
\hline Formula weight & 671.53 & 1016.95 & 1061.02 & 815.69 & 850.77 \\
\hline Temperature & $150(2) \mathrm{K}$ & $173(2) \mathrm{K}$ & $183(2) \mathrm{K}$ & $173(2) \mathrm{K}$ & $173(2) \mathrm{K}$ \\
\hline Wavelength & $0.71073 \AA$ & $0.71073 \AA$ & $0.71073 \AA$ & $0.71073 \AA$ & $0.71073 \AA$ \\
\hline Crystal system & Triclinic & Monoclinic & Monoclinic & Monoclinic & Monoclinic \\
\hline Space group & $\mathrm{P}-1$ & $\mathrm{P} 2(1) / \mathrm{c}$ & $\mathrm{P} 2(1) / \mathrm{n}$ & $\mathrm{C} 2 / \mathrm{c}$ & $\mathrm{I} 2 / \mathrm{a}$ \\
\hline Unit cell & $\mathrm{a}=11.1280(18) \AA$ & $\mathrm{a}=20.443(4) \AA$ & $\mathrm{a}=12.122(2) \AA$ & $a=14.720(3) \AA$ & $\mathrm{a}=20.919(4) \AA$ \\
\hline dimensions & $\mathrm{b}=11.1646(18) \AA$ & $\mathrm{b}=13.454(3) \AA$ & $\mathrm{b}=19.864(4) \AA$ & $\mathrm{b}=29.946(6) \AA$ & $\mathrm{b}=10.106(2) \AA$ \\
\hline & $\mathrm{c}=13.098(2) \AA$ & $c=20.069(4) \AA$ & $c=22.607(5) \AA$ & $\mathrm{c}=18.379(4) \AA$ & $\mathrm{c}=40.156(8) \AA$ \\
\hline & $\gamma=80.620(3)^{\circ}$ & $\gamma=90^{\circ}$ & $\gamma=90^{\circ}$ & $\gamma=90^{\circ}$ & $\gamma=90^{\circ}$ \\
\hline Volume & $1593.3(4) \AA^{3}$ & $5176.4(18) \AA^{3}$ & $5443.0(19) \AA^{3}$ & $8010(3) \AA^{3}$ & $8426(3) \AA^{3}$ \\
\hline $\mathrm{Z}$ & 2 & 4 & 4 & 8 & 8 \\
\hline $\begin{array}{l}\text { Density } \\
\text { (calculated) }\end{array}$ & $1.400 \mathrm{~g} / \mathrm{cm}^{3}$ & $1.305 \mathrm{~g} / \mathrm{cm}^{3}$ & $1.295 \mathrm{~g} / \mathrm{cm}^{3}$ & $1.353 \mathrm{~g} / \mathrm{cm}^{3}$ & $1.341 \mathrm{~g} / \mathrm{cm}^{3}$ \\
\hline $\begin{array}{l}\text { Absorption } \\
\text { coefficient }\end{array}$ & $0.664 \mathrm{~mm}^{-1}$ & $4.37 \mathrm{~cm}^{-1}$ & $4.48 \mathrm{~cm}^{-1}$ & $5.43 \mathrm{~cm}^{-1}$ & $5.21 \mathrm{~cm}^{-1}$ \\
\hline$F(000)$ & 692 & 2120 & 2236 & 3376 & 3552 \\
\hline \multirow[t]{2}{*}{ Crystal size } & $0.15 \times 0.10 \times$ & $0.25 \times 0.25 \times$ & $0.20 \times 0.20 \times$ & $0.35 \times 0.10 \times$ & $0.25 \times 0.10 \times$ \\
\hline & $0.08 \mathrm{~mm}^{3}$ & $0.25 \mathrm{~mm}^{3}$ & $0.20 \mathrm{~mm}^{3}$ & $0.08 \mathrm{~mm}^{3}$ & $0.08 \mathrm{~mm}^{3}$ \\
\hline $\begin{array}{l}\text { Theta range for } \\
\text { data collection }\end{array}$ & 1.86 to $28.26^{\circ}$ & 2.32 to $28.34^{\circ}$ & 2.65 to $27.90^{\circ}$ & 2.47 to $28.32^{\circ}$ & 2.41 to $28.31^{\circ}$ \\
\hline $\begin{array}{l}\text { Reflections } \\
\text { collected }\end{array}$ & 18538 & 19766 & 20683 & 17301 & 19140 \\
\hline $\begin{array}{l}\text { Independent } \\
\text { reflections }\end{array}$ & $\begin{array}{l}7376[\mathrm{R}(\mathrm{int})= \\
0.0420]\end{array}$ & $\begin{array}{l}12809[\mathrm{R}(\mathrm{int})= \\
0.0471]\end{array}$ & $\begin{array}{l}12640[\mathrm{R}(\mathrm{int})= \\
0.0634]\end{array}$ & $\begin{array}{l}9923[\mathrm{R}(\mathrm{int})= \\
0.0798]\end{array}$ & $\begin{array}{l}10339[\mathrm{R}(\text { int })= \\
0.0516]\end{array}$ \\
\hline $\begin{array}{l}\text { Completeness to } \\
\text { theta }=28.26^{\circ}\end{array}$ & $93.6 \%$ & $99.1 \%$ & $97.2 \%$ & $99.3 \%$ & $98.6 \%$ \\
\hline $\begin{array}{l}\text { Goodness-of-fit } \\
\text { on } \mathrm{F}^{2}\end{array}$ & 1.085 & 1.017 & 1.002 & 1.000 & 1.006 \\
\hline
\end{tabular}




\section{Experimental Procedure for the X-ray Diffraction of 2a}

\section{Data Collection}

An orange plate crystal of $\mathrm{C}_{38} \mathrm{H}_{36} \mathrm{NP}_{2} \mathrm{Rh}$ having approximate dimensions of $0.15 \mathrm{x} 0.10 \mathrm{x}$ $0.08 \mathrm{~mm}^{3}$ was mounted with epoxy cement on the tip of a fine glass fiber. All measurements were made on a Bruker Platform APEX-CCD diffractometer with graphite monochromated Mo$\mathrm{K} \alpha$ radiation.

Cell constants and an orientation matrix for data collection corresponded to a triclinic cell with dimensions:

$$
\begin{array}{ll}
\mathrm{a}=11.1280(18) \AA & \alpha=84.261(3)^{\mathrm{O}} \\
\mathrm{b}=11.1646(18) \AA & \beta=84.977(3)^{\mathrm{O}} \\
\mathrm{c}=13.098(2) \AA & \gamma=80.620(3)^{\mathrm{O}} \\
\mathrm{V}=1593.3(4) \AA^{3} &
\end{array}
$$

For $\mathrm{Z}=2$ and F.W. $=671.53$, the calculated density is $1.400 \mathrm{~g} / \mathrm{cm}^{3}$. Based on a statistical analysis of intensity distribution, and the successful solution and refinement of the structure, the space group was determined to be $P-1$ (\#2).

The data were collected at a temperature of $150(2) \mathrm{K}$ to a maximum $2 \theta$ value of $56.52^{\circ}$. Four omega/phi scans consisting 2400 data frames, respectively, were collected with a frame width of $0.3^{\circ}$ and a detector-to-crystal distance, Dx, of $49 \mathrm{~mm}$. The data frames were processed and scaled using the Bruker-SAINT software package. ${ }^{1}$

\section{Data Reduction}

A total of 18538 reflections were collected of which 7376 were unique and observed $\left(\mathrm{R}_{\text {int }}\right.$ $=0.0420$ ). The linear absorption coefficient, $\mu$, for Mo-K $\alpha$ radiation is $6.64 \mathrm{~cm}^{-1}$. An empirical absorption correction was applied and the data were corrected for Lorentz and polarization effects.

\section{$\underline{\text { Structure Solution and Refinement }}$}

The structure was solved by direct methods and expanded using Fourier techniques ${ }^{2}$. The non-hydrogen atoms were refined anisotropically, and hydrogen atoms were treated as idealized contributions. The final cycle of full-matrix least-squares refinement ${ }^{3}$ on $\mathrm{F}$ was based on 7376 observed reflections (I > 2.00 $\sigma(\mathrm{I})$ ) and 379 variable parameters and converged with unweighted and weighted agreement factors of:

$$
\begin{gathered}
\mathrm{R}=\Sigma\|\mathrm{Fo}|-| \mathrm{Fc}\| / \Sigma|\mathrm{Fo}|=0.0435 \\
\mathrm{R}_{\mathrm{W}}=\left\{\Sigma\left[\mathrm{w}\left(\mathrm{F}_{\mathrm{o}}^{2}-\mathrm{F}_{\mathrm{c}}^{2}\right)^{2}\right] / \Sigma\left[\mathrm{w}\left(\mathrm{F}_{\mathrm{o}}^{2}\right)^{2}\right]\right\}^{1 / 2}=0.1012
\end{gathered}
$$

The maximum and minimum peaks on the final difference Fourier map corresponded to 1.059 and $-0.477 \mathrm{e}^{-} / \AA^{3}$ respectively. 
REFERENCES

(1) Bruker-AXS, Inc., Madison, WI, 1997

(2) Acta Cryst. A46 (1990) 467-473

(3) Least Squares function minimized:

$$
\Sigma w\left(\mathrm{~F}_{\mathrm{o}}^{2}-\mathrm{F}_{\mathrm{c}}^{2}\right)^{2}
$$


Table S2. Crystal data and structure refinement for $\mathbf{2 a}$.

Empirical formula

Formula weight

Temperature

Wavelength

Crystal system

Space group

Unit cell dimensions

Volume

$\mathrm{Z}$

Density (calculated)

Absorption coefficient

$\mathrm{F}(000)$

Crystal size

Theta range for data collection

Index ranges

Reflections collected

Independent reflections

Completeness to theta $=28.26^{\circ}$

Absorption correction

Refinement method

Data / restraints / parameters

Goodness-of-fit on $\mathrm{F}^{2}$

Final R indices [I $>2 \operatorname{sigma}(\mathrm{I})]$

$\mathrm{R}$ indices (all data)

Largest diff. peak and hole
$\mathrm{C}_{38} \mathrm{H}_{36} \mathrm{~N} \mathrm{P}_{2} \mathrm{Rh}$

671.53

150(2) $\mathrm{K}$

$0.71073 \AA$

Triclinic

$\mathrm{P}-1$

$\mathrm{a}=11.1280(18) \AA \quad \alpha=84.261(3)^{\circ}$.

$\mathrm{b}=11.1646(18) \AA \quad \beta=84.977(3)^{\circ}$.

$\mathrm{c}=13.098(2) \AA \quad \gamma=80.620(3)^{\circ}$.

1593.3(4) $\AA^{3}$

2

$1.400 \mathrm{~g} / \mathrm{cm}^{3}$

$0.664 \mathrm{~mm}^{-1}$

692

$0.15 \times 0.10 \times 0.08 \mathrm{~mm}^{3}$

1.86 to $28.26^{\circ}$.

$-14<=\mathrm{h}<=14,-14<=\mathrm{k}<=14,-17<=1<=17$

18538

$7376[\mathrm{R}(\mathrm{int})=0.0420]$

$93.6 \%$

\section{SADABS}

Full-matrix least-squares on $\mathrm{F}^{2}$

7376 / 0 / 379

1.085

$\mathrm{R} 1=0.0435, \mathrm{wR} 2=0.1012$

$\mathrm{R} 1=0.0570, \mathrm{wR} 2=0.1066$

1.268 and -0.747 e. $\AA^{-3}$ 
Table S3. Atomic coordinates ( $x 10^{4}$ ) and equivalent isotropic displacement parameters $\left(\AA^{2} \times 10^{3}\right)$ for $\mathbf{2 a}$. U(eq) is defined as one third of the trace of the orthogonalized $\mathrm{U}^{\mathrm{ij}}$ tensor.

\begin{tabular}{|c|c|c|c|c|}
\hline & $\mathrm{x}$ & $\mathrm{y}$ & $\mathrm{z}$ & $\mathrm{U}(\mathrm{eq})$ \\
\hline $\mathrm{Rh}(1)$ & $7428(1)$ & $5897(1)$ & $6843(1)$ & $21(1)$ \\
\hline $\mathrm{P}(1)$ & $7287(1)$ & $6607(1)$ & $8347(1)$ & $23(1)$ \\
\hline $\mathrm{P}(2)$ & $7406(1)$ & $4068(1)$ & $7729(1)$ & $22(1)$ \\
\hline $\mathrm{N}(1)$ & $7514(2)$ & $5261(2)$ & $5353(2)$ & $27(1)$ \\
\hline $\mathrm{C}(1)$ & $5822(3)$ & $7515(3)$ & $8749(2)$ & $25(1)$ \\
\hline$C(2)$ & 4926(3) & $7809(3)$ & $8047(3)$ & $31(1)$ \\
\hline $\mathrm{C}(3)$ & $3809(3)$ & $8502(3)$ & $8323(3)$ & $39(1)$ \\
\hline $\mathrm{C}(4)$ & $3592(3)$ & $8906(3)$ & $9298(3)$ & $38(1)$ \\
\hline$C(5)$ & $4471(3)$ & $8612(3)$ & $9999(3)$ & $35(1)$ \\
\hline$C(6)$ & $5579(3)$ & $7918(3)$ & $9728(2)$ & $30(1)$ \\
\hline$C(7)$ & $8408(3)$ & $7541(3)$ & $8622(2)$ & $24(1)$ \\
\hline$C(8)$ & $9634(3)$ & $7002(3)$ & $8628(2)$ & $30(1)$ \\
\hline$C(9)$ & $10545(3)$ & $7689(3)$ & $8710(3)$ & $35(1)$ \\
\hline$C(10)$ & $10256(3)$ & $8930(3)$ & $8775(3)$ & $38(1)$ \\
\hline $\mathrm{C}(11)$ & $9052(3)$ & $9488(3)$ & $8762(3)$ & $35(1)$ \\
\hline$C(12)$ & $8127(3)$ & $8797(3)$ & $8688(2)$ & $29(1)$ \\
\hline $\mathrm{C}(13)$ & $7483(3)$ & $5371(3)$ & $9404(2)$ & $28(1)$ \\
\hline$C(14)$ & $6962(3)$ & $4276(3)$ & $9103(2)$ & $26(1)$ \\
\hline$C(15)$ & $8918(3)$ & $3121(2)$ & $7725(2)$ & $24(1)$ \\
\hline$C(16)$ & $9590(3)$ & $2848(3)$ & $8579(3)$ & $32(1)$ \\
\hline$C(17)$ & $10752(3)$ & $2186(3)$ & $8513(3)$ & $39(1)$ \\
\hline $\mathrm{C}(18)$ & $11249(3)$ & $1778(3)$ & $7586(3)$ & $39(1)$ \\
\hline C(19) & $10604(3)$ & $2045(3)$ & $6717(3)$ & $37(1)$ \\
\hline$C(20)$ & $9449(3)$ & $2732(3)$ & $6777(3)$ & $31(1)$ \\
\hline $\mathrm{C}(21)$ & $6400(3)$ & 2997(3) & $7490(2)$ & $24(1)$ \\
\hline $\mathrm{C}(22)$ & $6784(3)$ & $1779(3)$ & $7309(2)$ & $28(1)$ \\
\hline $\mathrm{C}(23)$ & $5947(3)$ & $1033(3)$ & $7149(2)$ & $33(1)$ \\
\hline$C(24)$ & $4718(3)$ & $1495(3)$ & $7168(3)$ & $39(1)$ \\
\hline$C(25)$ & $4322(3)$ & $2703(3)$ & $7326(3)$ & $40(1)$ \\
\hline$C(26)$ & $5155(3)$ & $3448(3)$ & $7487(3)$ & $34(1)$ \\
\hline $\mathrm{C}(27)$ & $7559(3)$ & $7631(3)$ & $6106(2)$ & $24(1)$ \\
\hline
\end{tabular}




$\begin{array}{lrrrr}\mathrm{C}(28) & 8537(3) & 8250(3) & 6184(2) & 28(1) \\ \mathrm{C}(29) & 8612(3) & 9403(3) & 5683(2) & 31(1) \\ \mathrm{C}(30) & 7714(3) & 9987(3) & 5063(2) & 33(1) \\ \mathrm{C}(31) & 6743(3) & 9377(3) & 4958(3) & 33(1) \\ \mathrm{C}(32) & 6678(3) & 8231(3) & 5474(2) & 30(1) \\ \mathrm{C}(33) & 7772(4) & 11234(3) & 4519(3) & 54(1) \\ \mathrm{C}(34) & 6650(3) & 4684(3) & 5052(2) & 31(1) \\ \mathrm{C}(35) & 6707(3) & 4254(3) & 4094(3) & 38(1) \\ \mathrm{C}(36) & 7704(4) & 4381(3) & 3421(3) & 46(1) \\ \mathrm{C}(37) & 8602(4) & 4959(3) & 3713(3) & 48(1) \\ \mathrm{C}(38) & 8452(3) & 5409(3) & 4672(3) & 35(1)\end{array}$


Table S4. Bond lengths $[\AA]$ and angles $\left[^{\circ}\right]$ for $2 \mathbf{a}$.

\begin{tabular}{|c|c|c|c|}
\hline $\mathrm{Rh}(1)-\mathrm{C}(27)$ & $2.097(3)$ & $\mathrm{C}(23)-\mathrm{C}(24)$ & $1.379(5)$ \\
\hline $\operatorname{Rh}(1)-\mathrm{N}(1)$ & $2.132(3)$ & $C(24)-C(25)$ & $1.378(5)$ \\
\hline $\mathrm{Rh}(1)-\mathrm{P}(1)$ & $2.1797(8)$ & $C(25)-C(26)$ & $1.384(4)$ \\
\hline $\mathrm{Rh}(1)-\mathrm{P}(2)$ & $2.2481(8)$ & $\mathrm{C}(27)-\mathrm{C}(32)$ & $1.382(4)$ \\
\hline $\mathrm{P}(1)-\mathrm{C}(7)$ & $1.830(3)$ & $\mathrm{C}(27)-\mathrm{C}(28)$ & $1.397(4)$ \\
\hline $\mathrm{P}(1)-\mathrm{C}(1)$ & $1.838(3)$ & $\mathrm{C}(28)-\mathrm{C}(29)$ & $1.397(4)$ \\
\hline $\mathrm{P}(1)-\mathrm{C}(13)$ & $1.855(3)$ & $C(29)-C(30)$ & $1.381(4)$ \\
\hline $\mathrm{P}(2)-\mathrm{C}(21)$ & $1.831(3)$ & $\mathrm{C}(30)-\mathrm{C}(31)$ & $1.390(5)$ \\
\hline$P(2)-C(15)$ & $1.835(3)$ & $C(30)-C(33)$ & $1.508(4)$ \\
\hline$P(2)-C(14)$ & $1.852(3)$ & $\mathrm{C}(31)-\mathrm{C}(32)$ & $1.396(4)$ \\
\hline $\mathrm{N}(1)-\mathrm{C}(38)$ & $1.334(4)$ & $C(34)-C(35)$ & $1.380(4)$ \\
\hline $\mathrm{N}(1)-\mathrm{C}(34)$ & $1.346(4)$ & $\mathrm{C}(35)-\mathrm{C}(36)$ & $1.372(5)$ \\
\hline$C(1)-C(6)$ & $1.391(4)$ & $C(36)-C(37)$ & $1.374(5)$ \\
\hline$C(1)-C(2)$ & $1.393(4)$ & $\mathrm{C}(37)-\mathrm{C}(38)$ & $1.385(5)$ \\
\hline$C(2)-C(3)$ & $1.392(4)$ & & \\
\hline$C(3)-C(4)$ & $1.385(5)$ & $\mathrm{C}(27)-\mathrm{Rh}(1)-\mathrm{N}(1)$ & $87.50(10)$ \\
\hline$C(4)-C(5)$ & $1.377(5)$ & $\mathrm{C}(27)-\mathrm{Rh}(1)-\mathrm{P}(1)$ & $90.96(8)$ \\
\hline$C(5)-C(6)$ & $1.383(4)$ & $\mathrm{N}(1)-\mathrm{Rh}(1)-\mathrm{P}(1)$ & $177.77(7)$ \\
\hline$C(7)-C(12)$ & $1.396(4)$ & $\mathrm{C}(27)-\mathrm{Rh}(1)-\mathrm{P}(2)$ & $174.94(8)$ \\
\hline$C(7)-C(8)$ & $1.399(4)$ & $\mathrm{N}(1)-\mathrm{Rh}(1)-\mathrm{P}(2)$ & $96.16(7)$ \\
\hline $\mathrm{C}(8)-\mathrm{C}(9)$ & $1.384(4)$ & $\mathrm{P}(1)-\mathrm{Rh}(1)-\mathrm{P}(2)$ & $85.47(3)$ \\
\hline$C(9)-C(10)$ & $1.380(5)$ & $\mathrm{C}(7)-\mathrm{P}(1)-\mathrm{C}(1)$ & $103.08(13)$ \\
\hline $\mathrm{C}(10)-\mathrm{C}(11)$ & $1.383(5)$ & $\mathrm{C}(7)-\mathrm{P}(1)-\mathrm{C}(13)$ & $101.22(14)$ \\
\hline$C(11)-C(12)$ & $1.398(4)$ & $\mathrm{C}(1)-\mathrm{P}(1)-\mathrm{C}(13)$ & $102.58(14)$ \\
\hline $\mathrm{C}(13)-\mathrm{C}(14)$ & $1.533(4)$ & $\mathrm{C}(7)-\mathrm{P}(1)-\mathrm{Rh}(1)$ & $118.75(10)$ \\
\hline$C(15)-C(16)$ & $1.382(4)$ & $\mathrm{C}(1)-\mathrm{P}(1)-\mathrm{Rh}(1)$ & $116.88(10)$ \\
\hline$C(15)-C(20)$ & $1.405(4)$ & $\mathrm{C}(13)-\mathrm{P}(1)-\mathrm{Rh}(1)$ & $112.03(10)$ \\
\hline$C(16)-C(17)$ & $1.381(5)$ & $\mathrm{C}(21)-\mathrm{P}(2)-\mathrm{C}(15)$ & $103.14(13)$ \\
\hline $\mathrm{C}(17)-\mathrm{C}(18)$ & $1.377(5)$ & $\mathrm{C}(21)-\mathrm{P}(2)-\mathrm{C}(14)$ & $100.55(13)$ \\
\hline $\mathrm{C}(18)-\mathrm{C}(19)$ & $1.380(5)$ & $\mathrm{C}(15)-\mathrm{P}(2)-\mathrm{C}(14)$ & $104.71(14)$ \\
\hline$C(19)-C(20)$ & $1.385(4)$ & $\mathrm{C}(21)-\mathrm{P}(2)-\mathrm{Rh}(1)$ & $123.90(10)$ \\
\hline $\mathrm{C}(21)-\mathrm{C}(22)$ & $1.394(4)$ & $\mathrm{C}(15)-\mathrm{P}(2)-\mathrm{Rh}(1)$ & $112.90(9)$ \\
\hline$C(21)-C(26)$ & $1.396(4)$ & $\mathrm{C}(14)-\mathrm{P}(2)-\mathrm{Rh}(1)$ & $109.55(10)$ \\
\hline$C(22)-C(23)$ & $1.388(4)$ & $\mathrm{C}(38)-\mathrm{N}(1)-\mathrm{C}(34)$ & $116.6(3)$ \\
\hline
\end{tabular}




$\begin{array}{llll}\mathrm{C}(38)-\mathrm{N}(1)-\mathrm{Rh}(1) & 120.7(2) & \mathrm{C}(32)-\mathrm{C}(27)-\mathrm{C}(28) & 115.1(3) \\ \mathrm{C}(34)-\mathrm{N}(1)-\mathrm{Rh}(1) & 122.7(2) & \mathrm{C}(32)-\mathrm{C}(27)-\mathrm{Rh}(1) & 121.3(2) \\ \mathrm{C}(6)-\mathrm{C}(1)-\mathrm{C}(2) & 119.0(3) & \mathrm{C}(28)-\mathrm{C}(27)-\mathrm{Rh}(1) & 123.6(2) \\ \mathrm{C}(6)-\mathrm{C}(1)-\mathrm{P}(1) & 122.3(2) & \mathrm{C}(27)-\mathrm{C}(28)-\mathrm{C}(29) & 122.8(3) \\ \mathrm{C}(2)-\mathrm{C}(1)-\mathrm{P}(1) & 118.8(2) & \mathrm{C}(30)-\mathrm{C}(29)-\mathrm{C}(28) & 120.9(3) \\ \mathrm{C}(3)-\mathrm{C}(2)-\mathrm{C}(1) & 120.3(3) & \mathrm{C}(29)-\mathrm{C}(30)-\mathrm{C}(31) & 117.3(3) \\ \mathrm{C}(4)-\mathrm{C}(3)-\mathrm{C}(2) & 119.8(3) & \mathrm{C}(29)-\mathrm{C}(30)-\mathrm{C}(33) & 121.9(3) \\ \mathrm{C}(5)-\mathrm{C}(4)-\mathrm{C}(3) & 120.3(3) & \mathrm{C}(31)-\mathrm{C}(30)-\mathrm{C}(33) & 120.9(3) \\ \mathrm{C}(4)-\mathrm{C}(5)-\mathrm{C}(6) & 120.0(3) & \mathrm{C}(30)-\mathrm{C}(31)-\mathrm{C}(32) & 120.9(3) \\ \mathrm{C}(5)-\mathrm{C}(6)-\mathrm{C}(1) & 120.7(3) & \mathrm{C}(27)-\mathrm{C}(32)-\mathrm{C}(31) & 123.0(3) \\ \mathrm{C}(12)-\mathrm{C}(7)-\mathrm{C}(8) & 118.1(3) & \mathrm{N}(1)-\mathrm{C}(34)-\mathrm{C}(35) & 123.1(3) \\ \mathrm{C}(12)-\mathrm{C}(7)-\mathrm{P}(1) & 123.1(2) & \mathrm{C}(36)-\mathrm{C}(35)-\mathrm{C}(34) & 119.1(3) \\ \mathrm{C}(8)-\mathrm{C}(7)-\mathrm{P}(1) & 118.2(2) & \mathrm{C}(35)-\mathrm{C}(36)-\mathrm{C}(37) & 118.9(3) \\ \mathrm{C}(9)-\mathrm{C}(8)-\mathrm{C}(7) & 121.2(3) & \mathrm{C}(36)-\mathrm{C}(37)-\mathrm{C}(38) & 118.5(3) \\ \mathrm{C}(10)-\mathrm{C}(9)-\mathrm{C}(8) & 120.2(3) & \mathrm{N}(1)-\mathrm{C}(38)-\mathrm{C}(37) & 123.7(3) \\ \mathrm{C}(9)-\mathrm{C}(10)-\mathrm{C}(11) & 119.9(3) & & \\ \mathrm{C}(10)-\mathrm{C}(11)-\mathrm{C}(12) & 120.2(3) & & \\ \mathrm{C}(7)-\mathrm{C}(12)-\mathrm{C}(11) & 120.5(3) & & \\ \mathrm{C}(14)-\mathrm{C}(13)-\mathrm{P}(1) & 108.7(2) & & \\ \mathrm{C}(13)-\mathrm{C}(14)-\mathrm{P}(2) & 109.2(2) & & \\ \mathrm{C}(16)-\mathrm{C}(15)-\mathrm{C}(20) & 118.7(3) & & \\ \mathrm{C}(16)-\mathrm{C}(15)-\mathrm{P}(2) & 123.7(2) & & \\ \mathrm{C}(20)-\mathrm{C}(15)-\mathrm{P}(2) & 117.4(2) & & \\ \mathrm{C}(17)-\mathrm{C}(16)-\mathrm{C}(15) & 120.9(3) & & \\ \mathrm{C}(18)-\mathrm{C}(17)-\mathrm{C}(16) & 119.9(3) & & \\ \mathrm{C}(17)-\mathrm{C}(18)-\mathrm{C}(19) & 120.5(3) & & \\ \mathrm{C}(18)-\mathrm{C}(19)-\mathrm{C}(20) & 119.8(3) & & \\ \mathrm{C}(19)-\mathrm{C}(20)-\mathrm{C}(15) & 120.2(3) & & \\ \mathrm{C}(22)-\mathrm{C}(21)-\mathrm{C}(26) & 118.1(3) & & \\ \mathrm{C}(22)-\mathrm{C}(21)-\mathrm{P}(2) & 125.1(2) & & \\ \mathrm{C}(26)-\mathrm{C}(21)-\mathrm{P}(2) & 116.8(2) & & \\ \mathrm{C}(23)-\mathrm{C}(22)-\mathrm{C}(21) & 120.9(3) & & \\ \mathrm{C}(24)-\mathrm{C}(23)-\mathrm{C}(22) & 119.9(3) & & \\ \mathrm{C}(25)-\mathrm{C}(24)-\mathrm{C}(23) & 120.1(3) & & \\ \mathrm{C}(24)-\mathrm{C}(25)-\mathrm{C}(26) & 120.0(3) & & \\ \mathrm{C}(25)-\mathrm{C}(26)-\mathrm{C}(21) & 120.9(3) & & \\ & & & \\ & & \\ \end{array}$


Table S5. Anisotropic displacement parameters $\left(\AA^{2} \times 10^{3}\right)$ for $\mathbf{2 a}$. The anisotropic displacement factor exponent takes the form: $-2 \pi^{2}\left[h^{2} a^{* 2} U^{11}+\ldots+2 h k a^{*} b^{*} U^{12}\right]$.

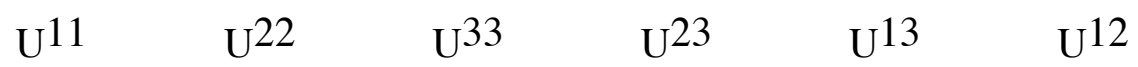

$\begin{array}{lllllll}\mathrm{Rh}(1) & 24(1) & 16(1) & 24(1) & -2(1) & -2(1) & -6(1) \\ \mathrm{P}(1) & 27(1) & 18(1) & 26(1) & -3(1) & -3(1) & -6(1) \\ \mathrm{P}(2) & 25(1) & 18(1) & 26(1) & -3(1) & -2(1) & -7(1) \\ \mathrm{N}(1) & 29(1) & 22(1) & 29(1) & -3(1) & -2(1) & -3(1) \\ \mathrm{C}(1) & 26(2) & 17(1) & 34(2) & -5(1) & 1(1) & -8(1) \\ \mathrm{C}(2) & 30(2) & 32(2) & 32(2) & -9(1) & -2(1) & -9(1) \\ \mathrm{C}(3) & 29(2) & 40(2) & 49(2) & -7(2) & -8(2) & -4(2) \\ \mathrm{C}(4) & 27(2) & 35(2) & 51(2) & -12(2) & 7(2) & -7(1) \\ \mathrm{C}(5) & 36(2) & 34(2) & 37(2) & -11(2) & 9(2) & -12(2) \\ \mathrm{C}(6) & 30(2) & 29(2) & 33(2) & -5(1) & 1(1) & -10(1) \\ \mathrm{C}(7) & 29(2) & 21(1) & 23(2) & -4(1) & -2(1) & -8(1) \\ \mathrm{C}(8) & 32(2) & 28(2) & 31(2) & -4(1) & -5(1) & -4(1) \\ \mathrm{C}(9) & 25(2) & 44(2) & 38(2) & -4(2) & -5(1) & -8(2) \\ \mathrm{C}(10) & 36(2) & 41(2) & 42(2) & -5(2) & -6(2) & -21(2) \\ \mathrm{C}(11) & 42(2) & 24(2) & 42(2) & -2(1) & -8(2) & -14(1) \\ \mathrm{C}(12) & 28(2) & 24(2) & 35(2) & -2(1) & -4(1) & -6(1) \\ \mathrm{C}(13) & 40(2) & 20(1) & 24(2) & -2(1) & -1(1) & -8(1) \\ \mathrm{C}(14) & 34(2) & 20(1) & 25(2) & -1(1) & 2(1) & -8(1) \\ \mathrm{C}(15) & 24(2) & 17(1) & 33(2) & -4(1) & -1(1) & -9(1) \\ \mathrm{C}(16) & 36(2) & 25(2) & 36(2) & -4(1) & -6(1) & -7(1) \\ \mathrm{C}(17) & 36(2) & 34(2) & 50(2) & 1(2) & -15(2) & -6(2) \\ \mathrm{C}(18) & 25(2) & 26(2) & 66(3) & 0(2) & -3(2) & -5(1) \\ \mathrm{C}(19) & 33(2) & 28(2) & 49(2) & -9(2) & 10(2) & -6(1) \\ \mathrm{C}(20) & 32(2) & 30(2) & 33(2) & -8(1) & 2(1) & -9(1) \\ \mathrm{C}(21) & 28(2) & 21(1) & 25(2) & 1(1) & -5(1) & -9(1) \\ \mathrm{C}(22) & 29(2) & 25(2) & 32(2) & -9(1) & 0(1) & -7(1) \\ \mathrm{C}(23) & 39(2) & 28(2) & 36(2) & -9(1) & 1(1) & -12(1) \\ \mathrm{C}(24) & 36(2) & 38(2) & 49(2) & -7(2) & -7(2) & -20(2) \\ \mathrm{C}(25) & 26(2) & 40(2) & 56(2) & 0(2) & -11(2) & -9(2) \\ \mathrm{C}(26) & 31(2) & 24(2) & 46(2) & -1(1) & -6(2) & -6(1) \\ \mathrm{C}(27) & 30(2) & 22(1) & 21(2) & -4(1) & 2(1) & -7(1)\end{array}$




$\begin{array}{lllllll}\mathrm{C}(28) & 32(2) & 24(2) & 28(2) & 0(1) & -2(1) & -7(1) \\ \mathrm{C}(29) & 38(2) & 26(2) & 31(2) & -4(1) & 1(1) & -14(1) \\ \mathrm{C}(30) & 46(2) & 22(2) & 29(2) & -2(1) & -1(1) & -6(1) \\ \mathrm{C}(31) & 39(2) & 24(2) & 35(2) & -3(1) & -9(1) & 3(1) \\ \mathrm{C}(32) & 30(2) & 30(2) & 32(2) & -7(1) & 1(1) & -9(1) \\ \mathrm{C}(33) & 78(3) & 30(2) & 56(3) & 9(2) & -10(2) & -14(2) \\ \mathrm{C}(34) & 35(2) & 26(2) & 33(2) & -5(1) & -6(1) & -6(1) \\ \mathrm{C}(35) & 49(2) & 27(2) & 38(2) & -6(1) & -14(2) & -5(2) \\ \mathrm{C}(36) & 73(3) & 35(2) & 31(2) & -13(2) & 1(2) & -9(2) \\ \mathrm{C}(37) & 60(3) & 45(2) & 39(2) & -11(2) & 13(2) & -14(2) \\ \mathrm{C}(38) & 39(2) & 31(2) & 36(2) & -6(1) & 2(2) & -11(2)\end{array}$


Table S6. Hydrogen coordinates (x 10 $)$ and isotropic displacement parameters $\left(\AA^{2} \times 10^{3}\right)$ for $2 a$.

\begin{tabular}{|c|c|c|c|c|}
\hline & $\mathrm{x}$ & $\mathrm{y}$ & $\mathrm{z}$ & $\mathrm{U}(\mathrm{eq})$ \\
\hline $\mathrm{H}(2 \mathrm{~A})$ & 5077 & 7536 & 7377 & 37 \\
\hline $\mathrm{H}(3 \mathrm{~A})$ & 3197 & 8696 & 7845 & 47 \\
\hline $\mathrm{H}(4 \mathrm{~A})$ & 2835 & 9387 & 9484 & 45 \\
\hline $\mathrm{H}(5 \mathrm{~A})$ & 4316 & 8887 & 10668 & 42 \\
\hline $\mathrm{H}(6 \mathrm{~A})$ & 6180 & 7714 & 10215 & 36 \\
\hline $\mathrm{H}(8 \mathrm{~A})$ & 9845 & 6150 & 8576 & 36 \\
\hline $\mathrm{H}(9 \mathrm{~A})$ & 11372 & 7304 & 8721 & 42 \\
\hline $\mathrm{H}(10 \mathrm{~A})$ & 10883 & 9400 & 8829 & 46 \\
\hline $\mathrm{H}(11 \mathrm{~A})$ & 8853 & 10343 & 8804 & 42 \\
\hline $\mathrm{H}(12 \mathrm{~A})$ & 7302 & 9185 & 8683 & 35 \\
\hline $\mathrm{H}(13 \mathrm{~A})$ & 8360 & 5132 & 9520 & 33 \\
\hline $\mathrm{H}(13 \mathrm{~B})$ & 7048 & 5657 & 10048 & 33 \\
\hline $\mathrm{H}(14 \mathrm{~A})$ & 6061 & 4418 & 9219 & 32 \\
\hline $\mathrm{H}(14 \mathrm{~B})$ & 7283 & 3533 & 9534 & 32 \\
\hline $\mathrm{H}(16 \mathrm{~A})$ & 9248 & 3120 & 9222 & 38 \\
\hline $\mathrm{H}(17 \mathrm{~A})$ & 11207 & 2011 & 9105 & 47 \\
\hline $\mathrm{H}(18 \mathrm{~A})$ & 12043 & 1310 & 7545 & 47 \\
\hline H(19A) & 10951 & 1759 & 6081 & 44 \\
\hline $\mathrm{H}(20 \mathrm{~A})$ & 9015 & 2941 & 6175 & 37 \\
\hline $\mathrm{H}(22 \mathrm{~A})$ & 7629 & 1456 & 7296 & 33 \\
\hline $\mathrm{H}(23 \mathrm{~A})$ & 6220 & 205 & 7027 & 40 \\
\hline $\mathrm{H}(24 \mathrm{~A})$ & 4144 & 981 & 7072 & 47 \\
\hline $\mathrm{H}(25 \mathrm{~A})$ & 3477 & 3023 & 7324 & 48 \\
\hline $\mathrm{H}(26 \mathrm{~A})$ & 4874 & 4278 & 7597 & 40 \\
\hline $\mathrm{H}(28 \mathrm{~A})$ & 9178 & 7870 & 6596 & 33 \\
\hline $\mathrm{H}(29 \mathrm{~A})$ & 9291 & 9791 & 5769 & 37 \\
\hline $\mathrm{H}(31 \mathrm{~A})$ & 6115 & 9746 & 4528 & 40 \\
\hline $\mathrm{H}(32 \mathrm{~A})$ & 5998 & 7845 & 5387 & 36 \\
\hline $\mathrm{H}(33 \mathrm{~A})$ & 8516 & 11518 & 4680 & 82 \\
\hline $\mathrm{H}(33 \mathrm{~B})$ & 7056 & 11803 & 4748 & 82 \\
\hline $\mathrm{H}(33 \mathrm{C})$ & 7783 & 11191 & 3774 & 82 \\
\hline
\end{tabular}




$\begin{array}{lllll}\mathrm{H}(34 \mathrm{~A}) & 5969 & 4568 & 5520 & 37 \\ \mathrm{H}(35 \mathrm{~A}) & 6065 & 3875 & 3903 & 45 \\ \mathrm{H}(36 \mathrm{~A}) & 7773 & 4074 & 2764 & 55 \\ \mathrm{H}(37 \mathrm{~A}) & 9308 & 5048 & 3268 & 57 \\ \mathrm{H}(38 \mathrm{~A}) & 9053 & 5848 & 4855 & 42\end{array}$


Experimental Procedure for X-ray Diffraction of 4

\section{Data Collection}

A red block crystal of $\mathrm{C}_{54} \mathrm{H}_{51} \mathrm{~N}_{2} \mathrm{O}_{2} \mathrm{P}_{2} \mathrm{Rh} \cdot \mathrm{C}_{7} \mathrm{H}_{8}, \mathrm{C}_{61} \mathrm{H}_{59} \mathrm{~N}_{2} \mathrm{O}_{2} \mathrm{P}_{2} \mathrm{Rh}$, having approximate dimensions of $0.25 \times 0.25 \times 0.25 \mathrm{~mm}$ was mounted with epoxy cement on the tip of a fine glass fiber. All measurements were made on a Nonius KappaCCD diffractometer with graphite monochromated Mo-K $\alpha$ radiation.

Cell constants and an orientation matrix for data collection corresponded to a primitive monoclinic cell with dimensions:

$$
\begin{array}{lll}
\mathrm{a}=20.443(4) \AA & \alpha=90^{\circ} \\
\mathrm{b}=13.454(3) \AA & \beta=110.31(3) \mathrm{O} \\
\mathrm{c}=20.069(4) \AA & \gamma=90^{\circ} \\
\mathrm{V}=5176.4(18) \AA^{3} &
\end{array}
$$

For $\mathrm{Z}=4$ and F.W. $=1016.95$, the calculated density is $1.305 \mathrm{~g} / \mathrm{cm}^{3}$. Based on a statistical analysis of intensity distribution, and the successful solution and refinement of the structure, the space group was determined to be: $P 2_{1} / c(\# 14)$

The data were collected at a temperature of $173(2) \mathrm{K}$ to a maximum $2 \theta$ value of $56.68^{\circ}$. Four omega scans consisting of 44, 44, 29, and 17 data frames, respectively, were collected with a frame width of $1.7^{\circ}$ and a detector-to-crystal distance, Dx, of $35.0 \mathrm{~mm}$. Each frame was exposed twice (for the purpose of de-zingering) for a total of 51 seconds. The data frames were processed and scaled using the DENZO software package. ${ }^{1}$

\section{Data Reduction}

A total of 19766 reflections were collected of which 12809 were unique and observed $\left(\mathrm{R}_{\mathrm{int}}=0.0471\right)$. The linear absorption coefficient, $\mu$, for Mo-K $\alpha$ radiation is $4.37 \mathrm{~cm}^{-1}$ and no absorption correction was applied. The data were corrected for Lorentz and polarization effects.

\section{$\underline{\text { Structure Solution and Refinement }}$}

The structure was solved by direct methods and expanded using Fourier techniques ${ }^{2}$. The non-hydrogen atoms were refined anisotropically and hydrogen atoms were treated as idealized contributions. The final cycle of full-matrix least-squares refinement ${ }^{3}$ on $\mathrm{F}$ was based on 12809 observed reflections (I > 2.00 $(\mathrm{I})$ ) and 641 variable parameters and converged with unweighted and weighted agreement factors of:

$$
\begin{gathered}
\mathrm{R}=\Sigma\|\mathrm{Fol}-|\mathrm{Fc} \| / \Sigma| \mathrm{Fo} \mid=0.0505 \\
\mathrm{R}_{\mathrm{W}}=\left\{\Sigma\left[\mathrm{w}\left(\mathrm{F}_{\mathrm{o}}{ }^{2}-\mathrm{F}_{\mathrm{c}}{ }^{2}\right)^{2}\right] / \Sigma\left[\mathrm{w}\left(\mathrm{F}_{\mathrm{o}}^{2}\right)^{2}\right]\right\}^{1 / 2}=0.1052
\end{gathered}
$$


The maximum and minimum peaks on the final difference Fourier map corresponded to 0.542 and $-0.567 \mathrm{e}^{-} / \AA^{3}$, respectively.

\section{REFERENCES}

(1) Z. Otwinowski and W. Minor, "Processing of X-Ray Diffraction Data Collected in Oscillation Mode," Methods in Enzymology, vol. 276: Macromolecular Crystallography, part A, 307-326, 1997, C.W. Carter, Jr. \& R.M. Sweet, Eds., Academic Press.

(2) Acta Cryst. A46 (1990) 467-473

(3) Least Squares function minimized: $\Sigma w\left(\mathrm{~F}_{\mathrm{o}}^{2}-\mathrm{F}_{\mathrm{c}}^{2}\right)^{2}$ 
Table S7. Crystal data and structure refinement for 4 .

Empirical formula

Formula weight

Temperature

Wavelength

Crystal system

Space group

Unit cell dimensions

Volume

$\mathrm{Z}$

Density (calculated)

Absorption coefficient

$\mathrm{F}(000)$

Crystal size

Theta range for data collection

Index ranges

Reflections collected

Independent reflections

Completeness to theta $=28.34^{\circ}$

Absorption correction

Max. and min. transmission

Refinement method

Data / restraints / parameters

Goodness-of-fit on $\mathrm{F}^{2}$

Final $\mathrm{R}$ indices [I $>2 \operatorname{sigma}(\mathrm{I})]$

$\mathrm{R}$ indices (all data)

Largest diff. peak and hole
$\mathrm{C}_{61} \mathrm{H}_{59} \mathrm{~N}_{2} \mathrm{O}_{2} \mathrm{P}_{2} \mathrm{Rh}$

1016.95

173(2) K

$0.71073 \AA$

Monoclinic

$\mathrm{P} 2(1) / \mathrm{c}$

$\mathrm{a}=20.443(4) \AA \quad \alpha=90^{\circ}$.

$\mathrm{b}=13.454(3) \AA$

$\beta=110.31(3)^{\circ}$.

$\mathrm{c}=20.069(4) \AA$

$\gamma=90^{\circ}$.

$5176.4(18) \AA^{3}$

4

$1.305 \mathrm{~g} / \mathrm{cm}^{3}$

$4.37 \mathrm{~cm}^{-1}$

2120

$0.25 \times 0.25 \times 0.25 \mathrm{~mm}^{3}$

2.32 to $28.34^{\circ}$.

$-27<=\mathrm{h}<=27,-17<=\mathrm{k}<=17,-26<=\mathrm{l}<=26$

19766

$12809[\mathrm{R}($ int $)=0.0471]$

$99.1 \%$

None

0.8986 and 0.8986

Full-matrix least-squares on $\mathrm{F}^{2}$

12809 / 0 / 641

1.017

$\mathrm{R} 1=0.0505, \mathrm{wR} 2=0.1052$

$\mathrm{R} 1=0.1024, \mathrm{wR} 2=0.1209$

0.542 and -0.567 e. $\AA^{-3}$ 
Table S8. Atomic coordinates (x $10^{4}$ ) and equivalent isotropic displacement parameters $\left(\AA^{2} \times 10^{3}\right)$ for 4 . U(eq) is defined as one third of the trace of the orthogonalized $U^{i j}$ tensor.

\begin{tabular}{|c|c|c|c|c|}
\hline & $\mathrm{x}$ & $\mathrm{y}$ & $\mathrm{z}$ & $\mathrm{U}(\mathrm{eq})$ \\
\hline $\mathrm{Rh}(1)$ & $7134(1)$ & $8529(1)$ & $3919(1)$ & $20(1)$ \\
\hline $\mathrm{P}(1)$ & $7520(1)$ & $8373(1)$ & $5087(1)$ & $22(1)$ \\
\hline $\mathrm{P}(2)$ & $6765(1)$ & $6990(1)$ & $3927(1)$ & $24(1)$ \\
\hline $\mathrm{O}(1)$ & $5584(1)$ & $12793(2)$ & $5104(1)$ & $46(1)$ \\
\hline $\mathrm{O}(2)$ & $6416(1)$ & $13866(2)$ & $5114(2)$ & $53(1)$ \\
\hline $\mathrm{N}(1)$ & $7477(1)$ & $10039(2)$ & $3905(1)$ & $22(1)$ \\
\hline $\mathrm{N}(2)$ & $6595(1)$ & $8638(2)$ & $2795(1)$ & $25(1)$ \\
\hline $\mathrm{C}(1)$ & $8353(2)$ & $8893(2)$ & $5654(2)$ & $25(1)$ \\
\hline $\mathrm{C}(2)$ & $8905(2)$ & $8297(3)$ & $6064(2)$ & $35(1)$ \\
\hline$C(3)$ & $9538(2)$ & $8737(3)$ & $6460(2)$ & $48(1)$ \\
\hline$C(4)$ & $9631(2)$ & $9747(3)$ & $6431(2)$ & $44(1)$ \\
\hline$C(5)$ & $9090(2)$ & 10330(3) & $6034(2)$ & $38(1)$ \\
\hline$C(6)$ & $8452(2)$ & $9916(2)$ & $5646(2)$ & $30(1)$ \\
\hline$C(7)$ & $6919(2)$ & $8842(2)$ & $5518(2)$ & $24(1)$ \\
\hline $\mathrm{C}(8)$ & $7138(2)$ & $9227(2)$ & $6200(2)$ & $32(1)$ \\
\hline $\mathrm{C}(9)$ & $6653(2)$ & $9565(3)$ & $6490(2)$ & $42(1)$ \\
\hline$C(10)$ & $5949(2)$ & $9515(3)$ & $6107(2)$ & $41(1)$ \\
\hline $\mathrm{C}(11)$ & $5724(2)$ & $9102(2)$ & $5436(2)$ & $34(1)$ \\
\hline $\mathrm{C}(12)$ & $6206(2)$ & $8779(2)$ & $5142(2)$ & $26(1)$ \\
\hline$C(13)$ & $7566(2)$ & $7043(2)$ & $5329(2)$ & $29(1)$ \\
\hline$C(14)$ & 6901(2) & $6550(2)$ & $4842(2)$ & $29(1)$ \\
\hline$C(15)$ & $5842(2)$ & $6790(2)$ & $3414(2)$ & $28(1)$ \\
\hline$C(16)$ & $5315(2)$ & $6999(2)$ & $3690(2)$ & $36(1)$ \\
\hline $\mathrm{C}(17)$ & $4630(2)$ & $7049(3)$ & $3248(2)$ & $48(1)$ \\
\hline$C(18)$ & $4444(2)$ & $6869(3)$ & $2529(2)$ & $50(1)$ \\
\hline $\mathrm{C}(19)$ & $4952(2)$ & $6626(3)$ & $2256(2)$ & $42(1)$ \\
\hline $\mathrm{C}(20)$ & $5645(2)$ & $6587(2)$ & $2695(2)$ & $34(1)$ \\
\hline $\mathrm{C}(21)$ & $7205(2)$ & $6005(2)$ & $3612(2)$ & $26(1)$ \\
\hline $\mathrm{C}(22)$ & $7819(2)$ & $6219(2)$ & $3496(2)$ & $33(1)$ \\
\hline$C(23)$ & $8180(2)$ & $5487(3)$ & $3286(2)$ & $45(1)$ \\
\hline $\mathrm{C}(24)$ & $7925(2)$ & $4527(3)$ & $3185(2)$ & $47(1)$ \\
\hline
\end{tabular}




\begin{tabular}{|c|c|c|c|c|}
\hline$C(25)$ & $7319(2)$ & $4288(3)$ & $3299(2)$ & $45(1)$ \\
\hline$C(26)$ & $6955(2)$ & $5028(2)$ & $3516(2)$ & $37(1)$ \\
\hline$C(27)$ & $7164(2)$ & $10796(2)$ & $4122(2)$ & $23(1)$ \\
\hline $\mathrm{C}(28)$ & $6537(1)$ & $10598(2)$ & $4256(2)$ & $23(1)$ \\
\hline$C(29)$ & $6213(2)$ & $11298(2)$ & $4527(2)$ & $25(1)$ \\
\hline$C(30)$ & $6465(2)$ & $12266(2)$ & $4667(2)$ & $27(1)$ \\
\hline$C(31)$ & $7068(2)$ & $12490(2)$ & $4518(2)$ & $28(1)$ \\
\hline$C(32)$ & $7410(2)$ & $11795(2)$ & $4254(2)$ & $26(1)$ \\
\hline$C(33)$ & $6107(2)$ & $12972(2)$ & $4972(2)$ & $33(1)$ \\
\hline$C(34)$ & $6092(2)$ & $14580(3)$ & $5429(3)$ & $64(1)$ \\
\hline$C(35)$ & $8129(2)$ & $10288(2)$ & $3791(2)$ & $24(1)$ \\
\hline$C(36)$ & $8033(2)$ & 10990(2) & $3167(2)$ & $23(1)$ \\
\hline$C(37)$ & $7407(2)$ & $11095(2)$ & $2606(2)$ & $31(1)$ \\
\hline$C(38)$ & $7346(2)$ & $11744(2)$ & $2049(2)$ & $35(1)$ \\
\hline$C(39)$ & $7910(2)$ & $12312(2)$ & $2037(2)$ & $32(1)$ \\
\hline $\mathrm{C}(40)$ & $8534(2)$ & $12197(2)$ & $2593(2)$ & $33(1)$ \\
\hline $\mathrm{C}(41)$ & $8594(2)$ & $11553(2)$ & $3154(2)$ & $30(1)$ \\
\hline$C(42)$ & $7839(2)$ & $13050(3)$ & $1445(2)$ & $47(1)$ \\
\hline$C(43)$ & $8536(2)$ & $9363(2)$ & $3711(2)$ & $29(1)$ \\
\hline$C(44)$ & $9071(2)$ & $9000(3)$ & $4291(2)$ & $40(1)$ \\
\hline $\mathrm{C}(45)$ & $9489(2)$ & $8224(3)$ & $4223(2)$ & $48(1)$ \\
\hline$C(46)$ & $9380(2)$ & $7786(3)$ & $3565(2)$ & $46(1)$ \\
\hline $\mathrm{C}(47)$ & $8843(2)$ & $8134(3)$ & 2992(2) & $41(1)$ \\
\hline $\mathrm{C}(48)$ & $8427(2)$ & $8923(2)$ & $3062(2)$ & $35(1)$ \\
\hline $\mathrm{C}(49)$ & $9864(2)$ & $6969(3)$ & $3489(3)$ & $67(1)$ \\
\hline$C(50)$ & $6008(2)$ & $9188(2)$ & $2578(2)$ & $34(1)$ \\
\hline $\mathrm{C}(51)$ & $5553(2)$ & $9198(3)$ & $1883(2)$ & $44(1)$ \\
\hline$C(52)$ & $5701(2)$ & $8633(3)$ & $1380(2)$ & $40(1)$ \\
\hline $\mathrm{C}(53)$ & $6311(2)$ & $8096(3)$ & 1592(2) & $36(1)$ \\
\hline$C(54)$ & $6737(2)$ & $8113(2)$ & $2296(2)$ & $31(1)$ \\
\hline$C(55)$ & $9343(3)$ & $5446(4)$ & $6532(2)$ & $61(1)$ \\
\hline$C(57)$ & $8293(3)$ & $4534(3)$ & $5849(3)$ & $75(1)$ \\
\hline $\mathrm{C}(59)$ & $9051(2)$ & $5282(3)$ & $5279(2)$ & $52(1)$ \\
\hline$C(61)$ & $10133(3)$ & $6235(5)$ & $5956(4)$ & $93(2)$ \\
\hline$C(56)$ & $8770(6)$ & 4949(6) & $6498(4)$ & $69(3)$ \\
\hline$C(58)$ & $8489(3)$ & $4721(4)$ & $5215(3)$ & $43(1)$ \\
\hline
\end{tabular}




$\begin{array}{llllc}\mathrm{C}(60) & 9515(3) & 5686(4) & 5888(3) & 42(1) \\ \mathrm{C}\left(56^{\prime}\right) & 9891(9) & 5803(9) & 6679(8) & 79(5) \\ \mathrm{C}\left(58^{\prime}\right) & 9597(13) & 5807(13) & 5391(16) & 139(11) \\ \mathrm{C}\left(60^{\prime}\right) & 8827(7) & 5044(10) & 6020(13) & 90(7)\end{array}$


Table S9. Bond lengths $[\AA ̊]$ and angles $\left[^{\circ}\right]$ for 4.

\begin{tabular}{|c|c|c|c|}
\hline $\mathrm{Rh}(1)-\mathrm{N}(2)$ & $2.145(3)$ & $\mathrm{C}(18)-\mathrm{C}(19)$ & $1.371(5)$ \\
\hline $\operatorname{Rh}(1)-\mathrm{N}(1)$ & $2.153(2)$ & $C(19)-C(20)$ & $1.385(5)$ \\
\hline $\mathrm{Rh}(1)-\mathrm{P}(2)$ & $2.2055(9)$ & $C(21)-C(22)$ & $1.386(4)$ \\
\hline $\mathrm{Rh}(1)-\mathrm{P}(1)$ & $2.2073(10)$ & $C(21)-C(26)$ & $1.399(4)$ \\
\hline $\mathrm{P}(1)-\mathrm{C}(1)$ & $1.828(3)$ & $C(22)-C(23)$ & $1.381(4)$ \\
\hline $\mathrm{P}(1)-\mathrm{C}(7)$ & $1.842(3)$ & $C(23)-C(24)$ & $1.382(5)$ \\
\hline $\mathrm{P}(1)-\mathrm{C}(13)$ & $1.848(3)$ & $C(24)-C(25)$ & $1.375(5)$ \\
\hline$P(2)-C(15)$ & $1.829(3)$ & $C(25)-C(26)$ & $1.399(5)$ \\
\hline $\mathrm{P}(2)-\mathrm{C}(21)$ & $1.832(3)$ & $C(27)-C(28)$ & $1.424(4)$ \\
\hline $\mathrm{P}(2)-\mathrm{C}(14)$ & $1.856(3)$ & $\mathrm{C}(27)-\mathrm{C}(32)$ & $1.427(4)$ \\
\hline $\mathrm{O}(1)-\mathrm{C}(33)$ & $1.210(4)$ & $\mathrm{C}(28)-\mathrm{C}(29)$ & $1.368(4)$ \\
\hline $\mathrm{O}(2)-\mathrm{C}(33)$ & $1.343(4)$ & $C(29)-C(30)$ & $1.392(4)$ \\
\hline $\mathrm{O}(2)-\mathrm{C}(34)$ & $1.432(4)$ & $\mathrm{C}(30)-\mathrm{C}(31)$ & $1.399(4)$ \\
\hline $\mathrm{N}(1)-\mathrm{C}(27)$ & $1.353(4)$ & $C(30)-C(33)$ & $1.458(4)$ \\
\hline $\mathrm{N}(1)-\mathrm{C}(35)$ & $1.465(3)$ & $\mathrm{C}(31)-\mathrm{C}(32)$ & $1.379(4)$ \\
\hline $\mathrm{N}(2)-\mathrm{C}(54)$ & $1.337(4)$ & $C(35)-C(36)$ & $1.526(4)$ \\
\hline $\mathrm{N}(2)-\mathrm{C}(50)$ & $1.347(4)$ & $C(35)-C(43)$ & $1.536(4)$ \\
\hline $\mathrm{C}(1)-\mathrm{C}(6)$ & $1.392(4)$ & $\mathrm{C}(36)-\mathrm{C}(41)$ & $1.383(4)$ \\
\hline $\mathrm{C}(1)-\mathrm{C}(2)$ & $1.396(4)$ & $\mathrm{C}(36)-\mathrm{C}(37)$ & $1.389(4)$ \\
\hline$C(2)-C(3)$ & $1.394(5)$ & $\mathrm{C}(37)-\mathrm{C}(38)$ & $1.390(4)$ \\
\hline $\mathrm{C}(3)-\mathrm{C}(4)$ & $1.376(5)$ & $\mathrm{C}(38)-\mathrm{C}(39)$ & $1.390(4)$ \\
\hline$C(4)-C(5)$ & $1.363(5)$ & $\mathrm{C}(39)-\mathrm{C}(40)$ & $1.381(5)$ \\
\hline $\mathrm{C}(5)-\mathrm{C}(6)$ & $1.383(4)$ & $\mathrm{C}(39)-\mathrm{C}(42)$ & $1.515(4)$ \\
\hline $\mathrm{C}(7)-\mathrm{C}(8)$ & $1.384(4)$ & $\mathrm{C}(40)-\mathrm{C}(41)$ & $1.392(4)$ \\
\hline$C(7)-C(12)$ & $1.392(4)$ & $\mathrm{C}(43)-\mathrm{C}(48)$ & $1.376(4)$ \\
\hline $\mathrm{C}(8)-\mathrm{C}(9)$ & $1.388(4)$ & $\mathrm{C}(43)-\mathrm{C}(44)$ & $1.381(4)$ \\
\hline $\mathrm{C}(9)-\mathrm{C}(10)$ & $1.377(5)$ & $\mathrm{C}(44)-\mathrm{C}(45)$ & $1.386(5)$ \\
\hline $\mathrm{C}(10)-\mathrm{C}(11)$ & $1.380(5)$ & $\mathrm{C}(45)-\mathrm{C}(46)$ & $1.392(5)$ \\
\hline $\mathrm{C}(11)-\mathrm{C}(12)$ & $1.384(4)$ & $\mathrm{C}(46)-\mathrm{C}(47)$ & $1.366(5)$ \\
\hline$C(13)-C(14)$ & $1.523(4)$ & $C(46)-C(49)$ & $1.521(5)$ \\
\hline$C(15)-C(20)$ & $1.383(4)$ & $\mathrm{C}(47)-\mathrm{C}(48)$ & $1.398(5)$ \\
\hline$C(15)-C(16)$ & $1.399(4)$ & $C(50)-C(51)$ & $1.382(4)$ \\
\hline$C(16)-C(17)$ & $1.376(5)$ & $C(51)-C(52)$ & $1.378(5)$ \\
\hline $\mathrm{C}(17)-\mathrm{C}(18)$ & $1.380(5)$ & $\mathrm{C}(52)-\mathrm{C}(53)$ & $1.376(5)$ \\
\hline
\end{tabular}




\begin{tabular}{|c|c|c|c|}
\hline$C(53)-C(54)$ & $1.378(4)$ & $\mathrm{C}(27)-\mathrm{N}(1)-\mathrm{Rh}(1)$ & $120.90(18)$ \\
\hline$C(55)-C\left(56^{\prime}\right)$ & $1.158(17)$ & $\mathrm{C}(35)-\mathrm{N}(1)-\mathrm{Rh}(1)$ & $122.43(17)$ \\
\hline$C(55)-C(56)$ & $1.330(11)$ & $\mathrm{C}(54)-\mathrm{N}(2)-\mathrm{C}(50)$ & $116.8(3)$ \\
\hline$C(55)-C\left(60^{\prime}\right)$ & $1.308(18)$ & $\mathrm{C}(54)-\mathrm{N}(2)-\mathrm{Rh}(1)$ & $125.9(2)$ \\
\hline$C(55)-C(60)$ & $1.488(9)$ & $\mathrm{C}(50)-\mathrm{N}(2)-\mathrm{Rh}(1)$ & $116.8(2)$ \\
\hline $\mathrm{C}(57)-\mathrm{C}\left(60^{\prime}\right)$ & $1.232(15)$ & $\mathrm{C}(6)-\mathrm{C}(1)-\mathrm{C}(2)$ & $119.0(3)$ \\
\hline$C(57)-C(56)$ & $1.441(11)$ & $\mathrm{C}(6)-\mathrm{C}(1)-\mathrm{P}(1)$ & $118.6(2)$ \\
\hline$C(57)-C(58)$ & $1.482(8)$ & $\mathrm{C}(2)-\mathrm{C}(1)-\mathrm{P}(1)$ & $122.3(2)$ \\
\hline $\mathrm{C}(59)-\mathrm{C}\left(58^{\prime}\right)$ & $1.27(2)$ & $\mathrm{C}(3)-\mathrm{C}(2)-\mathrm{C}(1)$ & $119.5(3)$ \\
\hline$C(59)-C(58)$ & $1.343(7)$ & $\mathrm{C}(4)-\mathrm{C}(3)-\mathrm{C}(2)$ & $120.7(3)$ \\
\hline$C(59)-C(60)$ & $1.372(7)$ & $C(5)-C(4)-C(3)$ & $119.8(3)$ \\
\hline $\mathrm{C}(59)-\mathrm{C}\left(60^{\prime}\right)$ & $1.73(3)$ & $\mathrm{C}(4)-\mathrm{C}(5)-\mathrm{C}(6)$ & $120.8(3)$ \\
\hline $\mathrm{C}(61)-\mathrm{C}\left(58^{\prime}\right)$ & $1.40(3)$ & $C(5)-C(6)-C(1)$ & $120.3(3)$ \\
\hline$C(61)-C(60)$ & $1.429(9)$ & $\mathrm{C}(8)-\mathrm{C}(7)-\mathrm{C}(12)$ & $118.5(3)$ \\
\hline \multirow[t]{2}{*}{$\mathrm{C}(61)-\mathrm{C}\left(56^{\prime}\right)$} & $1.785(19)$ & $\mathrm{C}(8)-\mathrm{C}(7)-\mathrm{P}(1)$ & $123.6(2)$ \\
\hline & & $\mathrm{C}(12)-\mathrm{C}(7)-\mathrm{P}(1)$ & $117.9(2)$ \\
\hline $\mathrm{N}(2)-\mathrm{Rh}(1)-\mathrm{N}(1)$ & $88.44(9)$ & $\mathrm{C}(7)-\mathrm{C}(8)-\mathrm{C}(9)$ & $120.3(3)$ \\
\hline $\mathrm{N}(2)-\mathrm{Rh}(1)-\mathrm{P}(2)$ & $91.09(7)$ & $C(10)-C(9)-C(8)$ & $120.7(3)$ \\
\hline $\mathrm{N}(1)-\mathrm{Rh}(1)-\mathrm{P}(2)$ & $179.14(7)$ & $\mathrm{C}(9)-\mathrm{C}(10)-\mathrm{C}(11)$ & 119.6(3) \\
\hline $\mathrm{N}(2)-\mathrm{Rh}(1)-\mathrm{P}(1)$ & $170.71(7)$ & $C(12)-C(11)-C(10)$ & $119.8(3)$ \\
\hline $\mathrm{N}(1)-\mathrm{Rh}(1)-\mathrm{P}(1)$ & $96.09(7)$ & $\mathrm{C}(11)-\mathrm{C}(12)-\mathrm{C}(7)$ & 121.1(3) \\
\hline $\mathrm{P}(2)-\mathrm{Rh}(1)-\mathrm{P}(1)$ & $84.27(3)$ & $\mathrm{C}(14)-\mathrm{C}(13)-\mathrm{P}(1)$ & $107.5(2)$ \\
\hline $\mathrm{C}(1)-\mathrm{P}(1)-\mathrm{C}(7)$ & $101.84(14)$ & $\mathrm{C}(13)-\mathrm{C}(14)-\mathrm{P}(2)$ & $106.8(2)$ \\
\hline $\mathrm{C}(1)-\mathrm{P}(1)-\mathrm{C}(13)$ & $104.80(14)$ & $C(20)-C(15)-C(16)$ & $117.9(3)$ \\
\hline $\mathrm{C}(7)-\mathrm{P}(1)-\mathrm{C}(13)$ & $100.93(14)$ & $\mathrm{C}(20)-\mathrm{C}(15)-\mathrm{P}(2)$ & $119.1(2)$ \\
\hline $\mathrm{C}(1)-\mathrm{P}(1)-\mathrm{Rh}(1)$ & $122.49(10)$ & $\mathrm{C}(16)-\mathrm{C}(15)-\mathrm{P}(2)$ & $122.2(2)$ \\
\hline $\mathrm{C}(7)-\mathrm{P}(1)-\mathrm{Rh}(1)$ & $114.53(10)$ & $C(17)-C(16)-C(15)$ & $120.4(3)$ \\
\hline $\mathrm{C}(13)-\mathrm{P}(1)-\mathrm{Rh}(1)$ & 109.77(10) & $\mathrm{C}(16)-\mathrm{C}(17)-\mathrm{C}(18)$ & $121.0(4)$ \\
\hline $\mathrm{C}(15)-\mathrm{P}(2)-\mathrm{C}(21)$ & 103.51(14) & $\mathrm{C}(19)-\mathrm{C}(18)-\mathrm{C}(17)$ & 119.1(3) \\
\hline $\mathrm{C}(15)-\mathrm{P}(2)-\mathrm{C}(14)$ & $106.33(15)$ & $\mathrm{C}(18)-\mathrm{C}(19)-\mathrm{C}(20)$ & $120.3(3)$ \\
\hline $\mathrm{C}(21)-\mathrm{P}(2)-\mathrm{C}(14)$ & $100.78(14)$ & $C(15)-C(20)-C(19)$ & 121.2(3) \\
\hline $\mathrm{C}(15)-\mathrm{P}(2)-\mathrm{Rh}(1)$ & 114.99(10) & $C(22)-C(21)-C(26)$ & 118.7(3) \\
\hline $\mathrm{C}(21)-\mathrm{P}(2)-\mathrm{Rh}(1)$ & $117.83(10)$ & $\mathrm{C}(22)-\mathrm{C}(21)-\mathrm{P}(2)$ & $119.4(2)$ \\
\hline $\mathrm{C}(14)-\mathrm{P}(2)-\mathrm{Rh}(1)$ & $111.87(10)$ & $\mathrm{C}(26)-\mathrm{C}(21)-\mathrm{P}(2)$ & $121.9(2)$ \\
\hline $\mathrm{C}(33)-\mathrm{O}(2)-\mathrm{C}(34)$ & $116.0(3)$ & $\mathrm{C}(23)-\mathrm{C}(22)-\mathrm{C}(21)$ & $121.0(3)$ \\
\hline $\mathrm{C}(27)-\mathrm{N}(1)-\mathrm{C}(35)$ & $115.7(2)$ & $\mathrm{C}(22)-\mathrm{C}(23)-\mathrm{C}(24)$ & $119.8(3)$ \\
\hline
\end{tabular}




\begin{tabular}{|c|c|c|c|}
\hline$C(25)-C(24)-C(23)$ & $120.6(3)$ & $C(45)-C(46)-C(49)$ & $120.3(4)$ \\
\hline$C(24)-C(25)-C(26)$ & $119.5(3)$ & $\mathrm{C}(46)-\mathrm{C}(47)-\mathrm{C}(48)$ & $121.0(4)$ \\
\hline$C(25)-C(26)-C(21)$ & $120.3(3)$ & $\mathrm{C}(43)-\mathrm{C}(48)-\mathrm{C}(47)$ & $121.2(3)$ \\
\hline $\mathrm{N}(1)-\mathrm{C}(27)-\mathrm{C}(28)$ & $118.5(3)$ & $\mathrm{N}(2)-\mathrm{C}(50)-\mathrm{C}(51)$ & $122.8(3)$ \\
\hline $\mathrm{N}(1)-\mathrm{C}(27)-\mathrm{C}(32)$ & $126.5(3)$ & $C(52)-C(51)-C(50)$ & $119.5(3)$ \\
\hline$C(28)-C(27)-C(32)$ & $115.1(3)$ & $C(53)-C(52)-C(51)$ & $117.9(3)$ \\
\hline$C(29)-C(28)-C(27)$ & $122.5(3)$ & $C(52)-C(53)-C(54)$ & $119.4(3)$ \\
\hline$C(28)-C(29)-C(30)$ & $121.9(3)$ & $\mathrm{N}(2)-\mathrm{C}(54)-\mathrm{C}(53)$ & $123.5(3)$ \\
\hline$C(29)-C(30)-C(31)$ & $116.7(3)$ & $\mathrm{C}\left(56^{\prime}\right)-\mathrm{C}(55)-\mathrm{C}(56)$ & $167.9(10)$ \\
\hline$C(29)-C(30)-C(33)$ & $119.4(3)$ & $\mathrm{C}\left(56^{\prime}\right)-\mathrm{C}(55)-\mathrm{C}\left(60^{\prime}\right)$ & $144.8(14)$ \\
\hline$C(31)-C(30)-C(33)$ & $123.9(3)$ & $\mathrm{C}(56)-\mathrm{C}(55)-\mathrm{C}\left(60^{\prime}\right)$ & $45.2(10)$ \\
\hline$C(32)-C(31)-C(30)$ & $122.6(3)$ & $\mathrm{C}\left(56^{\prime}\right)-\mathrm{C}(55)-\mathrm{C}(60)$ & $68.4(9)$ \\
\hline$C(31)-C(32)-C(27)$ & 121.1(3) & $C(56)-C(55)-C(60)$ & $122.3(6)$ \\
\hline $\mathrm{O}(1)-\mathrm{C}(33)-\mathrm{O}(2)$ & $121.2(3)$ & $\mathrm{C}\left(60^{\prime}\right)-\mathrm{C}(55)-\mathrm{C}(60)$ & $77.1(11)$ \\
\hline $\mathrm{O}(1)-\mathrm{C}(33)-\mathrm{C}(30)$ & $124.9(3)$ & $\mathrm{C}\left(60^{\prime}\right)-\mathrm{C}(57)-\mathrm{C}(56)$ & $43.7(12)$ \\
\hline $\mathrm{O}(2)-\mathrm{C}(33)-\mathrm{C}(30)$ & $113.9(3)$ & $\mathrm{C}\left(60^{\prime}\right)-\mathrm{C}(57)-\mathrm{C}(58)$ & $70.5(13)$ \\
\hline $\mathrm{N}(1)-\mathrm{C}(35)-\mathrm{C}(36)$ & $113.9(2)$ & $C(56)-C(57)-C(58)$ & $114.2(6)$ \\
\hline $\mathrm{N}(1)-\mathrm{C}(35)-\mathrm{C}(43)$ & $112.7(2)$ & $\mathrm{C}\left(58^{\prime}\right)-\mathrm{C}(59)-\mathrm{C}(58)$ & $175.6(14)$ \\
\hline$C(36)-C(35)-C(43)$ & $109.6(2)$ & $\mathrm{C}\left(58^{\prime}\right)-\mathrm{C}(59)-\mathrm{C}(60)$ & $48.0(12)$ \\
\hline$C(41)-C(36)-C(37)$ & 117.7(3) & $C(58)-C(59)-C(60)$ & $127.7(6)$ \\
\hline$C(41)-C(36)-C(35)$ & $119.0(3)$ & $\mathrm{C}\left(58^{\prime}\right)-\mathrm{C}(59)-\mathrm{C}\left(60^{\prime}\right)$ & $115.4(14)$ \\
\hline$C(37)-C(36)-C(35)$ & $123.2(3)$ & $\mathrm{C}(58)-\mathrm{C}(59)-\mathrm{C}\left(60^{\prime}\right)$ & $60.3(6)$ \\
\hline $\mathrm{C}(36)-\mathrm{C}(37)-\mathrm{C}(38)$ & 121.1(3) & $\mathrm{C}(60)-\mathrm{C}(59)-\mathrm{C}\left(60^{\prime}\right)$ & $67.5(6)$ \\
\hline $\mathrm{C}(39)-\mathrm{C}(38)-\mathrm{C}(37)$ & $121.0(3)$ & $\mathrm{C}\left(58^{\prime}\right)-\mathrm{C}(61)-\mathrm{C}(60)$ & $44.9(7)$ \\
\hline $\mathrm{C}(40)-\mathrm{C}(39)-\mathrm{C}(38)$ & $117.7(3)$ & $\mathrm{C}\left(58^{\prime}\right)-\mathrm{C}(61)-\mathrm{C}\left(56^{\prime}\right)$ & $99.5(10)$ \\
\hline $\mathrm{C}(40)-\mathrm{C}(39)-\mathrm{C}(42)$ & 121.1(3) & $\mathrm{C}(60)-\mathrm{C}(61)-\mathrm{C}\left(56^{\prime}\right)$ & $54.8(6)$ \\
\hline $\mathrm{C}(38)-\mathrm{C}(39)-\mathrm{C}(42)$ & 121.2(3) & $\mathrm{C}(55)-\mathrm{C}(56)-\mathrm{C}(57)$ & $123.3(6)$ \\
\hline$C(39)-C(40)-C(41)$ & $121.3(3)$ & C(59)-C(58)-C(57) & $119.4(5)$ \\
\hline$C(36)-C(41)-C(40)$ & 121.1(3) & $\mathrm{C}(59)-\mathrm{C}(60)-\mathrm{C}(61)$ & $127.3(7)$ \\
\hline$C(48)-C(43)-C(44)$ & $117.8(3)$ & C(59)-C(60)-C(55) & $112.9(6)$ \\
\hline $\mathrm{C}(48)-\mathrm{C}(43)-\mathrm{C}(35)$ & $122.1(3)$ & $\mathrm{C}(61)-\mathrm{C}(60)-\mathrm{C}(55)$ & $119.8(6)$ \\
\hline$C(44)-C(43)-C(35)$ & $119.9(3)$ & $\mathrm{C}(55)-\mathrm{C}\left(56^{\prime}\right)-\mathrm{C}(61)$ & $116.4(11)$ \\
\hline$C(43)-C(44)-C(45)$ & $121.3(4)$ & $\mathrm{C}(59)-\mathrm{C}\left(58^{\prime}\right)-\mathrm{C}(61)$ & $139.8(19)$ \\
\hline$C(44)-C(45)-C(46)$ & $120.7(4)$ & $\mathrm{C}(57)-\mathrm{C}\left(60^{\prime}\right)-\mathrm{C}(55)$ & $148(2)$ \\
\hline$C(47)-C(46)-C(45)$ & $118.1(3)$ & $\mathrm{C}(57)-\mathrm{C}\left(60^{\prime}\right)-\mathrm{C}(59)$ & $109.7(16)$ \\
\hline$C(47)-C(46)-C(49)$ & $121.6(4)$ & $\mathrm{C}(55)-\mathrm{C}\left(60^{\prime}\right)-\mathrm{C}(59)$ & $102.4(12)$ \\
\hline
\end{tabular}


Table S10. Anisotropic displacement parameters $\left(\AA^{2} \times 10^{3}\right)$ for 4 . The anisotropic displacement factor exponent takes the form: $-2 \pi^{2}\left[h^{2} a^{* 2} U^{11}+\ldots+2 h k a^{*} b^{*} U^{12}\right]$.

$\begin{array}{lcccccc} & \mathrm{U}^{11} & \mathrm{U}^{22} & \mathrm{U}^{33} & \mathrm{U}^{23} & \mathrm{U}^{13} & \mathrm{U} \\ & & & & & & \\ \mathrm{Rh}(1) & 23(1) & 19(1) & 19(1) & 0(1) & 8(1) & -1(1) \\ \mathrm{P}(1) & 22(1) & 22(1) & 21(1) & 0(1) & 8(1) & 1(1) \\ \mathrm{P}(2) & 29(1) & 20(1) & 23(1) & -1(1) & 10(1) & -3(1) \\ \mathrm{O}(1) & 44(2) & 45(2) & 60(2) & -12(1) & 31(1) & 2(1) \\ \mathrm{O}(2) & 76(2) & 25(1) & 82(2) & -11(1) & 60(2) & -4(1) \\ \mathrm{N}(1) & 24(1) & 16(1) & 28(1) & 1(1) & 12(1) & -1(1) \\ \mathrm{N}(2) & 29(1) & 23(1) & 21(1) & 2(1) & 7(1) & -4(1) \\ \mathrm{C}(1) & 23(2) & 33(2) & 22(2) & -3(1) & 10(1) & 1(1) \\ \mathrm{C}(2) & 28(2) & 37(2) & 38(2) & 7(2) & 10(2) & 1(2) \\ \mathrm{C}(3) & 21(2) & 66(3) & 49(2) & 12(2) & 4(2) & 8(2) \\ \mathrm{C}(4) & 25(2) & 63(3) & 40(2) & -14(2) & 8(2) & -13(2) \\ \mathrm{C}(5) & 33(2) & 38(2) & 44(2) & -11(2) & 16(2) & -6(2) \\ \mathrm{C}(6) & 28(2) & 35(2) & 29(2) & -6(2) & 11(1) & -2(1) \\ \mathrm{C}(7) & 29(2) & 23(2) & 23(2) & 1(1) & 13(1) & -1(1) \\ \mathrm{C}(8) & 33(2) & 37(2) & 26(2) & -5(2) & 12(2) & -2(2) \\ \mathrm{C}(9) & 47(2) & 49(2) & 36(2) & -14(2) & 23(2) & -3(2) \\ \mathrm{C}(10) & 41(2) & 44(2) & 48(2) & 3(2) & 30(2) & 8(2) \\ \mathrm{C}(11) & 24(2) & 40(2) & 41(2) & 11(2) & 16(2) & 1(2) \\ \mathrm{C}(12) & 28(2) & 29(2) & 23(2) & 3(1) & 10(1) & -3(1) \\ \mathrm{C}(13) & 36(2) & 25(2) & 26(2) & 3(1) & 12(2) & 3(1) \\ \mathrm{C}(14) & 41(2) & 23(2) & 28(2) & 1(1) & 17(2) & -3(1) \\ \mathrm{C}(15) & 29(2) & 23(2) & 31(2) & -2(1) & 10(2) & -4(1) \\ \mathrm{C}(16) & 33(2) & 39(2) & 37(2) & -8(2) & 15(2) & -10(2) \\ \mathrm{C}(17) & 29(2) & 51(2) & 68(3) & -10(2) & 20(2) & -7(2) \\ \mathrm{C}(18) & 33(2) & 55(2) & 54(3) & -4(2) & 5(2) & -11(2) \\ \mathrm{C}(19) & 36(2) & 53(2) & 31(2) & -4(2) & 5(2) & -16(2) \\ \mathrm{C}(20) & 35(2) & 37(2) & 31(2) & -1(2) & 11(2) & -10(2) \\ \mathrm{C}(21) & 35(2) & 24(2) & 20(2) & -3(1) & 8(1) & -1(1) \\ \mathrm{C}(22) & 37(2) & 27(2) & 32(2) & 0(2) & 8(2) & 1(2) \\ \mathrm{C}(23) & 42(2) & 53(2) & 42(2) & -2(2) & 17(2) & 15(2) \\ \mathrm{C}(24) & 62(3) & 38(2) & 40(2) & -5(2) & 14(2) & 22(2)\end{array}$




\begin{tabular}{|c|c|c|c|c|c|c|}
\hline$C(25)$ & $72(3)$ & $22(2)$ & $35(2)$ & $0(2)$ & $11(2)$ & $4(2)$ \\
\hline$C(26)$ & $53(2)$ & $27(2)$ & $31(2)$ & $-2(2)$ & $15(2)$ & $-2(2)$ \\
\hline$C(27)$ & $24(2)$ & $23(2)$ & $21(2)$ & $2(1)$ & $7(1)$ & $1(1)$ \\
\hline $\mathrm{C}(28)$ & $23(2)$ & $22(2)$ & $23(2)$ & $2(1)$ & $8(1)$ & $1(1)$ \\
\hline $\mathrm{C}(29)$ & $23(2)$ & $28(2)$ & $26(2)$ & $2(1)$ & $10(1)$ & $1(1)$ \\
\hline$C(30)$ & $27(2)$ & $29(2)$ & $27(2)$ & $2(1)$ & $11(1)$ & $5(1)$ \\
\hline $\mathrm{C}(31)$ & $33(2)$ & $22(2)$ & $31(2)$ & $0(1)$ & $15(2)$ & $-1(1)$ \\
\hline$C(32)$ & $28(2)$ & $25(2)$ & $29(2)$ & $0(1)$ & $14(1)$ & $-3(1)$ \\
\hline$C(33)$ & $40(2)$ & $33(2)$ & $29(2)$ & $0(2)$ & $17(2)$ & $6(2)$ \\
\hline$C(34)$ & $93(3)$ & $32(2)$ & $99(4)$ & $-10(2)$ & $74(3)$ & $5(2)$ \\
\hline$C(35)$ & $24(2)$ & $24(2)$ & $26(2)$ & $1(1)$ & $13(1)$ & $-2(1)$ \\
\hline$C(36)$ & $28(2)$ & $21(2)$ & $25(2)$ & $1(1)$ & $15(1)$ & $4(1)$ \\
\hline$C(37)$ & $28(2)$ & $30(2)$ & $39(2)$ & $3(2)$ & $16(2)$ & $-6(1)$ \\
\hline $\mathrm{C}(38)$ & $32(2)$ & $41(2)$ & $31(2)$ & $10(2)$ & $9(2)$ & $5(2)$ \\
\hline$C(39)$ & $42(2)$ & $28(2)$ & $31(2)$ & $1(2)$ & $18(2)$ & $-2(2)$ \\
\hline $\mathrm{C}(40)$ & $35(2)$ & $27(2)$ & $42(2)$ & $2(2)$ & $20(2)$ & $-6(2)$ \\
\hline$C(41)$ & $24(2)$ & $32(2)$ & $34(2)$ & $2(2)$ & 11(1) & $0(1)$ \\
\hline$C(42)$ & $65(3)$ & $42(2)$ & $37(2)$ & $9(2)$ & $21(2)$ & $-6(2)$ \\
\hline$C(43)$ & $32(2)$ & $25(2)$ & $37(2)$ & $6(2)$ & $20(2)$ & $1(1)$ \\
\hline$C(44)$ & $39(2)$ & $44(2)$ & $43(2)$ & $13(2)$ & $23(2)$ & $16(2)$ \\
\hline $\mathrm{C}(45)$ & $46(2)$ & $50(2)$ & $55(3)$ & $20(2)$ & $27(2)$ & $17(2)$ \\
\hline$C(46)$ & $47(2)$ & $29(2)$ & $79(3)$ & $7(2)$ & $43(2)$ & $6(2)$ \\
\hline$C(47)$ & $42(2)$ & $34(2)$ & $54(2)$ & $-2(2)$ & $27(2)$ & $-1(2)$ \\
\hline $\mathrm{C}(48)$ & $35(2)$ & $29(2)$ & $45(2)$ & $-1(2)$ & $19(2)$ & $-1(2)$ \\
\hline $\mathrm{C}(49)$ & 64(3) & $42(2)$ & 115(4) & $0(3)$ & $56(3)$ & $16(2)$ \\
\hline$C(50)$ & $39(2)$ & $30(2)$ & $32(2)$ & $-2(2)$ & $9(2)$ & $-1(2)$ \\
\hline$C(51)$ & $39(2)$ & $47(2)$ & $37(2)$ & $11(2)$ & $2(2)$ & $3(2)$ \\
\hline$C(52)$ & $49(2)$ & $41(2)$ & $22(2)$ & $3(2)$ & $3(2)$ & $-14(2)$ \\
\hline$C(53)$ & $54(2)$ & $34(2)$ & $23(2)$ & $-4(2)$ & $15(2)$ & $-10(2)$ \\
\hline$C(54)$ & $39(2)$ & $29(2)$ & $28(2)$ & $2(2)$ & $14(2)$ & $-1(2)$ \\
\hline$C(55)$ & $70(3)$ & $49(3)$ & $49(3)$ & $-7(2)$ & $2(3)$ & $15(3)$ \\
\hline$C(57)$ & $93(4)$ & $48(3)$ & $76(4)$ & $3(3)$ & $17(3)$ & $10(3)$ \\
\hline $\mathrm{C}(59)$ & $70(3)$ & $41(2)$ & $39(2)$ & $3(2)$ & $10(2)$ & $16(2)$ \\
\hline $\mathrm{C}(61)$ & $59(3)$ & $79(4)$ & $124(5)$ & $-38(4)$ & $8(3)$ & $7(3)$ \\
\hline$C(56)$ & 130(9) & $40(4)$ & $53(5)$ & $12(4)$ & $51(6)$ & $22(5)$ \\
\hline $\mathrm{C}(58)$ & $40(3)$ & $36(3)$ & $45(4)$ & $9(3)$ & $6(3)$ & $7(3)$ \\
\hline
\end{tabular}




$\begin{array}{ccccccc}\mathrm{C}(60) & 43(4) & 27(3) & 52(4) & -6(3) & 12(3) & 13(3) \\ \mathrm{C}\left(56^{\prime}\right) & 104(12) & 33(7) & 74(11) & -12(7) & 0(10) & 12(8) \\ \mathrm{C}\left(58^{\prime}\right) & 180(20) & 56(11) & 280(30) & 83(15) & 200(20) & 76(13) \\ \mathrm{C}\left(60^{\prime}\right) & 27(8) & 27(7) & 190(20) & -9(12) & 4(11) & 15(6)\end{array}$


Table S11. Hydrogen coordinates $\left(\mathrm{x} 10^{4}\right)$ and isotropic displacement parameters $\left(\AA^{2} \times 10^{3}\right)$ for 4.

$\begin{array}{lrrrr} & x & y & \mathrm{z} & \mathrm{U}(\mathrm{eq}) \\ \mathrm{H}(2 \mathrm{~A}) & & & & \\ \mathrm{H}(3 \mathrm{~A}) & 8849 & 7597 & 6074 & 42 \\ \mathrm{H}(4 \mathrm{~A}) & 10070 & 10038 & 6687 & 57 \\ \mathrm{H}(5 \mathrm{~A}) & 9153 & 11029 & 6023 & 53 \\ \mathrm{H}(6 \mathrm{~A}) & 8080 & 10331 & 5372 & 36 \\ \mathrm{H}(8 \mathrm{~A}) & 7621 & 9259 & 6471 & 38 \\ \mathrm{H}(9 \mathrm{~A}) & 6809 & 9834 & 6956 & 50 \\ \mathrm{H}(10 \mathrm{~A}) & 5621 & 9763 & 6305 & 49 \\ \mathrm{H}(11 \mathrm{~A}) & 5238 & 9040 & 5177 & 41 \\ \mathrm{H}(12 \mathrm{~A}) & 6048 & 8510 & 4675 & 32 \\ \mathrm{H}(13 \mathrm{~A}) & 7979 & 6730 & 5267 & 34 \\ \mathrm{H}(13 \mathrm{~B}) & 7603 & 6968 & 5831 & 34 \\ \mathrm{H}(14 \mathrm{~A}) & 6500 & 6738 & 4983 & 35 \\ \mathrm{H}(14 \mathrm{~B}) & 6950 & 5817 & 4868 & 35 \\ \mathrm{H}(16 \mathrm{~A}) & 5432 & 7108 & 4185 & 43 \\ \mathrm{H}(17 \mathrm{~A}) & 4279 & 7210 & 3440 & 58 \\ \mathrm{H}(18 \mathrm{~A}) & 3969 & 6913 & 2226 & 60 \\ \mathrm{H}(19 \mathrm{~A}) & 4829 & 6484 & 1764 & 50 \\ \mathrm{H}(20 \mathrm{~A}) & 5992 & 6418 & 2499 & 41 \\ \mathrm{H}(22 \mathrm{~A}) & 7995 & 6879 & 3561 & 39 \\ \mathrm{H}(23 \mathrm{~A}) & 8602 & 5644 & 3211 & 54 \\ \mathrm{H}(24 \mathrm{~A}) & 8171 & 4026 & 3035 & 57 \\ \mathrm{H}(25 \mathrm{~A}) & 7148 & 3626 & 3232 & 54 \\ \mathrm{H}(26 \mathrm{~A}) & 6537 & 4866 & 3598 & 45 \\ \mathrm{H}(28 \mathrm{~A}) & 6336 & 9954 & 4153 & 27 \\ \mathrm{H}(29 \mathrm{~A}) & 5805 & 11119 & 4622 & 30 \\ \mathrm{H}(31 \mathrm{~A}) & 7249 & 13147 & 4602 & 34 \\ \mathrm{H}(32 \mathrm{~A}) & 6358 & 15202 & 5512 & 31 \\ \mathrm{H}(34 \mathrm{~A}) & 5614 & 14704 & 5109 & 96 \\ \mathrm{H}(34 \mathrm{~B}) & & & & 96 \\ \mathrm{H}(34 \mathrm{C}) & & 11985 & 4159 & \end{array}$


$\mathrm{H}(35 \mathrm{~A})$

$\mathrm{H}(37 \mathrm{~A})$

$\mathrm{H}(38 \mathrm{~A})$

$\mathrm{H}(40 \mathrm{~A})$

$\mathrm{H}(41 \mathrm{~A})$

$\mathrm{H}(42 \mathrm{~A})$

$\mathrm{H}(42 \mathrm{~B})$

$\mathrm{H}(42 \mathrm{C})$

$\mathrm{H}(44 \mathrm{~A})$

$\mathrm{H}(45 \mathrm{~A})$

$\mathrm{H}(47 \mathrm{~A})$

$\mathrm{H}(48 \mathrm{~A})$

$\mathrm{H}(49 \mathrm{~A})$

$\mathrm{H}(49 \mathrm{~B})$

$\mathrm{H}(49 \mathrm{C})$

$\mathrm{H}(50 \mathrm{~A})$

$\mathrm{H}(51 \mathrm{~A})$

$\mathrm{H}(52 \mathrm{~A})$

$\mathrm{H}(53 \mathrm{~A})$

$\mathrm{H}(54 \mathrm{~A})$
8429

7013

6912

8930

9028

8288

7486

7696

9154

9854

8752

8063

9711

9852

10341

5902

5142

5390

6439

7154
10643

10717

11801

12566

11499

13378

13549

12699

9288

7988

7835

9160

6746

6409

7228

9587

9591

8614

7718

7731
$4228 \quad 28$

$2602 \quad 38$

$1670 \quad 42$

$2592 \quad 40$

$3533 \quad 36$

$1528 \quad 71$

$1436 \quad 71$

$989 \quad 71$

$4745 \quad 47$

$4631 \quad 58$

$2540 \quad 49$

$2654 \quad 42$

$2994 \quad 101$

$3797 \quad 101$

$3628 \quad 101$

$2918 \quad 41$

$1753 \quad 53$

$902 \quad 48$

$1257 \quad 44$

$2434 \quad 37$ 


\section{Experimental Procedure for the X-ray Diffraction of 6}

\section{Data Collection}

A yellow block crystal of $\mathrm{C}_{54} \mathrm{H}_{59} \mathrm{NO}_{2} \mathrm{P}_{3} \mathrm{Rh} \cdot 1.5 \mathrm{Et}_{2} \mathrm{O}, \mathrm{C}_{60} \mathrm{H}_{74} \mathrm{NO}_{3.5} \mathrm{P}_{3} \mathrm{Rh}$, having approximate dimensions of $0.20 \times 0.20 \times 0.20 \mathrm{~mm}$ was mounted with epoxy cement on the tip of a fine glass fiber. All measurements were made on a Nonius KappaCCD diffractometer with graphite monochromated Mo-K $\alpha$ radiation.

Cell constants and an orientation matrix for data collection corresponded to a primitive monoclinic cell with dimensions:

$$
\begin{array}{lll}
\mathrm{a}= & 12.122(2) \AA & \alpha=90 \mathrm{o} \\
\mathrm{b}= & 19.864(4) \AA & \beta=90.85(3) \mathrm{o} \\
\mathrm{c}= & 22.607(5) \AA & \gamma=90^{\circ} \\
\mathrm{V}= & 5443.0(19) \AA^{3} &
\end{array}
$$

For $\mathrm{Z}=4$ and F.W. $=1061.02$, the calculated density is $1.295 \mathrm{~g} / \mathrm{cm}^{3}$. Based on a statistical analysis of intensity distribution, and the successful solution and refinement of the structure, the space group was determined to be: $P 2_{1} / n$ (\#14)

The data were collected at a temperature of $183(2) \mathrm{K}$ to a maximum $2 \theta$ value of $55.80^{\circ}$. Three omega scans consisting of 99, 82, and 17 data frames, respectively, were collected with a frame width of $1.2^{\circ}$ and a detector-to-crystal distance, Dx, of $35 \mathrm{~mm}$. Each frame was exposed twice (for the purpose of de-zingering) for a total of 48 seconds. The data frames were processed and scaled using the DENZO software package. ${ }^{1}$

\section{Data Reduction}

A total of 20683 reflections were collected of which 12640 were unique and observed $\left(\mathrm{R}_{\text {int }}=0.0634\right)$. The linear absorption coefficient, $\mu$, for Mo-K $\alpha$ radiation is $4.48 \mathrm{~cm}^{-1}$ and no absorption correction was applied. The data were corrected for Lorentz and polarization effects.

\section{$\underline{\text { Structure Solution and Refinement }}$}

The structure was solved by direct methods and expanded using Fourier techniques ${ }^{2}$. The non-hydrogen atoms were refined anisotropically and hydrogen atoms were treated as idealized contributions. The final cycle of full-matrix least-squares refinement ${ }^{3}$ on $\mathrm{F}_{\text {was }}$ based on 12640 observed reflections (I > 2.00б(I)) and 625 variable parameters and converged with unweighted and weighted agreement factors of:

$$
\mathrm{R}=\Sigma\|\mathrm{Fol}-|\mathrm{Fc} \| / \Sigma| \mathrm{Fol}=0.0544
$$




$$
\mathrm{R}_{\mathrm{W}}=\left[\Sigma \mathrm{w}(|\mathrm{Fol}-| \mathrm{Fcl})^{2} / \Sigma \mathrm{w} \mathrm{Fo}^{2}\right]^{1 / 2}=0.0967
$$

The maximum and minimum peaks on the final difference Fourier map corresponded to 0.938 and $-0.506 \mathrm{e}^{-} / \AA^{3}$, respectively.

\section{REFERENCES}

(1) Z. Otwinowski and W. Minor, "Processing of X-Ray Diffraction Data Collected in Oscillation Mode," Methods in Enzymology, vol. 276: Macromolecular Crystallography, part A, 307-326, 1997, C.W. Carter, Jr. \& R.M. Sweet, Eds., Academic Press.

(2) Acta Cryst. A46 (1990) 467-473

(3) Least Squares function minimized:

$$
\Sigma w\left(\left|\mathrm{~F}_{\mathrm{O}}\right|-\left|\mathrm{F}_{\mathrm{C}}\right|\right)^{2}
$$


Table S12. Crystal data and structure refinement for $\mathbf{6 .}$

Empirical formula

Formula weight

Temperature

Wavelength

Crystal system

Space group

Unit cell dimensions

Volume

$\mathrm{Z}$

Density (calculated)

Absorption coefficient

$\mathrm{F}(000)$

Crystal size

Theta range for data collection

Index ranges

Reflections collected

Independent reflections

Completeness to theta $=27.90^{\circ}$

Absorption correction

Max. and min. transmission

Refinement method

Data / restraints / parameters

Goodness-of-fit on $\mathrm{F}^{2}$

Final R indices [I $>2 \operatorname{sigma}(\mathrm{I})]$

$\mathrm{R}$ indices (all data)

Largest diff. peak and hole
$\mathrm{C}_{60} \mathrm{H}_{74} \mathrm{~N} \mathrm{O}_{3.50} \mathrm{P}_{3} \mathrm{Rh}$

1061.02

183(2) K

$0.71073 \AA$

Monoclinic

$\mathrm{P} 2(1) / \mathrm{n}$

$$
\begin{array}{ll}
\mathrm{a}=12.122(2) \AA & \alpha=90^{\circ} . \\
\mathrm{b}=19.864(4) \AA & \beta=90.85(3)^{\circ} . \\
\mathrm{c}=22.607(5) \AA & \gamma=90^{\circ} .
\end{array}
$$

$5443.0(19) \AA^{3}$

4

$1.295 \mathrm{~g} / \mathrm{cm}^{3}$

$4.48 \mathrm{~cm}^{-1}$

2236

$0.20 \times 0.20 \times 0.20 \mathrm{~mm}^{3}$

2.65 to $27.90^{\circ}$.

$-15<=\mathrm{h}<=15,-24<=\mathrm{k}<=26,-29<=\mathrm{l}<=29$

20683

$12640[\mathrm{R}(\mathrm{int})=0.0634]$

$97.2 \%$

None

0.9158 and 0.9158

Full-matrix least-squares on $\mathrm{F}^{2}$

12640 / 0 / 625

1.002

$\mathrm{R} 1=0.0544, \mathrm{wR} 2=0.0967$

$\mathrm{R} 1=0.1407, \mathrm{wR} 2=0.1159$

0.938 and -0.506 e. $\AA^{-3}$ 
Table S13. Atomic coordinates (x 10 4 ) and equivalent isotropic displacement parameters $\left(\AA^{2} \times 10^{3}\right)$ for 6 . U(eq) is defined as one third of the trace of the orthogonalized $U^{i j}$ tensor.

\begin{tabular}{|c|c|c|c|c|}
\hline & $\mathrm{x}$ & $\mathrm{y}$ & $\mathrm{z}$ & $\mathrm{U}(\mathrm{eq})$ \\
\hline $\mathrm{Rh}(1)$ & $5380(1)$ & $1568(1)$ & 8191(1) & $28(1)$ \\
\hline $\mathrm{P}(1)$ & $4827(1)$ & $472(1)$ & $8097(1)$ & $32(1)$ \\
\hline $\mathrm{P}(2)$ & $4771(1)$ & $1438(1)$ & $9109(1)$ & $32(1)$ \\
\hline $\mathrm{P}(3)$ & $6254(1)$ & $2585(1)$ & $8430(1)$ & $35(1)$ \\
\hline $\mathrm{O}(1)$ & $10589(2)$ & $583(2)$ & $6768(1)$ & $53(1)$ \\
\hline $\mathrm{O}(2)$ & $10447(2)$ & $1386(1)$ & $6063(1)$ & $45(1)$ \\
\hline $\mathrm{N}(1)$ & $5735(2)$ & $1709(1)$ & $7262(1)$ & $28(1)$ \\
\hline $\mathrm{C}(1)$ & $5817(3)$ & $-168(2)$ & $8358(2)$ & $33(1)$ \\
\hline $\mathrm{C}(2)$ & $5532(3)$ & $-847(2)$ & $8368(2)$ & $44(1)$ \\
\hline$C(3)$ & $6288(4)$ & $-1327(2)$ & $8553(2)$ & $54(1)$ \\
\hline $\mathrm{C}(4)$ & $7324(4)$ & $-1147(2)$ & $8734(2)$ & $56(1)$ \\
\hline$C(5)$ & $7612(3)$ & $-475(2)$ & $8744(2)$ & $51(1)$ \\
\hline$C(6)$ & $6864(3)$ & $10(2)$ & $8552(2)$ & $39(1)$ \\
\hline$C(7)$ & $4349(3)$ & $69(2)$ & $7415(2)$ & $35(1)$ \\
\hline $\mathrm{C}(8)$ & $3241(3)$ & $33(2)$ & $7255(2)$ & $43(1)$ \\
\hline $\mathrm{C}(9)$ & 2901(4) & $-253(2)$ & $6721(2)$ & $54(1)$ \\
\hline$C(10)$ & $3686(4)$ & $-515(2)$ & $6349(2)$ & $61(1)$ \\
\hline $\mathrm{C}(11)$ & $4780(4)$ & $-485(2)$ & $6495(2)$ & $58(1)$ \\
\hline $\mathrm{C}(12)$ & $5111(3)$ & $-190(2)$ & $7024(2)$ & $45(1)$ \\
\hline$C(13)$ & $3696(3)$ & $338(2)$ & $8623(2)$ & $37(1)$ \\
\hline$C(14)$ & $4165(3)$ & $595(2)$ & $9215(2)$ & $39(1)$ \\
\hline$C(15)$ & $3594(3)$ & $1977(2)$ & $9287(2)$ & $33(1)$ \\
\hline$C(16)$ & $3122(3)$ & $2371(2)$ & $8851(2)$ & $38(1)$ \\
\hline $\mathrm{C}(17)$ & $2232(3)$ & $2783(2)$ & $8966(2)$ & $50(1)$ \\
\hline $\mathrm{C}(18)$ & 1791(3) & $2803(2)$ & $9519(2)$ & $49(1)$ \\
\hline$C(19)$ & $2230(3)$ & $2401(2)$ & $9958(2)$ & $49(1)$ \\
\hline$C(20)$ & $3121(3)$ & 1979(2) & $9842(2)$ & $45(1)$ \\
\hline $\mathrm{C}(21)$ & $5673(3)$ & $1493(2)$ & $9774(1)$ & $33(1)$ \\
\hline$C(22)$ & $5640(3)$ & $2008(2)$ & $10185(2)$ & $42(1)$ \\
\hline$C(23)$ & $6352(3)$ & $2006(2)$ & $10680(2)$ & $49(1)$ \\
\hline $\mathrm{C}(24)$ & 7104(4) & $1500(2)$ & $10750(2)$ & $50(1)$ \\
\hline
\end{tabular}




\begin{tabular}{|c|c|c|c|c|}
\hline $\mathrm{C}(25)$ & $7185(3)$ & $991(2)$ & $10342(2)$ & $48(1)$ \\
\hline$C(26)$ & $6457(3)$ & $986(2)$ & $9859(2)$ & $41(1)$ \\
\hline $\mathrm{C}(27)$ & $6772(3)$ & $3091(2)$ & $7813(2)$ & $44(1)$ \\
\hline $\mathrm{C}(28)$ & $7522(4)$ & $3689(2)$ & $7975(2)$ & $66(1)$ \\
\hline$C(29)$ & $5596(3)$ & $3239(2)$ & $8892(2)$ & $44(1)$ \\
\hline$C(30)$ & 4793(4) & $3707(2)$ & $8566(2)$ & $55(1)$ \\
\hline $\mathrm{C}(31)$ & $7503(3)$ & $2440(2)$ & $8882(2)$ & $46(1)$ \\
\hline$C(32)$ & $8342(4)$ & 1988(3) & $8590(2)$ & $80(2)$ \\
\hline$C(33)$ & $6748(3)$ & $1568(2)$ & $7052(1)$ & $28(1)$ \\
\hline$C(34)$ & 7397(3) & $1063(2)$ & $7335(2)$ & $36(1)$ \\
\hline$C(35)$ & $8432(3)$ & $895(2)$ & $7156(2)$ & $39(1)$ \\
\hline$C(36)$ & $8933(3)$ & $1225(2)$ & $6682(2)$ & $33(1)$ \\
\hline$C(37)$ & $8316(3)$ & $1713(2)$ & $6391(2)$ & $33(1)$ \\
\hline $\mathrm{C}(38)$ & $7263(3)$ & $1881(2)$ & $6562(1)$ & $31(1)$ \\
\hline $\mathrm{C}(39)$ & $10047(3)$ & $1022(2)$ & $6518(2)$ & $40(1)$ \\
\hline $\mathrm{C}(40)$ & 11541(3) & $1201(2)$ & $5878(2)$ & $58(1)$ \\
\hline $\mathrm{C}(41)$ & $5072(3)$ & $2177(2)$ & $6901(1)$ & $29(1)$ \\
\hline $\mathrm{C}(42)$ & $4827(3)$ & $1934(2)$ & $6267(2)$ & $30(1)$ \\
\hline $\mathrm{C}(43)$ & $4507(3)$ & $2395(2)$ & $5840(2)$ & $40(1)$ \\
\hline $\mathrm{C}(44)$ & $4162(3)$ & 2191(3) & $5279(2)$ & $53(1)$ \\
\hline $\mathrm{C}(45)$ & $4152(3)$ & $1518(3)$ & $5132(2)$ & $56(1)$ \\
\hline $\mathrm{C}(46)$ & $4483(3)$ & $1056(2)$ & $5548(2)$ & $53(1)$ \\
\hline $\mathrm{C}(47)$ & $4825(3)$ & $1266(2)$ & $6112(2)$ & $44(1)$ \\
\hline $\mathrm{C}(48)$ & $3939(3)$ & $2311(2)$ & $7162(1)$ & $29(1)$ \\
\hline C(49) & $3202(3)$ & $1787(2)$ & $7251(2)$ & $36(1)$ \\
\hline $\mathrm{C}(50)$ & $2122(3)$ & $1915(2)$ & $7401(2)$ & $41(1)$ \\
\hline $\mathrm{C}(51)$ & $1735(3)$ & $2561(2)$ & $7466(2)$ & $41(1)$ \\
\hline $\mathrm{C}(52)$ & $2466(3)$ & $3084(2)$ & $7386(2)$ & $41(1)$ \\
\hline $\mathrm{C}(53)$ & $3551(3)$ & $2965(2)$ & $7236(1)$ & $34(1)$ \\
\hline $\mathrm{C}(54)$ & $552(4)$ & $2674(3)$ & $7618(2)$ & $95(2)$ \\
\hline $\mathrm{O}(3)$ & $727(3)$ & $310(2)$ & $9058(1)$ & $73(1)$ \\
\hline$C(55)$ & $643(7)$ & $871(3)$ & $9967(3)$ & $152(3)$ \\
\hline$C(56)$ & $604(6)$ & $927(3)$ & $9357(3)$ & $105(2)$ \\
\hline$C(57)$ & 490(4) & $370(2)$ & $8454(2)$ & $58(1)$ \\
\hline$C(58)$ & $605(4)$ & $-305(2)$ & $8166(2)$ & $64(1)$ \\
\hline $\mathrm{O}(4)$ & $10466(4)$ & $70(3)$ & 4791(2) & $141(2)$ \\
\hline
\end{tabular}


$\mathrm{C}(59)$

$\mathrm{C}(60)$
12304(10)

11410(6)
$-172(6)$

$4475(5)$
$-412(4) \quad 4876(3) \quad 108(4)$

109(5) 
Table S14. Bond lengths $[\AA]$ and angles $\left[{ }^{\circ}\right]$ for 6 .

\begin{tabular}{|c|c|c|c|}
\hline $\mathrm{Rh}(1)-\mathrm{N}(1)$ & $2.170(3)$ & $\mathrm{C}(17)-\mathrm{C}(18)$ & $1.366(5)$ \\
\hline $\mathrm{Rh}(1)-\mathrm{P}(2)$ & $2.2266(11)$ & $\mathrm{C}(18)-\mathrm{C}(19)$ & $1.376(5)$ \\
\hline $\mathrm{Rh}(1)-\mathrm{P}(1)$ & $2.2866(11)$ & $C(19)-C(20)$ & $1.395(5)$ \\
\hline $\mathrm{Rh}(1)-\mathrm{P}(3)$ & $2.3416(11)$ & $C(21)-C(22)$ & $1.384(5)$ \\
\hline $\mathrm{P}(1)-\mathrm{C}(7)$ & $1.823(4)$ & $C(21)-C(26)$ & $1.395(5)$ \\
\hline $\mathrm{P}(1)-\mathrm{C}(1)$ & $1.840(4)$ & $C(22)-C(23)$ & $1.402(5)$ \\
\hline $\mathrm{P}(1)-\mathrm{C}(13)$ & $1.848(3)$ & $C(23)-C(24)$ & $1.364(6)$ \\
\hline $\mathrm{P}(2)-\mathrm{C}(15)$ & $1.834(4)$ & $C(24)-C(25)$ & $1.373(5)$ \\
\hline $\mathrm{P}(2)-\mathrm{C}(21)$ & $1.851(4)$ & $C(25)-C(26)$ & $1.394(5)$ \\
\hline $\mathrm{P}(2)-\mathrm{C}(14)$ & $1.846(4)$ & $\mathrm{C}(27)-\mathrm{C}(28)$ & $1.537(5)$ \\
\hline $\mathrm{P}(3)-\mathrm{C}(27)$ & $1.838(4)$ & $C(29)-C(30)$ & $1.527(5)$ \\
\hline $\mathrm{P}(3)-\mathrm{C}(31)$ & $1.836(4)$ & $\mathrm{C}(31)-\mathrm{C}(32)$ & $1.515(6)$ \\
\hline $\mathrm{P}(3)-\mathrm{C}(29)$ & $1.854(4)$ & $\mathrm{C}(33)-\mathrm{C}(38)$ & $1.422(4)$ \\
\hline $\mathrm{O}(1)-\mathrm{C}(39)$ & $1.225(4)$ & $\mathrm{C}(33)-\mathrm{C}(34)$ & $1.422(5)$ \\
\hline $\mathrm{O}(2)-\mathrm{C}(39)$ & $1.353(4)$ & $\mathrm{C}(34)-\mathrm{C}(35)$ & $1.365(5)$ \\
\hline $\mathrm{O}(2)-\mathrm{C}(40)$ & $1.445(4)$ & $C(35)-C(36)$ & $1.402(5)$ \\
\hline $\mathrm{N}(1)-\mathrm{C}(33)$ & $1.352(4)$ & $C(36)-C(37)$ & $1.385(5)$ \\
\hline $\mathrm{N}(1)-\mathrm{C}(41)$ & $1.467(4)$ & $\mathrm{C}(36)-\mathrm{C}(39)$ & $1.462(5)$ \\
\hline $\mathrm{C}(1)-\mathrm{C}(6)$ & $1.382(5)$ & $\mathrm{C}(37)-\mathrm{C}(38)$ & $1.379(4)$ \\
\hline$C(1)-C(2)$ & $1.393(5)$ & $\mathrm{C}(41)-\mathrm{C}(48)$ & $1.527(5)$ \\
\hline$C(2)-C(3)$ & $1.383(5)$ & $\mathrm{C}(41)-\mathrm{C}(42)$ & $1.537(5)$ \\
\hline$C(3)-C(4)$ & $1.363(6)$ & $\mathrm{C}(42)-\mathrm{C}(47)$ & $1.373(5)$ \\
\hline $\mathrm{C}(4)-\mathrm{C}(5)$ & $1.379(6)$ & $\mathrm{C}(42)-\mathrm{C}(43)$ & $1.382(5)$ \\
\hline$C(5)-C(6)$ & $1.387(5)$ & $\mathrm{C}(43)-\mathrm{C}(44)$ & $1.390(5)$ \\
\hline$C(7)-C(12)$ & $1.388(5)$ & $C(44)-C(45)$ & $1.379(6)$ \\
\hline $\mathrm{C}(7)-\mathrm{C}(8)$ & $1.388(5)$ & $C(45)-C(46)$ & $1.370(6)$ \\
\hline $\mathrm{C}(8)-\mathrm{C}(9)$ & $1.390(5)$ & $\mathrm{C}(46)-\mathrm{C}(47)$ & $1.397(5)$ \\
\hline $\mathrm{C}(9)-\mathrm{C}(10)$ & $1.381(6)$ & $\mathrm{C}(48)-\mathrm{C}(53)$ & $1.393(5)$ \\
\hline$C(10)-C(11)$ & $1.363(6)$ & $\mathrm{C}(48)-\mathrm{C}(49)$ & $1.389(5)$ \\
\hline$C(11)-C(12)$ & $1.385(5)$ & $C(49)-C(50)$ & $1.380(5)$ \\
\hline $\mathrm{C}(13)-\mathrm{C}(14)$ & $1.534(5)$ & $\mathrm{C}(50)-\mathrm{C}(51)$ & $1.375(5)$ \\
\hline$C(15)-C(20)$ & $1.387(5)$ & $\mathrm{C}(51)-\mathrm{C}(52)$ & $1.379(5)$ \\
\hline$C(15)-C(16)$ & $1.377(5)$ & $\mathrm{C}(51)-\mathrm{C}(54)$ & $1.497(6)$ \\
\hline $\mathrm{C}(16)-\mathrm{C}(17)$ & $1.382(5)$ & $\mathrm{C}(52)-\mathrm{C}(53)$ & $1.383(5)$ \\
\hline
\end{tabular}




\begin{tabular}{|c|c|c|c|}
\hline $\mathrm{O}(3)-\mathrm{C}(57)$ & $1.396(5)$ & $C(6)-C(1)-C(2)$ & $118.0(4)$ \\
\hline $\mathrm{O}(3)-\mathrm{C}(56)$ & $1.411(6)$ & $\mathrm{C}(6)-\mathrm{C}(1)-\mathrm{P}(1)$ & $121.1(3)$ \\
\hline$C(55)-C(56)$ & $1.382(7)$ & $\mathrm{C}(2)-\mathrm{C}(1)-\mathrm{P}(1)$ & $120.9(3)$ \\
\hline$C(57)-C(58)$ & $1.497(6)$ & $\mathrm{C}(3)-\mathrm{C}(2)-\mathrm{C}(1)$ & $120.6(4)$ \\
\hline $\mathrm{O}(4)-\mathrm{C}(60)$ & $1.502(8)$ & $\mathrm{C}(4)-\mathrm{C}(3)-\mathrm{C}(2)$ & $120.9(4)$ \\
\hline $\mathrm{O}(4)-\mathrm{O}(4) \# 1$ & $1.509(8)$ & $C(3)-C(4)-C(5)$ & $119.4(4)$ \\
\hline \multirow[t]{2}{*}{$C(59)-C(60)$} & $1.501(12)$ & $C(4)-C(5)-C(6)$ & $120.2(4)$ \\
\hline & & $C(1)-C(6)-C(5)$ & $120.9(4)$ \\
\hline $\mathrm{N}(1)-\mathrm{Rh}(1)-\mathrm{P}(2)$ & $172.06(8)$ & $C(12)-C(7)-C(8)$ & $117.7(4)$ \\
\hline $\mathrm{N}(1)-\mathrm{Rh}(1)-\mathrm{P}(1)$ & $95.43(8)$ & $\mathrm{C}(12)-\mathrm{C}(7)-\mathrm{P}(1)$ & $119.7(3)$ \\
\hline $\mathrm{P}(2)-\mathrm{Rh}(1)-\mathrm{P}(1)$ & $82.88(4)$ & $\mathrm{C}(8)-\mathrm{C}(7)-\mathrm{P}(1)$ & $122.5(3)$ \\
\hline $\mathrm{N}(1)-\mathrm{Rh}(1)-\mathrm{P}(3)$ & $90.91(8)$ & $\mathrm{C}(7)-\mathrm{C}(8)-\mathrm{C}(9)$ & $121.4(4)$ \\
\hline $\mathrm{P}(2)-\mathrm{Rh}(1)-\mathrm{P}(3)$ & $92.33(4)$ & $C(10)-C(9)-C(8)$ & $118.9(4)$ \\
\hline $\mathrm{P}(1)-\mathrm{Rh}(1)-\mathrm{P}(3)$ & $166.97(4)$ & $\mathrm{C}(11)-\mathrm{C}(10)-\mathrm{C}(9)$ & $120.9(4)$ \\
\hline $\mathrm{C}(7)-\mathrm{P}(1)-\mathrm{C}(1)$ & $99.53(17)$ & $C(10)-C(11)-C(12)$ & $119.7(4)$ \\
\hline $\mathrm{C}(7)-\mathrm{P}(1)-\mathrm{C}(13)$ & $104.55(17)$ & $C(7)-C(12)-C(11)$ & $121.3(4)$ \\
\hline$C(1)-P(1)-C(13)$ & $100.42(17)$ & $\mathrm{C}(14)-\mathrm{C}(13)-\mathrm{P}(1)$ & $104.2(2)$ \\
\hline $\mathrm{C}(7)-\mathrm{P}(1)-\mathrm{Rh}(1)$ & $125.89(12)$ & $\mathrm{C}(13)-\mathrm{C}(14)-\mathrm{P}(2)$ & $109.3(2)$ \\
\hline $\mathrm{C}(1)-\mathrm{P}(1)-\mathrm{Rh}(1)$ & $116.03(13)$ & $C(20)-C(15)-C(16)$ & $118.3(4)$ \\
\hline $\mathrm{C}(13)-\mathrm{P}(1)-\mathrm{Rh}(1)$ & 107.21(12) & $\mathrm{C}(20)-\mathrm{C}(15)-\mathrm{P}(2)$ & $122.2(3)$ \\
\hline$C(15)-P(2)-C(21)$ & $103.85(17)$ & $\mathrm{C}(16)-\mathrm{C}(15)-\mathrm{P}(2)$ & $119.4(3)$ \\
\hline$C(15)-P(2)-C(14)$ & $100.92(17)$ & $C(17)-C(16)-C(15)$ & $121.2(3)$ \\
\hline$C(21)-P(2)-C(14)$ & $100.33(17)$ & $\mathrm{C}(18)-\mathrm{C}(17)-\mathrm{C}(16)$ & $120.5(4)$ \\
\hline $\mathrm{C}(15)-\mathrm{P}(2)-\mathrm{Rh}(1)$ & $114.01(12)$ & $\mathrm{C}(17)-\mathrm{C}(18)-\mathrm{C}(19)$ & $119.4(4)$ \\
\hline $\mathrm{C}(21)-\mathrm{P}(2)-\mathrm{Rh}(1)$ & $123.37(11)$ & $C(18)-C(19)-C(20)$ & $120.4(4)$ \\
\hline $\mathrm{C}(14)-\mathrm{P}(2)-\mathrm{Rh}(1)$ & $111.37(12)$ & $C(15)-C(20)-C(19)$ & $120.2(4)$ \\
\hline $\mathrm{C}(27)-\mathrm{P}(3)-\mathrm{C}(31)$ & 102.72(19) & $C(22)-C(21)-C(26)$ & $117.9(3)$ \\
\hline $\mathrm{C}(27)-\mathrm{P}(3)-\mathrm{C}(29)$ & $101.46(18)$ & $\mathrm{C}(22)-\mathrm{C}(21)-\mathrm{P}(2)$ & $124.5(3)$ \\
\hline $\mathrm{C}(31)-\mathrm{P}(3)-\mathrm{C}(29)$ & $98.88(18)$ & $\mathrm{C}(26)-\mathrm{C}(21)-\mathrm{P}(2)$ & $117.5(3)$ \\
\hline $\mathrm{C}(27)-\mathrm{P}(3)-\mathrm{Rh}(1)$ & 117.11(13) & $C(21)-C(22)-C(23)$ & $120.7(4)$ \\
\hline $\mathrm{C}(31)-\mathrm{P}(3)-\mathrm{Rh}(1)$ & $111.07(14)$ & $\mathrm{C}(24)-\mathrm{C}(23)-\mathrm{C}(22)$ & $119.7(4)$ \\
\hline $\mathrm{C}(29)-\mathrm{P}(3)-\mathrm{Rh}(1)$ & $122.51(13)$ & $\mathrm{C}(23)-\mathrm{C}(24)-\mathrm{C}(25)$ & $121.3(4)$ \\
\hline $\mathrm{C}(39)-\mathrm{O}(2)-\mathrm{C}(40)$ & $115.2(3)$ & $C(24)-C(25)-C(26)$ & $118.7(4)$ \\
\hline $\mathrm{C}(33)-\mathrm{N}(1)-\mathrm{C}(41)$ & $115.4(3)$ & $\mathrm{C}(25)-\mathrm{C}(26)-\mathrm{C}(21)$ & $121.6(4)$ \\
\hline $\mathrm{C}(33)-\mathrm{N}(1)-\mathrm{Rh}(1)$ & $120.5(2)$ & $\mathrm{C}(28)-\mathrm{C}(27)-\mathrm{P}(3)$ & $116.6(3)$ \\
\hline $\mathrm{C}(41)-\mathrm{N}(1)-\mathrm{Rh}(1)$ & $120.3(2)$ & $\mathrm{C}(30)-\mathrm{C}(29)-\mathrm{P}(3)$ & $115.5(3)$ \\
\hline
\end{tabular}




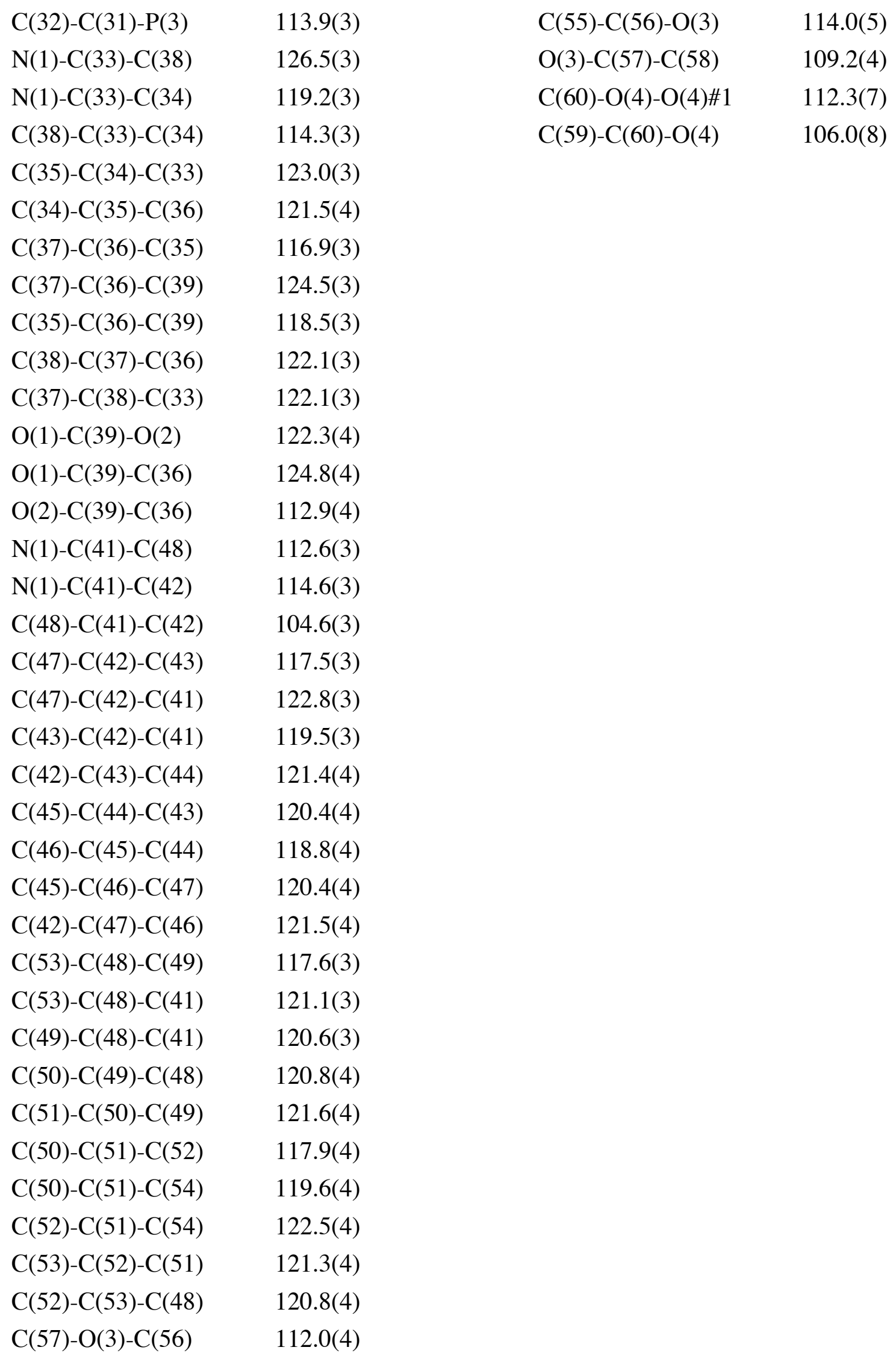


Table S15. Anisotropic displacement parameters $\AA^{2} \times 10^{3}$ ) for 6 . The anisotropic displacement factor exponent takes the form: $-2 \pi^{2}\left[h^{2} a^{* 2} U^{11}+\ldots+2 h k a^{*} b^{*} U^{12}\right]$.

\begin{tabular}{|c|c|c|c|c|c|c|}
\hline & $\mathrm{U}^{11}$ & $\mathrm{U}^{22}$ & $\mathrm{U}^{33}$ & $\mathrm{U}^{23}$ & $\mathrm{U}^{13}$ & $\mathrm{U}^{12}$ \\
\hline $\mathrm{Rh}(1)$ & $28(1)$ & $27(1)$ & $28(1)$ & $4(1)$ & $0(1)$ & $-1(1)$ \\
\hline $\mathrm{P}(1)$ & $30(1)$ & $28(1)$ & $37(1)$ & $3(1)$ & $1(1)$ & $1(1)$ \\
\hline $\mathrm{P}(2)$ & $35(1)$ & $31(1)$ & $30(1)$ & $5(1)$ & $2(1)$ & $1(1)$ \\
\hline $\mathrm{P}(3)$ & $38(1)$ & $34(1)$ & $32(1)$ & $2(1)$ & $-3(1)$ & $-7(1)$ \\
\hline $\mathrm{O}(1)$ & $35(2)$ & $58(2)$ & $67(2)$ & $7(2)$ & $7(1)$ & $11(2)$ \\
\hline $\mathrm{O}(2)$ & $31(2)$ & $52(2)$ & $54(2)$ & $2(1)$ & $12(1)$ & $0(2)$ \\
\hline $\mathrm{N}(1)$ & $25(2)$ & $34(2)$ & $26(2)$ & $3(1)$ & $0(1)$ & $-1(2)$ \\
\hline $\mathrm{C}(1)$ & $34(2)$ & $29(2)$ & $34(2)$ & $6(2)$ & $3(2)$ & $8(2)$ \\
\hline $\mathrm{C}(2)$ & $51(3)$ & $38(3)$ & $42(2)$ & $5(2)$ & $2(2)$ & $9(2)$ \\
\hline$C(3)$ & $80(4)$ & $35(3)$ & $47(3)$ & $12(2)$ & $7(3)$ & $13(3)$ \\
\hline$C(4)$ & $69(4)$ & $58(3)$ & $42(3)$ & $21(2)$ & $9(2)$ & $29(3)$ \\
\hline$C(5)$ & $40(3)$ & $62(3)$ & $49(3)$ & $17(2)$ & $5(2)$ & $11(3)$ \\
\hline$C(6)$ & $41(3)$ & $39(2)$ & $36(2)$ & $17(2)$ & $4(2)$ & $6(2)$ \\
\hline$C(7)$ & $36(2)$ & $19(2)$ & $49(2)$ & $-3(2)$ & $-2(2)$ & $4(2)$ \\
\hline $\mathrm{C}(8)$ & $43(3)$ & $27(2)$ & $58(3)$ & $4(2)$ & $-6(2)$ & $-4(2)$ \\
\hline $\mathrm{C}(9)$ & $55(3)$ & $35(3)$ & $71(3)$ & $2(2)$ & $-22(3)$ & $-6(2)$ \\
\hline $\mathrm{C}(10)$ & $88(4)$ & $29(3)$ & $66(3)$ & $-7(2)$ & $-29(3)$ & $4(3)$ \\
\hline $\mathrm{C}(11)$ & $83(4)$ & $44(3)$ & $46(3)$ & $-10(2)$ & $-13(3)$ & $25(3)$ \\
\hline$C(12)$ & $42(3)$ & $35(3)$ & $56(3)$ & $-3(2)$ & $-9(2)$ & $10(2)$ \\
\hline$C(13)$ & $34(2)$ & $31(2)$ & $47(2)$ & $4(2)$ & $7(2)$ & $-6(2)$ \\
\hline$C(14)$ & $39(2)$ & $37(2)$ & $41(2)$ & $9(2)$ & $13(2)$ & $-2(2)$ \\
\hline$C(15)$ & $32(2)$ & $32(2)$ & $33(2)$ & $1(2)$ & $2(2)$ & $-3(2)$ \\
\hline$C(16)$ & $42(3)$ & $43(3)$ & $28(2)$ & $0(2)$ & $2(2)$ & $4(2)$ \\
\hline $\mathrm{C}(17)$ & $57(3)$ & $52(3)$ & $40(2)$ & $6(2)$ & $7(2)$ & $16(3)$ \\
\hline$C(18)$ & $53(3)$ & $47(3)$ & $48(3)$ & $-4(2)$ & $7(2)$ & $17(2)$ \\
\hline$C(19)$ & $51(3)$ & $60(3)$ & $37(2)$ & $-4(2)$ & $13(2)$ & $2(3)$ \\
\hline$C(20)$ & $49(3)$ & $49(3)$ & $38(2)$ & $6(2)$ & $4(2)$ & $3(2)$ \\
\hline $\mathrm{C}(21)$ & $39(2)$ & $37(2)$ & $24(2)$ & $11(2)$ & $3(2)$ & $-5(2)$ \\
\hline$C(22)$ & $51(3)$ & $41(3)$ & $35(2)$ & $8(2)$ & $-2(2)$ & $-5(2)$ \\
\hline $\mathrm{C}(23)$ & $53(3)$ & $53(3)$ & $39(2)$ & $2(2)$ & $-2(2)$ & $-13(3)$ \\
\hline $\mathrm{C}(24)$ & $47(3)$ & $65(3)$ & $39(2)$ & $14(2)$ & $-11(2)$ & $-14(3)$ \\
\hline
\end{tabular}




\begin{tabular}{|c|c|c|c|c|c|c|}
\hline$C(25)$ & $45(3)$ & $53(3)$ & $46(3)$ & $19(2)$ & $-1(2)$ & $-1(2)$ \\
\hline$C(26)$ & $46(3)$ & $39(3)$ & $37(2)$ & $9(2)$ & $1(2)$ & $0(2)$ \\
\hline$C(27)$ & $55(3)$ & $38(3)$ & $38(2)$ & $4(2)$ & $-1(2)$ & $-16(2)$ \\
\hline $\mathrm{C}(28)$ & $89(4)$ & $62(3)$ & $46(3)$ & $3(2)$ & $3(2)$ & $-42(3)$ \\
\hline $\mathrm{C}(29)$ & $54(3)$ & $37(3)$ & $40(2)$ & $-5(2)$ & $-6(2)$ & $-8(2)$ \\
\hline$C(30)$ & $67(3)$ & $39(3)$ & $58(3)$ & $-3(2)$ & $-8(2)$ & $9(2)$ \\
\hline $\mathrm{C}(31)$ & $43(3)$ & $52(3)$ & $42(2)$ & $2(2)$ & $-10(2)$ & $-11(2)$ \\
\hline$C(32)$ & $47(3)$ & $91(4)$ & $100(4)$ & $-11(3)$ & $-27(3)$ & $7(3)$ \\
\hline$C(33)$ & $26(2)$ & $28(2)$ & $29(2)$ & $1(2)$ & $0(2)$ & $-3(2)$ \\
\hline$C(34)$ & $35(3)$ & $40(3)$ & $34(2)$ & $9(2)$ & $2(2)$ & $2(2)$ \\
\hline$C(35)$ & $32(2)$ & $44(3)$ & $40(2)$ & $7(2)$ & $-5(2)$ & $6(2)$ \\
\hline$C(36)$ & $30(2)$ & $32(2)$ & $36(2)$ & $-1(2)$ & $0(2)$ & $3(2)$ \\
\hline$C(37)$ & $31(2)$ & $36(2)$ & $32(2)$ & $0(2)$ & $6(2)$ & $-5(2)$ \\
\hline$C(38)$ & $35(2)$ & $27(2)$ & $32(2)$ & $4(2)$ & $-3(2)$ & $2(2)$ \\
\hline C(39) & $36(3)$ & $40(3)$ & $44(3)$ & $-6(2)$ & $-2(2)$ & $-2(2)$ \\
\hline$C(40)$ & $38(3)$ & $64(3)$ & $72(3)$ & $-8(3)$ & $21(2)$ & $1(3)$ \\
\hline$C(41)$ & $27(2)$ & $29(2)$ & $31(2)$ & $2(2)$ & $1(2)$ & $1(2)$ \\
\hline$C(42)$ & $22(2)$ & $35(2)$ & $32(2)$ & $-1(2)$ & $1(2)$ & $5(2)$ \\
\hline$C(43)$ & $35(2)$ & $51(3)$ & $35(2)$ & $0(2)$ & $2(2)$ & $9(2)$ \\
\hline$C(44)$ & $48(3)$ & $84(4)$ & $28(2)$ & $5(2)$ & $-5(2)$ & $20(3)$ \\
\hline$C(45)$ & $37(3)$ & $92(4)$ & $38(2)$ & $-13(3)$ & $-8(2)$ & $10(3)$ \\
\hline$C(46)$ & $47(3)$ & $56(3)$ & $56(3)$ & $-26(2)$ & $-3(2)$ & $0(2)$ \\
\hline$C(47)$ & $43(3)$ & $46(3)$ & $42(2)$ & $-1(2)$ & $-1(2)$ & $-4(2)$ \\
\hline$C(48)$ & $34(2)$ & $32(2)$ & $20(2)$ & $2(2)$ & $-4(2)$ & $0(2)$ \\
\hline $\mathrm{C}(49)$ & $39(3)$ & $30(2)$ & $38(2)$ & $5(2)$ & $-1(2)$ & $-1(2)$ \\
\hline$C(50)$ & $34(3)$ & $47(3)$ & $42(2)$ & $2(2)$ & $6(2)$ & $-6(2)$ \\
\hline $\mathrm{C}(51)$ & $29(2)$ & $61(3)$ & $33(2)$ & $-1(2)$ & $6(2)$ & $7(2)$ \\
\hline$C(52)$ & $42(3)$ & $41(3)$ & $39(2)$ & $-5(2)$ & $0(2)$ & $16(2)$ \\
\hline$C(53)$ & $36(2)$ & $32(2)$ & $33(2)$ & $2(2)$ & $0(2)$ & $2(2)$ \\
\hline$C(54)$ & $75(4)$ & $105(5)$ & $106(5)$ & $3(4)$ & $1(3)$ & $3(4)$ \\
\hline $\mathrm{O}(3)$ & 104(3) & $55(2)$ & $59(2)$ & $-1(2)$ & $5(2)$ & $-7(2)$ \\
\hline$C(55)$ & $277(10)$ & $97(6)$ & $84(5)$ & $-32(4)$ & $49(6)$ & $-70(6)$ \\
\hline$C(56)$ & $165(7)$ & $66(4)$ & $83(5)$ & $-17(4)$ & $-14(4)$ & $-2(4)$ \\
\hline$C(57)$ & $55(3)$ & $55(3)$ & $63(3)$ & $3(3)$ & $-4(2)$ & $-1(3)$ \\
\hline$C(58)$ & $67(4)$ & $67(4)$ & $59(3)$ & $-8(3)$ & $4(2)$ & $4(3)$ \\
\hline $\mathrm{O}(4)$ & $183(6)$ & $147(5)$ & $94(4)$ & $-3(3)$ & $-7(3)$ & $-28(4)$ \\
\hline
\end{tabular}




$\begin{array}{ccccccc}\mathrm{C}(59) & 102(10) & 118(12) & 108(10) & -47(8) & 20(8) & -28(9) \\ \mathrm{C}(60) & 125(8) & 98(7) & 99(6) & -27(5) & -51(5) & 45(5)\end{array}$


Table S16. Hydrogen coordinates $\left(\times 10^{4}\right)$ and isotropic displacement parameters $\left(\AA^{2} \times 10^{3}\right)$ for 6.

$\begin{array}{lrrrr} & x & y & \mathrm{z} & \mathrm{U}(\mathrm{eq}) \\ \mathrm{H}(2 \mathrm{~A}) & & & & \\ \mathrm{H}(3 \mathrm{~A}) & 4811 & -982 & 8248 & 52 \\ \mathrm{H}(4 \mathrm{~A}) & 6083 & -1789 & 8553 & 65 \\ \mathrm{H}(5 \mathrm{~A}) & 7843 & -1480 & 8853 & 68 \\ \mathrm{H}(6 \mathrm{~A}) & 8324 & -344 & 8882 & 61 \\ \mathrm{H}(8 \mathrm{~A}) & 7074 & 470 & 8553 & 46 \\ \mathrm{H}(9 \mathrm{~A}) & 2703 & 208 & 7515 & 51 \\ \mathrm{H}(10 \mathrm{~A}) & 2140 & -268 & 6614 & 64 \\ \mathrm{H}(11 \mathrm{~A}) & 3460 & -719 & 5987 & 74 \\ \mathrm{H}(12 \mathrm{~A}) & 5312 & -666 & 6235 & 69 \\ \mathrm{H}(13 \mathrm{~A}) & 5875 & -165 & 7120 & 54 \\ \mathrm{H}(13 \mathrm{~B}) & 3031 & 597 & 8502 & 45 \\ \mathrm{H}(14 \mathrm{~A}) & 3501 & -145 & 8648 & 45 \\ \mathrm{H}(14 \mathrm{~B}) & 4738 & 280 & 9365 & 47 \\ \mathrm{H}(16 \mathrm{~A}) & 3570 & 619 & 9509 & 47 \\ \mathrm{H}(17 \mathrm{~A}) & 3414 & 2360 & 8463 & 45 \\ \mathrm{H}(18 \mathrm{~A}) & 1924 & 3054 & 8659 & 60 \\ \mathrm{H}(19 \mathrm{~A}) & 1188 & 3093 & 9599 & 59 \\ \mathrm{H}(20 \mathrm{~A}) & 1925 & 2410 & 10342 & 59 \\ \mathrm{H}(22 \mathrm{~A}) & 3405 & 1692 & 10144 & 54 \\ \mathrm{H}(23 \mathrm{~A}) & 5130 & 2367 & 10132 & 50 \\ \mathrm{H}(24 \mathrm{~A}) & 6311 & 2356 & 10965 & 58 \\ \mathrm{H}(25 \mathrm{~A}) & 7580 & 1500 & 11087 & 60 \\ \mathrm{H}(26 \mathrm{~A}) & 7728 & 650 & 10387 & 58 \\ \mathrm{H}(27 \mathrm{~A}) & 6495 & 629 & 9580 & 49 \\ \mathrm{H}(27 \mathrm{~B}) & 7183 & 2789 & 7546 & 53 \\ \mathrm{H}(28 \mathrm{~A}) & 6129 & 3267 & 7586 & 53 \\ \mathrm{H}(28 \mathrm{~B}) & 7745 & 3921 & 7614 & 99 \\ \mathrm{H}(28 \mathrm{C}) & 8179 & 3524 & 8188 & 99 \\ \mathrm{H}(29 \mathrm{~A}) & 7121 & 4002 & 8229 & 99 \\ \mathrm{H}(29 \mathrm{~B}) & 5196 & 3012 & 9214 & 53 \\ & 6185 & 3517 & 9077 & 53\end{array}$




\begin{tabular}{|c|c|c|c|c|}
\hline $\mathrm{H}(30 \mathrm{~A})$ & 4491 & 4033 & 8846 & 82 \\
\hline $\mathrm{H}(30 \mathrm{~B})$ & 4191 & 3441 & 8391 & 82 \\
\hline $\mathrm{H}(30 \mathrm{C})$ & 5183 & 3946 & 8253 & 82 \\
\hline $\mathrm{H}(31 \mathrm{~A})$ & 7853 & 2880 & 8970 & 55 \\
\hline $\mathrm{H}(31 \mathrm{~B})$ & 7287 & 2236 & 9262 & 55 \\
\hline $\mathrm{H}(32 \mathrm{~A})$ & 8983 & 1932 & 8855 & 119 \\
\hline $\mathrm{H}(32 \mathrm{~B})$ & 8576 & 2192 & 8218 & 119 \\
\hline $\mathrm{H}(32 \mathrm{C})$ & 8009 & 1547 & 8510 & 119 \\
\hline $\mathrm{H}(34 \mathrm{~A})$ & 7097 & 832 & 7663 & 44 \\
\hline $\mathrm{H}(35 \mathrm{~A})$ & 8822 & 547 & 7358 & 46 \\
\hline $\mathrm{H}(37 \mathrm{~A})$ & 8627 & 1940 & 6064 & 40 \\
\hline $\mathrm{H}(38 \mathrm{~A})$ & 6870 & 2216 & 6346 & 37 \\
\hline $\mathrm{H}(40 \mathrm{~A})$ & 11760 & 1489 & 5547 & 87 \\
\hline $\mathrm{H}(40 \mathrm{~B})$ & 11543 & 730 & 5751 & 87 \\
\hline $\mathrm{H}(40 \mathrm{C})$ & 12063 & 1260 & 6209 & 87 \\
\hline $\mathrm{H}(41 \mathrm{~A})$ & 5478 & 2614 & 6879 & 35 \\
\hline $\mathrm{H}(43 \mathrm{~A})$ & 4524 & 2862 & 5932 & 48 \\
\hline $\mathrm{H}(44 \mathrm{~A})$ & 3932 & 2517 & 4996 & 64 \\
\hline $\mathrm{H}(45 \mathrm{~A})$ & 3920 & 1376 & 4748 & 67 \\
\hline $\mathrm{H}(46 \mathrm{~A})$ & 4480 & 590 & 5454 & 64 \\
\hline $\mathrm{H}(47 \mathrm{~A})$ & 5061 & 940 & 6393 & 52 \\
\hline $\mathrm{H}(49 \mathrm{~A})$ & 3443 & 1335 & 7209 & 43 \\
\hline $\mathrm{H}(50 \mathrm{~A})$ & 1634 & 1547 & 7460 & 49 \\
\hline $\mathrm{H}(52 \mathrm{~A})$ & 2219 & 3534 & 7434 & 49 \\
\hline $\mathrm{H}(53 \mathrm{~A})$ & 4037 & 3335 & 7182 & 40 \\
\hline $\mathrm{H}(54 \mathrm{~A})$ & 178 & 2239 & 7653 & 143 \\
\hline $\mathrm{H}(54 \mathrm{~B})$ & 192 & 2941 & 7306 & 143 \\
\hline $\mathrm{H}(54 \mathrm{C})$ & 512 & 2916 & 7995 & 143 \\
\hline $\mathrm{H}(55 \mathrm{~A})$ & 555 & 1317 & 10145 & 229 \\
\hline $\mathrm{H}(55 \mathrm{~B})$ & 1355 & 680 & 10091 & 229 \\
\hline $\mathrm{H}(55 \mathrm{C})$ & 46 & 575 & 10097 & 229 \\
\hline $\mathrm{H}(56 \mathrm{~A})$ & 1195 & 1238 & 9232 & 126 \\
\hline $\mathrm{H}(56 \mathrm{~B})$ & -111 & 1130 & 9238 & 126 \\
\hline $\mathrm{H}(57 \mathrm{~A})$ & 1003 & 694 & 8272 & 69 \\
\hline $\mathrm{H}(57 \mathrm{~B})$ & -272 & 539 & 8395 & 69 \\
\hline $\mathrm{H}(58 \mathrm{~A})$ & 441 & -265 & 7742 & 97 \\
\hline
\end{tabular}




$\begin{array}{lrrrr}\mathrm{H}(58 B) & 88 & -623 & 8345 & 97 \\ \mathrm{H}(58 \mathrm{C}) & 1361 & -469 & 8224 & 97 \\ \mathrm{H}(59 \mathrm{~A}) & 12945 & -471 & 4513 & 164 \\ \mathrm{H}(59 B) & 12519 & 287 & 4585 & 164 \\ \mathrm{H}(59 \mathrm{C}) & 12031 & -177 & 4064 & 164 \\ \mathrm{H}(60 \mathrm{~A}) & 11672 & -410 & 5293 & 130 \\ \mathrm{H}(60 B) & 11181 & -875 & 4770 & 130\end{array}$




\section{Experimental Procedure for the X-ray Diffraction of 9}

\section{Data Collection}

A dark red needle crystal of $\mathrm{C}_{48} \mathrm{H}_{44} \mathrm{NOP}_{2} \mathrm{Rh}$ having approximate dimensions of $0.35 \mathrm{x}$ $0.10 \times 0.08 \mathrm{~mm}$ was mounted with epoxy cement on the tip of a fine glass fiber. All measurements were made on a Nonius KappaCCD diffractometer with graphite monochromated Mo-K $\alpha$ radiation.

Cell constants and an orientation matrix for data collection corresponded to a $C$-centered monoclinic cell with dimensions:

$$
\begin{array}{lll}
\mathrm{a}=14.720(3) \AA & \alpha=90^{\circ} \\
\mathrm{b}=29.946(6) \AA & \beta=98.62(3) \mathrm{O} \\
\mathrm{c}=18.379(4) \AA & \gamma=90^{\circ} \\
\mathrm{V}=8010(3) \AA^{3} &
\end{array}
$$

For $\mathrm{Z}=8$ and F.W. $=815.69$, the calculated density is $1.353 \mathrm{~g} / \mathrm{cm}^{3}$. Based on a statistical analysis of intensity distribution, and the successful solution and refinement of the structure, the space group was determined to be: $C 2 / c$ (\#15)

The data were collected at a temperature of $173(2) \mathrm{K}$ to a maximum $2 \theta$ value of $56.64 \mathrm{O}$. Four omega scans consisting of 42, 38, 42, and 24 data frames, respectively, were collected with a frame width of $1.8^{\circ}$ and a detector-to-crystal distance, Dx, of $35.0 \mathrm{~mm}$. Each frame was exposed twice (for the purpose of de-zingering) for a total of 216 seconds. The data frames were processed and scaled using the DENZO software package. ${ }^{1}$

\section{Data Reduction}

A total of 17301 reflections were collected of which 9923 were unique and observed $\left(\mathrm{R}_{\mathrm{int}}\right.$ $=0.0798$ ). The linear absorption coefficient, $\mu$, for Mo-K $\alpha$ radiation is $5.43 \mathrm{~cm}^{-1}$ and no absorption correction was applied. The data were corrected for Lorentz and polarization effects.

\section{$\underline{\text { Structure Solution and Refinement }}$}

The structure was solved by direct methods and expanded using Fourier techniques ${ }^{2}$. The non-hydrogen atoms were refined anisotropically and hydrogen atoms were treated as idealized contributions. The final cycle of full-matrix least-squares refinement ${ }^{3}$ on $\mathrm{F}$ was based on 9923 observed reflections (I > 2.00厅(I)) and 478 variable parameters and converged with unweighted and weighted agreement factors of:

$$
\begin{gathered}
\mathrm{R}=\Sigma\|\mathrm{Fo}|-| \mathrm{Fc}\| / \Sigma|\mathrm{Fo}|=0.0555 \\
\mathrm{R}_{\mathrm{W}}=\left\{\Sigma\left[\mathrm{w}\left(\mathrm{F}_{\mathrm{o}}^{2}-\mathrm{F}_{\mathrm{c}}^{2}\right)^{2}\right] / \Sigma\left[\mathrm{w}\left(\mathrm{F}_{\mathrm{o}}^{2}\right)^{2}\right]\right\}^{1 / 2}=0.0916
\end{gathered}
$$


The maximum and minimum peaks on the final difference Fourier map corresponded to 0.429 and $-0.768 \mathrm{e}^{-} / \AA^{3}$, respectively.

\section{REFERENCES}

(1) Z. Otwinowski and W. Minor, "Processing of X-Ray Diffraction Data Collected in Oscillation Mode," Methods in Enzymology, vol. 276: Macromolecular Crystallography, part A, 307-326, 1997, C.W. Carter, Jr. \& R.M. Sweet, Eds., Academic Press.

(2) Acta Cryst. A46 (1990) 467-473

(3) Least Squares function minimized: $\Sigma w\left(\mathrm{~F}_{\mathrm{o}}^{2}-\mathrm{F}_{\mathrm{c}}^{2}\right)^{2}$ 
Table S17. Crystal data and structure refinement for 9 .

Empirical formula

Formula weight

Temperature

Wavelength

Crystal system

Space group

Unit cell dimensions

Volume

$\mathrm{Z}$

Density (calculated)

Absorption coefficient

$\mathrm{F}(000)$

Crystal size

Theta range for data collection

Index ranges

Reflections collected

Independent reflections

Completeness to theta $=28.32^{\circ}$

Absorption correction

Max. and min. transmission

Refinement method

Data / restraints / parameters

Goodness-of-fit on $\mathrm{F}^{2}$

Final $\mathrm{R}$ indices [I $>2 \operatorname{sigma}(\mathrm{I})]$

$\mathrm{R}$ indices (all data)

Largest diff. peak and hole
$\mathrm{C}_{48} \mathrm{H}_{44} \mathrm{~N} \mathrm{O} \mathrm{P} 2 \mathrm{Rh}$

815.69

173(2) K

$0.71073 \AA$

Monoclinic

$\mathrm{C} 2 / \mathrm{c}$

$$
\begin{array}{ll}
\mathrm{a}=14.720(3) \AA & \alpha=90^{\circ} . \\
\mathrm{b}=29.946(6) \AA & \beta=98.62(3)^{\circ} . \\
\mathrm{c}=18.379(4) \AA & \gamma=90^{\circ} .
\end{array}
$$

8010(3) $\AA^{3}$

8

$1.353 \mathrm{~g} / \mathrm{cm}^{3}$

$5.43 \mathrm{~cm}^{-1}$

3376

$0.35 \times 0.10 \times 0.08 \mathrm{~mm}^{3}$

2.47 to $28.32^{\circ}$.

$-19<=\mathrm{h}<=19,-39<=\mathrm{k}<=39,-24<=\mathrm{l}<=24$

17301

$9923[\mathrm{R}(\mathrm{int})=0.0798]$

$99.3 \%$

None

0.9578 and 0.8326

Full-matrix least-squares on $\mathrm{F}^{2}$

9923 / 0 / 478

1.000

$\mathrm{R} 1=0.0555, \mathrm{wR} 2=0.0916$

$\mathrm{R} 1=0.1402, \mathrm{wR} 2=0.1125$

0.429 and -0.768 e. $\AA^{-3}$ 
Table S18. Atomic coordinates $\left(\times 10^{4}\right)$ and equivalent isotropic displacement parameters $\left(\AA^{2} \times 10^{3}\right)$ for 9 . $U(e q)$ is defined as one third of the trace of the orthogonalized Uij tensor.

\begin{tabular}{|c|c|c|c|c|}
\hline & $\mathrm{x}$ & $\mathrm{y}$ & $\mathrm{z}$ & $\mathrm{U}(\mathrm{eq})$ \\
\hline $\operatorname{Rh}(1)$ & $6499(1)$ & $1417(1)$ & $4607(1)$ & $29(1)$ \\
\hline $\mathrm{P}(1)$ & $5086(1)$ & $1509(1)$ & $4948(1)$ & $32(1)$ \\
\hline $\mathrm{P}(2)$ & $6447(1)$ & $751(1)$ & $5096(1)$ & $34(1)$ \\
\hline $\mathrm{O}(1)$ & $4427(2)$ & $3546(1)$ & $3928(2)$ & $49(1)$ \\
\hline $\mathrm{N}(1)$ & $6659(2)$ & 2030(1) & $4076(1)$ & $28(1)$ \\
\hline $\mathrm{C}(1)$ & $4167(3)$ & $1348(1)$ & $4206(2)$ & $34(1)$ \\
\hline $\mathrm{C}(2)$ & $3277(3)$ & $1238(1)$ & $4325(2)$ & $45(1)$ \\
\hline $\mathrm{C}(3)$ & $2621(3)$ & 1089(1) & $3750(3)$ & $54(1)$ \\
\hline $\mathrm{C}(4)$ & $2848(3)$ & $1055(1)$ & $3047(3)$ & $54(1)$ \\
\hline $\mathrm{C}(5)$ & $3704(3)$ & $1173(1)$ & 2919(2) & $52(1)$ \\
\hline $\mathrm{C}(6)$ & $4364(3)$ & 1314(1) & $3496(2)$ & $40(1)$ \\
\hline $\mathrm{C}(7)$ & $4611(2)$ & $2010(1)$ & $5324(2)$ & $31(1)$ \\
\hline $\mathrm{C}(8)$ & $4933(3)$ & $2140(1)$ & $6042(2)$ & $43(1)$ \\
\hline $\mathrm{C}(9)$ & $4618(3)$ & $2532(1)$ & $6322(2)$ & $51(1)$ \\
\hline $\mathrm{C}(10)$ & $4001(3)$ & $2803(1)$ & $5893(2)$ & $50(1)$ \\
\hline $\mathrm{C}(11)$ & $3681(3)$ & 2679(1) & $5181(2)$ & $45(1)$ \\
\hline $\mathrm{C}(12)$ & $3986(3)$ & $2286(1)$ & $4900(2)$ & $39(1)$ \\
\hline $\mathrm{C}(13)$ & $4955(3)$ & 1081(1) & $5656(2)$ & $39(1)$ \\
\hline $\mathrm{C}(14)$ & $5329(3)$ & $643(1)$ & $5405(2)$ & $38(1)$ \\
\hline $\mathrm{C}(15)$ & $6528(3)$ & $280(1)$ & $4466(2)$ & $36(1)$ \\
\hline $\mathrm{C}(16)$ & $7052(3)$ & $-100(1)$ & $4626(2)$ & $44(1)$ \\
\hline $\mathrm{C}(17)$ & 7113(3) & $-418(1)$ & 4084(3) & $54(1)$ \\
\hline $\mathrm{C}(18)$ & $6662(4)$ & $-357(1)$ & $3387(3)$ & $64(1)$ \\
\hline $\mathrm{C}(19)$ & $6139(4)$ & $17(2)$ & $3224(2)$ & $69(2)$ \\
\hline $\mathrm{C}(20)$ & $6073(3)$ & $334(1)$ & $3764(2)$ & $55(1)$ \\
\hline $\mathrm{C}(21)$ & $7295(3)$ & $627(1)$ & $5913(2)$ & $35(1)$ \\
\hline $\mathrm{C}(22)$ & $7256(3)$ & $259(1)$ & $6364(2)$ & $45(1)$ \\
\hline $\mathrm{C}(23)$ & 7909(3) & $189(2)$ & $6969(2)$ & $56(1)$ \\
\hline $\mathrm{C}(24)$ & $8619(3)$ & $487(2)$ & $7140(2)$ & $58(1)$ \\
\hline $\mathrm{C}(25)$ & $8675(3)$ & $858(1)$ & $6700(2)$ & $55(1)$ \\
\hline$C(26)$ & $8012(3)$ & $925(1)$ & $6088(2)$ & $40(1)$ \\
\hline
\end{tabular}




$\begin{array}{lrrrr}\mathrm{C}(27) & 7299(2) & 2033(1) & 3654(2) & 28(1) \\ \mathrm{C}(28) & 7892(2) & 1638(1) & 3692(2) & 29(1) \\ \mathrm{C}(29) & 7673(2) & 1286(1) & 4151(2) & 31(1) \\ \mathrm{C}(30) & 8262(3) & 917(1) & 4181(2) & 36(1) \\ \mathrm{C}(31) & 9013(3) & 887(1) & 3811(2) & 38(1) \\ \mathrm{C}(32) & 9219(3) & 1245(1) & 3389(2) & 40(1) \\ \mathrm{C}(33) & 8659(3) & 1621(1) & 3327(2) & 37(1) \\ \mathrm{C}(34) & 9611(3) & 472(1) & 3882(2) & 55(1) \\ \mathrm{C}(35) & 7435(2) & 2411(1) & 3152(2) & 29(1) \\ \mathrm{C}(36) & 7362(3) & 2328(1) & 2400(2) & 37(1) \\ \mathrm{C}(37) & 7500(3) & 2668(1) & 1919(2) & 39(1) \\ \mathrm{C}(38) & 7729(2) & 3095(1) & 2170(2) & 36(1) \\ \mathrm{C}(39) & 7800(3) & 3175(1) & 2922(2) & 40(1) \\ \mathrm{C}(40) & 7654(3) & 2839(1) & 3409(2) & 37(1) \\ \mathrm{C}(41) & 7880(3) & 3465(1) & 1645(2) & 57(1) \\ \mathrm{C}(42) & 6066(2) & 2410(1) & 4065(2) & 27(1) \\ \mathrm{C}(43) & 6157(2) & 2705(1) & 4650(2) & 30(1) \\ \mathrm{C}(44) & 5627(3) & 3088(1) & 4628(2) & 35(1) \\ \mathrm{C}(45) & 4987(3) & 3172(1) & 4017(2) & 35(1) \\ \mathrm{C}(46) & 4863(3) & 2872(1) & 3434(2) & 37(1) \\ \mathrm{C}(47) & 5402(3) & 2493(1) & 3464(2) & 33(1) \\ \mathrm{C}(48) & 4548(3) & 3867(1) & 4507(2) & 61(1)\end{array}$


Table S19. Bond lengths $[\AA]$ and angles $\left[{ }^{\circ}\right]$ for 9 .

\begin{tabular}{|c|c|c|c|}
\hline $\mathrm{Rh}(1)-\mathrm{C}(29)$ & $2.068(4)$ & $\mathrm{C}(21)-\mathrm{C}(22)$ & $1.388(5)$ \\
\hline $\mathrm{Rh}(1)-\mathrm{N}(1)$ & $2.108(3)$ & $C(22)-C(23)$ & $1.372(5)$ \\
\hline $\mathrm{Rh}(1)-\mathrm{P}(2)$ & $2.1939(10)$ & $C(23)-C(24)$ & $1.376(6)$ \\
\hline $\mathrm{Rh}(1)-\mathrm{P}(1)$ & $2.2766(11)$ & $C(24)-C(25)$ & $1.381(6)$ \\
\hline $\mathrm{P}(1)-\mathrm{C}(7)$ & $1.835(3)$ & $C(25)-C(26)$ & $1.389(5)$ \\
\hline $\mathrm{P}(1)-\mathrm{C}(1)$ & $1.834(4)$ & $C(27)-C(28)$ & $1.466(5)$ \\
\hline $\mathrm{P}(1)-\mathrm{C}(13)$ & $1.857(3)$ & $C(27)-C(35)$ & $1.493(4)$ \\
\hline $\mathrm{P}(2)-\mathrm{C}(21)$ & $1.840(4)$ & $C(28)-C(33)$ & $1.398(5)$ \\
\hline $\mathrm{P}(2)-\mathrm{C}(15)$ & $1.840(4)$ & $C(28)-C(29)$ & $1.417(5)$ \\
\hline $\mathrm{P}(2)-\mathrm{C}(14)$ & $1.849(4)$ & $C(29)-C(30)$ & $1.401(5)$ \\
\hline $\mathrm{O}(1)-\mathrm{C}(45)$ & $1.383(4)$ & $C(30)-C(31)$ & $1.386(5)$ \\
\hline $\mathrm{O}(1)-\mathrm{C}(48)$ & $1.424(4)$ & $C(31)-C(32)$ & $1.381(5)$ \\
\hline $\mathrm{N}(1)-\mathrm{C}(27)$ & $1.306(4)$ & $C(31)-C(34)$ & $1.516(5)$ \\
\hline $\mathrm{N}(1)-\mathrm{C}(42)$ & $1.434(4)$ & $\mathrm{C}(32)-\mathrm{C}(33)$ & $1.391(5)$ \\
\hline $\mathrm{C}(1)-\mathrm{C}(6)$ & $1.384(5)$ & $C(35)-C(40)$ & $1.386(4)$ \\
\hline$C(1)-C(2)$ & $1.399(5)$ & $C(35)-C(36)$ & $1.392(5)$ \\
\hline$C(2)-C(3)$ & $1.394(5)$ & $C(36)-C(37)$ & $1.382(5)$ \\
\hline $\mathrm{C}(3)-\mathrm{C}(4)$ & $1.385(6)$ & $\mathrm{C}(37)-\mathrm{C}(38)$ & $1.385(5)$ \\
\hline $\mathrm{C}(4)-\mathrm{C}(5)$ & $1.362(6)$ & $\mathrm{C}(38)-\mathrm{C}(39)$ & $1.392(5)$ \\
\hline$C(5)-C(6)$ & $1.392(5)$ & $C(38)-C(41)$ & $1.506(5)$ \\
\hline $\mathrm{C}(7)-\mathrm{C}(12)$ & $1.386(5)$ & $C(39)-C(40)$ & $1.384(5)$ \\
\hline $\mathrm{C}(7)-\mathrm{C}(8)$ & $1.389(5)$ & $\mathrm{C}(42)-\mathrm{C}(43)$ & $1.382(4)$ \\
\hline $\mathrm{C}(8)-\mathrm{C}(9)$ & $1.390(5)$ & $\mathrm{C}(42)-\mathrm{C}(47)$ & $1.383(5)$ \\
\hline$C(9)-C(10)$ & $1.374(6)$ & $C(43)-C(44)$ & $1.384(5)$ \\
\hline$C(10)-C(11)$ & $1.373(5)$ & $C(44)-C(45)$ & $1.377(5)$ \\
\hline $\mathrm{C}(11)-\mathrm{C}(12)$ & $1.385(5)$ & $C(45)-C(46)$ & $1.391(5)$ \\
\hline $\mathrm{C}(13)-\mathrm{C}(14)$ & $1.520(5)$ & $\mathrm{C}(46)-\mathrm{C}(47)$ & $1.381(5)$ \\
\hline$C(15)-C(20)$ & $1.371(5)$ & & \\
\hline$C(15)-C(16)$ & $1.380(5)$ & $\mathrm{C}(29)-\mathrm{Rh}(1)-\mathrm{N}(1)$ & $79.57(12)$ \\
\hline$C(16)-C(17)$ & $1.391(5)$ & $\mathrm{C}(29)-\mathrm{Rh}(1)-\mathrm{P}(2)$ & $94.36(10)$ \\
\hline $\mathrm{C}(17)-\mathrm{C}(18)$ & $1.363(6)$ & $\mathrm{N}(1)-\mathrm{Rh}(1)-\mathrm{P}(2)$ & 173.84(8) \\
\hline $\mathrm{C}(18)-\mathrm{C}(19)$ & $1.367(6)$ & $\mathrm{C}(29)-\mathrm{Rh}(1)-\mathrm{P}(1)$ & $170.98(10)$ \\
\hline$C(19)-C(20)$ & $1.387(5)$ & $\mathrm{N}(1)-\mathrm{Rh}(1)-\mathrm{P}(1)$ & $101.13(8)$ \\
\hline $\mathrm{C}(21)-\mathrm{C}(26)$ & $1.381(5)$ & $\mathrm{P}(2)-\mathrm{Rh}(1)-\mathrm{P}(1)$ & $84.70(4)$ \\
\hline
\end{tabular}




\begin{tabular}{|c|c|c|c|}
\hline $\mathrm{C}(7)-\mathrm{P}(1)-\mathrm{C}(1)$ & $102.37(16)$ & $\mathrm{C}(16)-\mathrm{C}(15)-\mathrm{P}(2)$ & $125.7(3)$ \\
\hline $\mathrm{C}(7)-\mathrm{P}(1)-\mathrm{C}(13)$ & $102.42(16)$ & $C(15)-C(16)-C(17)$ & $120.3(4)$ \\
\hline $\mathrm{C}(1)-\mathrm{P}(1)-\mathrm{C}(13)$ & $101.41(17)$ & $C(18)-C(17)-C(16)$ & $120.5(4)$ \\
\hline $\mathrm{C}(7)-\mathrm{P}(1)-\mathrm{Rh}(1)$ & $128.11(12)$ & $\mathrm{C}(17)-\mathrm{C}(18)-\mathrm{C}(19)$ & $119.6(4)$ \\
\hline $\mathrm{C}(1)-\mathrm{P}(1)-\mathrm{Rh}(1)$ & $111.51(12)$ & $\mathrm{C}(18)-\mathrm{C}(19)-\mathrm{C}(20)$ & $120.1(4)$ \\
\hline $\mathrm{C}(13)-\mathrm{P}(1)-\mathrm{Rh}(1)$ & $107.75(13)$ & $C(15)-C(20)-C(19)$ & 121.1(4) \\
\hline $\mathrm{C}(21)-\mathrm{P}(2)-\mathrm{C}(15)$ & $105.03(17)$ & $C(26)-C(21)-C(22)$ & $118.2(4)$ \\
\hline $\mathrm{C}(21)-\mathrm{P}(2)-\mathrm{C}(14)$ & 103.91(17) & $\mathrm{C}(26)-\mathrm{C}(21)-\mathrm{P}(2)$ & $117.5(3)$ \\
\hline $\mathrm{C}(15)-\mathrm{P}(2)-\mathrm{C}(14)$ & 101.71(16) & $\mathrm{C}(22)-\mathrm{C}(21)-\mathrm{P}(2)$ & $124.3(3)$ \\
\hline $\mathrm{C}(21)-\mathrm{P}(2)-\mathrm{Rh}(1)$ & $117.16(12)$ & $\mathrm{C}(23)-\mathrm{C}(22)-\mathrm{C}(21)$ & 121.3(4) \\
\hline $\mathrm{C}(15)-\mathrm{P}(2)-\mathrm{Rh}(1)$ & $115.47(12)$ & $C(22)-C(23)-C(24)$ & $120.1(4)$ \\
\hline $\mathrm{C}(14)-\mathrm{P}(2)-\mathrm{Rh}(1)$ & $111.84(12)$ & $\mathrm{C}(23)-\mathrm{C}(24)-\mathrm{C}(25)$ & $119.9(4)$ \\
\hline $\mathrm{C}(45)-\mathrm{O}(1)-\mathrm{C}(48)$ & $116.8(3)$ & $C(24)-C(25)-C(26)$ & $119.6(4)$ \\
\hline $\mathrm{C}(27)-\mathrm{N}(1)-\mathrm{C}(42)$ & $118.5(3)$ & $C(21)-C(26)-C(25)$ & $121.0(4)$ \\
\hline $\mathrm{C}(27)-\mathrm{N}(1)-\mathrm{Rh}(1)$ & $115.0(2)$ & $\mathrm{N}(1)-\mathrm{C}(27)-\mathrm{C}(28)$ & $116.3(3)$ \\
\hline $\mathrm{C}(42)-\mathrm{N}(1)-\mathrm{Rh}(1)$ & $126.0(2)$ & $\mathrm{N}(1)-\mathrm{C}(27)-\mathrm{C}(35)$ & $123.3(3)$ \\
\hline$C(6)-C(1)-C(2)$ & $117.6(4)$ & $\mathrm{C}(28)-\mathrm{C}(27)-\mathrm{C}(35)$ & $120.4(3)$ \\
\hline $\mathrm{C}(6)-\mathrm{C}(1)-\mathrm{P}(1)$ & $119.0(3)$ & $\mathrm{C}(33)-\mathrm{C}(28)-\mathrm{C}(29)$ & $122.1(3)$ \\
\hline $\mathrm{C}(2)-\mathrm{C}(1)-\mathrm{P}(1)$ & $123.4(3)$ & $\mathrm{C}(33)-\mathrm{C}(28)-\mathrm{C}(27)$ & $121.7(3)$ \\
\hline $\mathrm{C}(3)-\mathrm{C}(2)-\mathrm{C}(1)$ & $121.1(4)$ & $\mathrm{C}(29)-\mathrm{C}(28)-\mathrm{C}(27)$ & $116.2(3)$ \\
\hline $\mathrm{C}(2)-\mathrm{C}(3)-\mathrm{C}(4)$ & 119.6(4) & $\mathrm{C}(30)-\mathrm{C}(29)-\mathrm{C}(28)$ & $114.5(3)$ \\
\hline$C(5)-C(4)-C(3)$ & $120.0(4)$ & $\mathrm{C}(30)-\mathrm{C}(29)-\mathrm{Rh}(1)$ & $133.1(3)$ \\
\hline$C(4)-C(5)-C(6)$ & $120.4(4)$ & $\mathrm{C}(28)-\mathrm{C}(29)-\mathrm{Rh}(1)$ & $112.3(2)$ \\
\hline$C(1)-C(6)-C(5)$ & $121.3(4)$ & $\mathrm{C}(31)-\mathrm{C}(30)-\mathrm{C}(29)$ & $124.6(3)$ \\
\hline $\mathrm{C}(12)-\mathrm{C}(7)-\mathrm{C}(8)$ & $118.0(3)$ & $\mathrm{C}(32)-\mathrm{C}(31)-\mathrm{C}(30)$ & $118.9(3)$ \\
\hline $\mathrm{C}(12)-\mathrm{C}(7)-\mathrm{P}(1)$ & $122.3(3)$ & $\mathrm{C}(32)-\mathrm{C}(31)-\mathrm{C}(34)$ & $120.7(3)$ \\
\hline $\mathrm{C}(8)-\mathrm{C}(7)-\mathrm{P}(1)$ & $119.5(3)$ & $\mathrm{C}(30)-\mathrm{C}(31)-\mathrm{C}(34)$ & $120.4(3)$ \\
\hline $\mathrm{C}(9)-\mathrm{C}(8)-\mathrm{C}(7)$ & $120.2(4)$ & $\mathrm{C}(31)-\mathrm{C}(32)-\mathrm{C}(33)$ & $119.8(4)$ \\
\hline $\mathrm{C}(10)-\mathrm{C}(9)-\mathrm{C}(8)$ & $121.0(4)$ & $\mathrm{C}(32)-\mathrm{C}(33)-\mathrm{C}(28)$ & $120.1(3)$ \\
\hline $\mathrm{C}(11)-\mathrm{C}(10)-\mathrm{C}(9)$ & 119.3(4) & $\mathrm{C}(40)-\mathrm{C}(35)-\mathrm{C}(36)$ & $118.9(3)$ \\
\hline $\mathrm{C}(10)-\mathrm{C}(11)-\mathrm{C}(12)$ & $120.1(4)$ & $\mathrm{C}(40)-\mathrm{C}(35)-\mathrm{C}(27)$ & $122.4(3)$ \\
\hline$C(11)-C(12)-C(7)$ & $121.4(4)$ & $\mathrm{C}(36)-\mathrm{C}(35)-\mathrm{C}(27)$ & $118.7(3)$ \\
\hline $\mathrm{C}(14)-\mathrm{C}(13)-\mathrm{P}(1)$ & $107.6(2)$ & $\mathrm{C}(37)-\mathrm{C}(36)-\mathrm{C}(35)$ & $120.4(3)$ \\
\hline $\mathrm{C}(13)-\mathrm{C}(14)-\mathrm{P}(2)$ & $108.7(2)$ & $\mathrm{C}(36)-\mathrm{C}(37)-\mathrm{C}(38)$ & $121.3(3)$ \\
\hline$C(20)-C(15)-C(16)$ & $118.4(4)$ & $\mathrm{C}(37)-\mathrm{C}(38)-\mathrm{C}(39)$ & $117.9(3)$ \\
\hline $\mathrm{C}(20)-\mathrm{C}(15)-\mathrm{P}(2)$ & $115.7(3)$ & $\mathrm{C}(37)-\mathrm{C}(38)-\mathrm{C}(41)$ & $121.2(3)$ \\
\hline
\end{tabular}




$\begin{array}{ll}\mathrm{C}(39)-\mathrm{C}(38)-\mathrm{C}(41) & 120.9(4) \\ \mathrm{C}(40)-\mathrm{C}(39)-\mathrm{C}(38) & 121.4(3) \\ \mathrm{C}(39)-\mathrm{C}(40)-\mathrm{C}(35) & 120.2(3) \\ \mathrm{C}(43)-\mathrm{C}(42)-\mathrm{C}(47) & 118.8(3) \\ \mathrm{C}(43)-\mathrm{C}(42)-\mathrm{N}(1) & 120.6(3) \\ \mathrm{C}(47)-\mathrm{C}(42)-\mathrm{N}(1) & 120.6(3) \\ \mathrm{C}(42)-\mathrm{C}(43)-\mathrm{C}(44) & 121.2(3) \\ \mathrm{C}(45)-\mathrm{C}(44)-\mathrm{C}(43) & 119.3(3) \\ \mathrm{C}(44)-\mathrm{C}(45)-\mathrm{O}(1) & 124.6(3) \\ \mathrm{C}(44)-\mathrm{C}(45)-\mathrm{C}(46) & 120.3(3) \\ \mathrm{O}(1)-\mathrm{C}(45)-\mathrm{C}(46) & 115.1(3) \\ \mathrm{C}(47)-\mathrm{C}(46)-\mathrm{C}(45) & 119.5(3) \\ \mathrm{C}(46)-\mathrm{C}(47)-\mathrm{C}(42) & 120.8(3)\end{array}$


Table S20. Anisotropic displacement parameters $\left(\AA^{2} \times 10^{3}\right)$ for 9 . The anisotropic displacement factor exponent takes the form: $-2 \pi^{2}\left[h^{2} a^{* 2} U^{11}+\ldots+2 h k a^{*} b^{*} U^{12}\right]$.

$\begin{array}{lcccccc} & \mathrm{U}^{11} & \mathrm{U}^{22} & \mathrm{U}^{33} & \mathrm{U}^{23} & \mathrm{U}^{13} & \mathrm{U} \\ & & & & & & \\ \mathrm{Rh}(1) & 29(1) & 26(1) & 35(1) & 4(1) & 11(1) & 0(1) \\ \mathrm{P}(1) & 29(1) & 32(1) & 38(1) & 2(1) & 11(1) & 1(1) \\ \mathrm{P}(2) & 34(1) & 27(1) & 42(1) & 6(1) & 12(1) & 1(1) \\ \mathrm{O}(1) & 40(2) & 41(2) & 63(2) & -6(1) & -1(1) & 15(1) \\ \mathrm{N}(1) & 28(2) & 24(2) & 32(2) & 2(1) & 6(1) & -5(1) \\ \mathrm{C}(1) & 36(2) & 27(2) & 39(2) & -1(2) & 8(2) & 3(2) \\ \mathrm{C}(2) & 39(3) & 46(2) & 51(3) & 3(2) & 7(2) & -7(2) \\ \mathrm{C}(3) & 38(3) & 44(3) & 75(3) & 9(2) & -1(2) & -14(2) \\ \mathrm{C}(4) & 59(3) & 33(2) & 63(3) & -1(2) & -13(3) & -4(2) \\ \mathrm{C}(5) & 65(3) & 43(3) & 44(3) & -6(2) & -2(2) & 5(2) \\ \mathrm{C}(6) & 43(3) & 38(2) & 41(2) & -2(2) & 8(2) & 3(2) \\ \mathrm{C}(7) & 25(2) & 32(2) & 40(2) & 0(2) & 13(2) & 1(2) \\ \mathrm{C}(8) & 39(3) & 49(3) & 42(2) & 0(2) & 7(2) & 0(2) \\ \mathrm{C}(9) & 60(3) & 50(3) & 45(3) & -18(2) & 13(2) & -14(2) \\ \mathrm{C}(10) & 51(3) & 35(2) & 68(3) & -15(2) & 25(2) & -8(2) \\ \mathrm{C}(11) & 34(3) & 35(2) & 65(3) & -6(2) & 11(2) & 1(2) \\ \mathrm{C}(12) & 38(3) & 34(2) & 45(2) & -1(2) & 12(2) & 1(2) \\ \mathrm{C}(13) & 37(3) & 40(2) & 42(2) & 4(2) & 14(2) & -2(2) \\ \mathrm{C}(14) & 35(2) & 35(2) & 47(2) & 6(2) & 13(2) & -3(2) \\ \mathrm{C}(15) & 36(2) & 30(2) & 45(2) & 6(2) & 13(2) & -9(2) \\ \mathrm{C}(16) & 43(3) & 32(2) & 59(3) & 2(2) & 13(2) & -1(2) \\ \mathrm{C}(17) & 61(3) & 32(2) & 75(3) & -3(2) & 28(3) & 0(2) \\ \mathrm{C}(18) & 105(4) & 35(3) & 56(3) & -7(2) & 29(3) & -5(3) \\ \mathrm{C}(19) & 114(5) & 49(3) & 46(3) & -4(2) & 14(3) & 4(3) \\ \mathrm{C}(20) & 79(4) & 39(2) & 47(3) & 5(2) & 14(2) & 9(2) \\ \mathrm{C}(21) & 37(2) & 33(2) & 37(2) & 3(2) & 12(2) & 7(2) \\ \mathrm{C}(22) & 48(3) & 40(2) & 46(2) & 8(2) & 10(2) & -5(2) \\ \mathrm{C}(23) & 57(3) & 59(3) & 53(3) & 25(2) & 10(2) & 7(3) \\ \mathrm{C}(24) & 50(3) & 71(3) & 49(3) & 15(2) & -2(2) & 4(3) \\ \mathrm{C}(25) & 48(3) & 55(3) & 61(3) & 1(2) & 0(2) & -4(2) \\ \mathrm{C}(26) & 41(3) & 40(2) & 41(2) & 3(2) & 10(2) & 1(2)\end{array}$




$\begin{array}{lllllll}\mathrm{C}(27) & 26(2) & 27(2) & 30(2) & -1(2) & 4(2) & -5(2) \\ \mathrm{C}(28) & 24(2) & 31(2) & 30(2) & -2(2) & 5(2) & -5(2) \\ \mathrm{C}(29) & 30(2) & 26(2) & 36(2) & -2(2) & 10(2) & 0(2) \\ \mathrm{C}(30) & 35(2) & 25(2) & 49(2) & -3(2) & 10(2) & -4(2) \\ \mathrm{C}(31) & 32(2) & 33(2) & 48(2) & -7(2) & 9(2) & 1(2) \\ \mathrm{C}(32) & 33(2) & 50(2) & 40(2) & -3(2) & 16(2) & 4(2) \\ \mathrm{C}(33) & 33(2) & 37(2) & 44(2) & 3(2) & 9(2) & 0(2) \\ \mathrm{C}(34) & 53(3) & 47(3) & 66(3) & -5(2) & 16(2) & 14(2) \\ \mathrm{C}(35) & 24(2) & 29(2) & 37(2) & 2(2) & 10(2) & 2(2) \\ \mathrm{C}(36) & 38(2) & 35(2) & 38(2) & 3(2) & 11(2) & 0(2) \\ \mathrm{C}(37) & 32(2) & 49(2) & 37(2) & 9(2) & 10(2) & -2(2) \\ \mathrm{C}(38) & 26(2) & 37(2) & 46(2) & 16(2) & 12(2) & -1(2) \\ \mathrm{C}(39) & 40(3) & 27(2) & 54(3) & 5(2) & 12(2) & 0(2) \\ \mathrm{C}(40) & 38(2) & 35(2) & 41(2) & 1(2) & 13(2) & -3(2) \\ \mathrm{C}(41) & 59(3) & 49(3) & 65(3) & 27(2) & 17(2) & -6(2) \\ \mathrm{C}(42) & 27(2) & 28(2) & 28(2) & 3(2) & 6(2) & 0(2) \\ \mathrm{C}(43) & 26(2) & 33(2) & 31(2) & 1(2) & 3(2) & -1(2) \\ \mathrm{C}(44) & 36(2) & 31(2) & 38(2) & -9(2) & 4(2) & 0(2) \\ \mathrm{C}(45) & 29(2) & 27(2) & 51(2) & 0(2) & 8(2) & 1(2) \\ \mathrm{C}(46) & 34(2) & 42(2) & 33(2) & 4(2) & 0(2) & 4(2) \\ \mathrm{C}(47) & 36(2) & 37(2) & 27(2) & -5(2) & 5(2) & 0(2) \\ \mathrm{C}(48) & 56(3) & 40(2) & 86(3) & -19(2) & 4(3) & 14(2)\end{array}$


Table S21. Hydrogen coordinates $\left(\times 10^{4}\right)$ and isotropic displacement parameters $\left(\AA^{2} \times 10^{3}\right)$ for 9.

$\begin{array}{lrrrr} & x & y & z & \text { U(eq) } \\ \mathrm{H}(2 \mathrm{~A}) & & & & \\ \mathrm{H}(3 \mathrm{~A}) & 3117 & 1265 & 4805 & 54 \\ \mathrm{H}(4 \mathrm{~A}) & 2023 & 1010 & 3839 & 64 \\ \mathrm{H}(5 \mathrm{~A}) & 2407 & 950 & 2654 & 64 \\ \mathrm{H}(6 \mathrm{~A}) & 3851 & 1159 & 2434 & 62 \\ \mathrm{H}(8 \mathrm{~A}) & 4962 & 1388 & 3399 & 49 \\ \mathrm{H}(9 \mathrm{~A}) & 5370 & 1960 & 6342 & 52 \\ \mathrm{H}(10 \mathrm{~A}) & 4832 & 2614 & 6817 & 62 \\ \mathrm{H}(11 \mathrm{~A}) & 3797 & 3073 & 6087 & 60 \\ \mathrm{H}(12 \mathrm{~A}) & 3251 & 2862 & 4881 & 53 \\ \mathrm{H}(13 \mathrm{~A}) & 3761 & 2204 & 4407 & 46 \\ \mathrm{H}(13 \mathrm{~B}) & 5301 & 1171 & 6137 & 47 \\ \mathrm{H}(14 \mathrm{~A}) & 4299 & 1047 & 5710 & 47 \\ \mathrm{H}(14 \mathrm{~B}) & 4892 & 515 & 4996 & 46 \\ \mathrm{H}(16 \mathrm{~A}) & 5408 & 426 & 5817 & 46 \\ \mathrm{H}(17 \mathrm{~A}) & 7373 & -144 & 5109 & 53 \\ \mathrm{H}(18 \mathrm{~A}) & 7472 & -679 & 4200 & 65 \\ \mathrm{H}(19 \mathrm{~A}) & 6711 & -573 & 3017 & 76 \\ \mathrm{H}(20 \mathrm{~A}) & 5820 & 60 & 2740 & 83 \\ \mathrm{H}(22 \mathrm{~A}) & 5706 & 592 & 3646 & 66 \\ \mathrm{H}(23 \mathrm{~A}) & 6768 & 50 & 6252 & 54 \\ \mathrm{H}(24 \mathrm{~A}) & 7870 & -66 & 7271 & 67 \\ \mathrm{H}(25 \mathrm{~A}) & 9070 & 439 & 7559 & 69 \\ \mathrm{H}(26 \mathrm{~A}) & 9164 & 1065 & 6816 & 66 \\ \mathrm{H}(30 \mathrm{~A}) & 8053 & 1179 & 5785 & 48 \\ \mathrm{H}(32 \mathrm{~A}) & 8139 & 671 & 4476 & 43 \\ \mathrm{H}(33 \mathrm{~A}) & 9742 & 1233 & 3143 & 48 \\ \mathrm{H}(34 \mathrm{~A}) & 10103 & 507 & 3582 & 85 \\ \mathrm{H}(34 \mathrm{~B}) & 9879 & 212 & 3711 & 82 \\ \mathrm{H}(34 \mathrm{C}) & 430 & 4398 & 82 \\ \mathrm{H}(36 \mathrm{~A}) & 2036 & 2217 & 44\end{array}$


H(37A)

7436

2607

1407

47

H(39A)

7951

3466

3106

48

$\mathrm{H}(40 \mathrm{~A})$

7705

2901

3920

44

$\mathrm{H}(41 \mathrm{~A})$

8031

3741

1921

85

$\mathrm{H}(41 \mathrm{~B})$

7319

3509

1291

85

$\mathrm{H}(41 \mathrm{C})$

8388

3384

1381

85

$\mathrm{H}(43 \mathrm{~A})$

6592

2644

5075

36

$\mathrm{H}(44 \mathrm{~A})$

5705

3291

5031

42

$\mathrm{H}(46 \mathrm{~A})$

4412

2927

3017

44

$\mathrm{H}(47 \mathrm{~A})$

5315

2286

3068

40

$\mathrm{H}(48 \mathrm{~A})$

4117

4114

4383

92

$\mathrm{H}(48 \mathrm{~B})$

5179

3980

4570

92

$\mathrm{H}(48 \mathrm{C})$

4430

3726

4965

92 


\section{Experimental Procedure for the X-ray Diffraction of $\mathbf{2 6}$}

\section{Data Collection}

A yellow-orange blade crystal of $\mathrm{C}_{46} \mathrm{H}_{45} \mathrm{OP}_{2} \mathrm{Rh} \cdot \mathrm{C}_{4} \mathrm{H}_{8} \mathrm{O}, \mathrm{C}_{50} \mathrm{H}_{53} \mathrm{O}_{2} \mathrm{P}_{2} \mathrm{Rh}$, having approximate dimensions of $0.25 \times 0.10 \times 0.08 \mathrm{~mm}^{3}$ was mounted with epoxy cement on the tip of a fine glass fiber. All measurements were made on a Nonius KappaCCD diffractometer with graphite monochromated Mo-K $\alpha$ radiation.

Cell constants and an orientation matrix for data collection corresponded to an $I$-centered monoclinic cell with dimensions:

$$
\begin{array}{ll}
\mathrm{a}=20.919(4) \AA & \alpha=90^{\circ} \\
\mathrm{b}=10.106(2) \AA & \beta=97.01(3) \mathrm{O} \\
\mathrm{c}=40.156(8) \AA & \gamma=90^{\circ} \\
\mathrm{V}=8426(3) \AA^{3} &
\end{array}
$$

For $\mathrm{Z}=8$ and F.W. $=850.77$, the calculated density is $1.341 \mathrm{~g} / \mathrm{cm}^{3}$. Based on a statistical analysis of intensity distribution, and the successful solution and refinement of the structure, the space group was determined to be $I 2 / a$ (\#15).

The data were collected at a temperature of $173(2) \mathrm{K}$ to a maximum $2 \theta$ value of $56.62^{\circ}$. Five omega scans consisting of 85, 108, 99, 79 and 42 data frames, respectively, were collected with a frame width of $0.7^{\circ}$ and a detector-to-crystal distance, Dx, of $35.0 \mathrm{~mm}$. Each frame was exposed twice (for the purpose of de-zingering) for a total of $175 \mathrm{~s}$. The data frames were processed and scaled using the DENZO software package. ${ }^{1}$

\section{Data Reduction}

A total of 19140 reflections were collected of which 10339 were unique and observed $\left(\mathrm{R}_{\mathrm{int}}=0.0516\right)$. The linear absorption coefficient, $\mu$, for Mo-K $\alpha$ radiation is $5.21 \mathrm{~cm}^{-1}$, and no absorption correction was applied. The data were corrected for Lorentz and polarization effects.

\section{Structure Solution and Refinement}

The structure was solved by direct methods and expanded using Fourier techniques ${ }^{2}$. The non-hydrogen atoms were refined anisotropically, and hydrogen atoms were treated as idealized contributions. The final cycle of full-matrix least-squares refinement ${ }^{3}$ on $\mathrm{F}$ was based on 10339 observed reflections (I > 2.00 $(\mathrm{I})$ ) and 491 variable parameters and converged with unweighted and weighted agreement factors of:

$$
\begin{gathered}
\mathrm{R}=\Sigma\|\mathrm{Fol}-|\mathrm{Fc} \| / \Sigma| \mathrm{Fo} \mid=0.0501 \\
\mathrm{R}_{\mathrm{W}}=\left\{\Sigma\left[\mathrm{w}\left(\mathrm{F}_{\mathrm{o}}^{2}-\mathrm{F}_{\mathrm{c}}^{2}\right)^{2}\right] / \Sigma\left[\mathrm{w}\left(\mathrm{F}_{\mathrm{o}}^{2}\right)^{2}\right]\right\}^{1 / 2}=0.1122
\end{gathered}
$$


The maximum and minimum peaks on the final difference Fourier map corresponded to 0.836 and $-0.658 \mathrm{e}^{-} / \AA^{3}$ respectively.

\section{REFERENCES}

(1) Z. Otwinowski and W. Minor, "Processing of X-Ray Diffraction Data Collected in Oscillation Mode," Methods in Enzymology, vol. 276: Macromolecular Crystallography, part A, 307-326, 1997, C.W. Carter, Jr. \& R.M. Sweet, Eds., Academic Press.

(2) Acta Cryst. A46 (1990) 467-473

(3) Least Squares function minimized: $\Sigma w\left(\mathrm{~F}_{\mathrm{o}}^{2}-\mathrm{F}_{\mathrm{c}}^{2}\right)^{2}$ 
Table S22. Crystal data and structure refinement for $\mathbf{2 6}$.

Empirical formula

Formula weight

Temperature

Wavelength

Crystal system

Space group

Unit cell dimensions

Volume

$\mathrm{Z}$

Density (calculated)

Absorption coefficient

$\mathrm{F}(000)$

Crystal size

Theta range for data collection

Index ranges

Reflections collected

Independent reflections

Completeness to theta $=28.31^{\circ}$

Absorption correction

Max. and min. transmission

Refinement method

Data / restraints / parameters

Goodness-of-fit on $\mathrm{F}^{2}$

Final $\mathrm{R}$ indices [I $>2 \operatorname{sigma}(\mathrm{I})]$

$\mathrm{R}$ indices (all data)

Largest diff. peak and hole
$\mathrm{C}_{50} \mathrm{H}_{53} \mathrm{O}_{2} \mathrm{P}_{2} \mathrm{Rh}$

850.77

173(2) K

$0.71073 \AA$

Monoclinic

I $2 / \mathrm{a}$

$$
\begin{array}{ll}
\mathrm{a}=20.919(4) \AA & \alpha=90^{\circ} . \\
\mathrm{b}=10.106(2) \AA & \beta=97.01(3)^{\circ} . \\
\mathrm{c}=40.156(8) \AA & \gamma=90^{\circ} .
\end{array}
$$

$8426(3) \AA^{3}$

8

$1.341 \mathrm{~g} / \mathrm{cm}^{3}$

$5.21 \mathrm{~cm}^{-1}$

3552

$0.25 \times 0.10 \times 0.08 \mathrm{~mm}^{3}$

2.41 to $28.31^{\circ}$.

$-27<=\mathrm{h}<=27,-13<=\mathrm{k}<=13,-53<=\mathrm{l}<=53$

19140

$10339[\mathrm{R}(\mathrm{int})=0.0516]$

$98.6 \%$

None

0.9595 and 0.8809

Full-matrix least-squares on $\mathrm{F}^{2}$

10339 / 0 / 491

1.006

$\mathrm{R} 1=0.0501, \mathrm{wR} 2=0.1122$

$\mathrm{R} 1=0.0893, \mathrm{wR} 2=0.1270$

0.836 and -0.658 e. $\AA^{-3}$ 
Table S23. Atomic coordinates (x $\left.10^{4}\right)$ and equivalent isotropic displacement parameters ( $\left(\AA^{2} \mathrm{x}\right.$ $10^{3}$ ) for $\mathbf{2 6} . \mathrm{U}(\mathrm{eq})$ is defined as one third of the trace of the orthogonalized $\mathrm{U}^{\mathrm{ij}}$ tensor.

\begin{tabular}{|c|c|c|c|c|}
\hline & $\mathrm{x}$ & $\mathrm{y}$ & $\mathrm{Z}$ & $\mathrm{U}(\mathrm{eq})$ \\
\hline $\mathrm{Rh}(1)$ & $2747(1)$ & $7132(1)$ & $992(1)$ & $25(1)$ \\
\hline $\mathrm{P}(1)$ & 1937(1) & $7821(1)$ & $1286(1)$ & $28(1)$ \\
\hline $\mathrm{P}(2)$ & $3020(1)$ & $9338(1)$ & $982(1)$ & $27(1)$ \\
\hline $\mathrm{O}(1)$ & $3586(1)$ & $6363(2)$ & $1355(1)$ & $31(1)$ \\
\hline $\mathrm{C}(1)$ & $1956(2)$ & $7244(3)$ & $1719(1)$ & $32(1)$ \\
\hline $\mathrm{C}(2)$ & $2412(2)$ & $6313(3)$ & $1845(1)$ & $34(1)$ \\
\hline $\mathrm{C}(3)$ & $2416(2)$ & $5854(4)$ & $2170(1)$ & $42(1)$ \\
\hline $\mathrm{C}(4)$ & 1972(2) & $6324(4)$ & 2371(1) & $45(1)$ \\
\hline$C(5)$ & $1526(2)$ & $7248(4)$ & $2249(1)$ & $47(1)$ \\
\hline$C(6)$ & $1512(2)$ & $7708(3)$ & 1924(1) & $39(1)$ \\
\hline $\mathrm{C}(7)$ & $1096(2)$ & $7557(3)$ & $1118(1)$ & $31(1)$ \\
\hline $\mathrm{C}(8)$ & $764(2)$ & $6464(3)$ & $1221(1)$ & $38(1)$ \\
\hline $\mathrm{C}(9)$ & $151(2)$ & $6167(4)$ & 1071(1) & $49(1)$ \\
\hline$C(10)$ & $-139(2)$ & $6953(4)$ & $814(1)$ & $53(1)$ \\
\hline $\mathrm{C}(11)$ & $175(2)$ & $8057(4)$ & $712(1)$ & $48(1)$ \\
\hline$C(12)$ & $793(2)$ & $8350(3)$ & $866(1)$ & $37(1)$ \\
\hline $\mathrm{C}(13)$ & $1982(2)$ & $9637(3)$ & $1334(1)$ & $33(1)$ \\
\hline$C(14)$ & $2293(1)$ & $10292(3)$ & $1052(1)$ & $32(1)$ \\
\hline$C(15)$ & $3262(1)$ & $10129(3)$ & $606(1)$ & $30(1)$ \\
\hline$C(16)$ & $3149(2)$ & $11457(3)$ & $530(1)$ & 41(1) \\
\hline$C(17)$ & $3328(2)$ & $12004(4)$ & $243(1)$ & $50(1)$ \\
\hline $\mathrm{C}(18)$ & $3630(2)$ & $11231(4)$ & $25(1)$ & $55(1)$ \\
\hline $\mathrm{C}(19)$ & $3755(2)$ & $9909(4)$ & $97(1)$ & $55(1)$ \\
\hline$C(20)$ & $3566(2)$ & $9368(4)$ & $385(1)$ & $43(1)$ \\
\hline $\mathrm{C}(21)$ & $3624(1)$ & $9852(3)$ & $1325(1)$ & $29(1)$ \\
\hline$C(22)$ & $4113(2)$ & $10740(3)$ & $1282(1)$ & $36(1)$ \\
\hline $\mathrm{C}(23)$ & $4582(2)$ & $11052(4)$ & $1545(1)$ & $43(1)$ \\
\hline $\mathrm{C}(24)$ & $4560(2)$ & $10489(4)$ & $1858(1)$ & $46(1)$ \\
\hline$C(25)$ & $4082(2)$ & $9597(4)$ & 1904(1) & $41(1)$ \\
\hline$C(26)$ & $3619(2)$ & $9274(3)$ & $1643(1)$ & $35(1)$ \\
\hline $\mathrm{C}(27)$ & $4714(2)$ & $7562(4)$ & $1198(1)$ & $39(1)$ \\
\hline
\end{tabular}




\begin{tabular}{|c|c|c|c|c|}
\hline $\mathrm{C}(28)$ & $5300(2)$ & $8072(4)$ & $1130(1)$ & $52(1)$ \\
\hline$C(29)$ & $5528(2)$ & 7819(4) & $830(1)$ & $54(1)$ \\
\hline $\mathrm{C}(30)$ & $5163(2)$ & $7033(4)$ & $594(1)$ & $51(1)$ \\
\hline $\mathrm{C}(31)$ & $4580(2)$ & $6524(4)$ & $658(1)$ & $41(1)$ \\
\hline$C(32)$ & $4345(2)$ & $6780(3)$ & $964(1)$ & $33(1)$ \\
\hline $\mathrm{C}(33)$ & $3723(1)$ & $6209(3)$ & $1050(1)$ & $29(1)$ \\
\hline$C(34)$ & $3294(1)$ & $5515(3)$ & $814(1)$ & $30(1)$ \\
\hline$C(35)$ & $2675(2)$ & $5016(3)$ & $887(1)$ & $31(1)$ \\
\hline$C(36)$ & $2605(2)$ & $4162(3)$ & $1183(1)$ & $33(1)$ \\
\hline$C(37)$ & 1994(2) & $3864(3)$ & $1267(1)$ & $39(1)$ \\
\hline$C(38)$ & $1905(2)$ & $3116(3)$ & $1547(1)$ & $48(1)$ \\
\hline C(39) & $2430(2)$ & $2620(3)$ & $1754(1)$ & $50(1)$ \\
\hline $\mathrm{C}(40)$ & $3041(2)$ & $2863(3)$ & $1665(1)$ & $46(1)$ \\
\hline $\mathrm{C}(41)$ & $3128(2)$ & $3612(3)$ & $1385(1)$ & $38(1)$ \\
\hline $\mathrm{C}(42)$ & $2336(3)$ & $1828(4)$ & $2065(1)$ & $77(2)$ \\
\hline$C(43)$ & $2186(2)$ & $4796(3)$ & $574(1)$ & $36(1)$ \\
\hline $\mathrm{C}(44)$ & $1757(2)$ & $5979(4)$ & $496(1)$ & $46(1)$ \\
\hline$C(45)$ & $2147(2)$ & $7271(3)$ & $541(1)$ & $31(1)$ \\
\hline$C(46)$ & $1363(2)$ & $5914(4)$ & $153(1)$ & $43(1)$ \\
\hline $\mathrm{O}(2)$ & $-312(2)$ & $3573(4)$ & $2348(1)$ & $89(1)$ \\
\hline $\mathrm{C}(47)$ & $268(3)$ & $3334(6)$ & $2217(1)$ & $85(2)$ \\
\hline $\mathrm{C}(48)$ & $371(3)$ & $4430(6)$ & 1981(1) & $88(2)$ \\
\hline C(49) & $-140(3)$ & $5423(6)$ & $2034(2)$ & $104(2)$ \\
\hline$C(50)$ & $-644(3)$ & $4612(7)$ & $2166(1)$ & $99(2)$ \\
\hline
\end{tabular}


Table S24. Bond lengths $[\AA]$ and angles $\left[{ }^{\circ}\right]$ for $\mathbf{2 6}$.

\begin{tabular}{|c|c|c|c|}
\hline $\operatorname{Rh}(1)-C(45)$ & $2.079(3)$ & $C(21)-C(26)$ & $1.405(4)$ \\
\hline $\mathrm{Rh}(1)-\mathrm{C}(34)$ & $2.167(3)$ & $\mathrm{C}(22)-\mathrm{C}(23)$ & $1.386(5)$ \\
\hline $\operatorname{Rh}(1)-C(35)$ & 2.181(3) & $C(23)-C(24)$ & $1.386(5)$ \\
\hline $\mathrm{Rh}(1)-\mathrm{C}(33)$ & $2.232(3)$ & $C(24)-C(25)$ & $1.376(5)$ \\
\hline $\mathrm{Rh}(1)-\mathrm{O}(1)$ & $2.276(2)$ & $C(25)-C(26)$ & $1.376(5)$ \\
\hline $\mathrm{Rh}(1)-\mathrm{P}(1)$ & $2.2880(10)$ & $\mathrm{C}(27)-\mathrm{C}(28)$ & $1.385(5)$ \\
\hline $\mathrm{Rh}(1)-\mathrm{P}(2)$ & $2.3035(9)$ & $\mathrm{C}(27)-\mathrm{C}(32)$ & $1.388(5)$ \\
\hline$P(1)-C(7)$ & $1.825(3)$ & $C(28)-C(29)$ & $1.375(5)$ \\
\hline$P(1)-C(1)$ & $1.830(3)$ & $C(29)-C(30)$ & $1.390(6)$ \\
\hline $\mathrm{P}(1)-\mathrm{C}(13)$ & $1.847(3)$ & $C(30)-C(31)$ & $1.377(5)$ \\
\hline $\mathrm{P}(2)-\mathrm{C}(21)$ & $1.828(3)$ & $\mathrm{C}(31)-\mathrm{C}(32)$ & $1.399(4)$ \\
\hline $\mathrm{P}(2)-\mathrm{C}(15)$ & $1.833(3)$ & $\mathrm{C}(32)-\mathrm{C}(33)$ & $1.503(4)$ \\
\hline $\mathrm{P}(2)-\mathrm{C}(14)$ & $1.850(3)$ & $\mathrm{C}(33)-\mathrm{C}(34)$ & $1.411(4)$ \\
\hline $\mathrm{O}(1)-\mathrm{C}(33)$ & $1.300(3)$ & $\mathrm{C}(34)-\mathrm{C}(35)$ & $1.453(4)$ \\
\hline$C(1)-C(6)$ & $1.394(4)$ & $C(35)-C(36)$ & $1.488(4)$ \\
\hline$C(1)-C(2)$ & $1.391(5)$ & $C(35)-C(43)$ & $1.536(4)$ \\
\hline$C(2)-C(3)$ & $1.384(4)$ & $\mathrm{C}(36)-\mathrm{C}(37)$ & $1.396(4)$ \\
\hline$C(3)-C(4)$ & $1.386(5)$ & $\mathrm{C}(36)-\mathrm{C}(41)$ & $1.396(5)$ \\
\hline$C(4)-C(5)$ & $1.367(5)$ & $\mathrm{C}(37)-\mathrm{C}(38)$ & $1.387(5)$ \\
\hline$C(5)-C(6)$ & $1.382(5)$ & $\mathrm{C}(38)-\mathrm{C}(39)$ & $1.389(6)$ \\
\hline$C(7)-C(12)$ & $1.381(5)$ & $C(39)-C(40)$ & $1.391(5)$ \\
\hline$C(7)-C(8)$ & $1.394(5)$ & $\mathrm{C}(39)-\mathrm{C}(42)$ & $1.515(5)$ \\
\hline $\mathrm{C}(8)-\mathrm{C}(9)$ & $1.382(5)$ & $\mathrm{C}(40)-\mathrm{C}(41)$ & $1.385(5)$ \\
\hline $\mathrm{C}(9)-\mathrm{C}(10)$ & $1.381(6)$ & $\mathrm{C}(43)-\mathrm{C}(44)$ & $1.505(5)$ \\
\hline $\mathrm{C}(10)-\mathrm{C}(11)$ & $1.384(5)$ & $\mathrm{C}(44)-\mathrm{C}(46)$ & $1.518(5)$ \\
\hline $\mathrm{C}(11)-\mathrm{C}(12)$ & $1.395(5)$ & $\mathrm{C}(44)-\mathrm{C}(45)$ & $1.538(5)$ \\
\hline$C(13)-C(14)$ & $1.524(4)$ & $\mathrm{O}(2)-\mathrm{C}(47)$ & $1.401(6)$ \\
\hline$C(15)-C(20)$ & $1.385(4)$ & $\mathrm{O}(2)-\mathrm{C}(50)$ & $1.414(7)$ \\
\hline$C(15)-C(16)$ & $1.391(4)$ & $\mathrm{C}(47)-\mathrm{C}(48)$ & $1.491(7)$ \\
\hline$C(16)-C(17)$ & $1.372(5)$ & $\mathrm{C}(48)-\mathrm{C}(49)$ & $1.500(8)$ \\
\hline $\mathrm{C}(17)-\mathrm{C}(18)$ & $1.382(5)$ & $\mathrm{C}(49)-\mathrm{C}(50)$ & $1.484(7)$ \\
\hline $\mathrm{C}(18)-\mathrm{C}(19)$ & $1.385(6)$ & & \\
\hline$C(19)-C(20)$ & $1.380(5)$ & $C(45)-R h(1)-C(34)$ & $92.88(12)$ \\
\hline$C(21)-C(22)$ & $1.387(4)$ & $\mathrm{C}(45)-\mathrm{Rh}(1)-\mathrm{C}(35)$ & $82.98(12)$ \\
\hline
\end{tabular}




\begin{tabular}{|c|c|c|c|}
\hline$C(34)-\operatorname{Rh}(1)-C(35)$ & $39.06(11)$ & $\mathrm{C}(2)-\mathrm{C}(3)-\mathrm{C}(4)$ & $120.4(3)$ \\
\hline $\mathrm{C}(45)-\mathrm{Rh}(1)-\mathrm{C}(33)$ & $124.55(12)$ & $C(5)-C(4)-C(3)$ & $120.2(3)$ \\
\hline $\mathrm{C}(34)-\mathrm{Rh}(1)-\mathrm{C}(33)$ & $37.40(11)$ & $C(4)-C(5)-C(6)$ & $120.1(3)$ \\
\hline $\mathrm{C}(35)-\mathrm{Rh}(1)-\mathrm{C}(33)$ & $69.59(11)$ & $\mathrm{C}(5)-\mathrm{C}(6)-\mathrm{C}(1)$ & $120.4(3)$ \\
\hline $\mathrm{C}(45)-\mathrm{Rh}(1)-\mathrm{O}(1)$ & $156.50(10)$ & $\mathrm{C}(12)-\mathrm{C}(7)-\mathrm{C}(8)$ & $118.4(3)$ \\
\hline $\mathrm{C}(34)-\mathrm{Rh}(1)-\mathrm{O}(1)$ & $63.70(10)$ & $\mathrm{C}(12)-\mathrm{C}(7)-\mathrm{P}(1)$ & $121.5(3)$ \\
\hline $\mathrm{C}(35)-\mathrm{Rh}(1)-\mathrm{O}(1)$ & $79.55(10)$ & $\mathrm{C}(8)-\mathrm{C}(7)-\mathrm{P}(1)$ & $119.9(3)$ \\
\hline $\mathrm{C}(33)-\mathrm{Rh}(1)-\mathrm{O}(1)$ & $33.49(9)$ & $\mathrm{C}(9)-\mathrm{C}(8)-\mathrm{C}(7)$ & $120.8(4)$ \\
\hline $\mathrm{C}(45)-\mathrm{Rh}(1)-\mathrm{P}(1)$ & $91.28(9)$ & $C(10)-C(9)-C(8)$ & $120.0(4)$ \\
\hline $\mathrm{C}(34)-\mathrm{Rh}(1)-\mathrm{P}(1)$ & $148.69(8)$ & $\mathrm{C}(9)-\mathrm{C}(10)-\mathrm{C}(11)$ & $120.3(4)$ \\
\hline $\mathrm{C}(35)-\mathrm{Rh}(1)-\mathrm{P}(1)$ & $111.10(8)$ & $C(10)-C(11)-C(12)$ & $119.0(4)$ \\
\hline $\mathrm{C}(33)-\mathrm{Rh}(1)-\mathrm{P}(1)$ & $143.03(8)$ & $\mathrm{C}(7)-\mathrm{C}(12)-\mathrm{C}(11)$ & $121.4(3)$ \\
\hline $\mathrm{O}(1)-\mathrm{Rh}(1)-\mathrm{P}(1)$ & $109.59(6)$ & $\mathrm{C}(14)-\mathrm{C}(13)-\mathrm{P}(1)$ & $112.1(2)$ \\
\hline $\mathrm{C}(45)-\mathrm{Rh}(1)-\mathrm{P}(2)$ & $92.51(9)$ & $\mathrm{C}(13)-\mathrm{C}(14)-\mathrm{P}(2)$ & $108.6(2)$ \\
\hline $\mathrm{C}(34)-\mathrm{Rh}(1)-\mathrm{P}(2)$ & $125.58(8)$ & $C(20)-C(15)-C(16)$ & $118.3(3)$ \\
\hline $\mathrm{C}(35)-\mathrm{Rh}(1)-\mathrm{P}(2)$ & $163.12(8)$ & $\mathrm{C}(20)-\mathrm{C}(15)-\mathrm{P}(2)$ & $118.7(2)$ \\
\hline $\mathrm{C}(33)-\mathrm{Rh}(1)-\mathrm{P}(2)$ & $100.40(8)$ & $\mathrm{C}(16)-\mathrm{C}(15)-\mathrm{P}(2)$ & $123.0(2)$ \\
\hline $\mathrm{O}(1)-\mathrm{Rh}(1)-\mathrm{P}(2)$ & $99.69(6)$ & $C(17)-C(16)-C(15)$ & $121.1(3)$ \\
\hline $\mathrm{P}(1)-\mathrm{Rh}(1)-\mathrm{P}(2)$ & $85.16(3)$ & $C(16)-C(17)-C(18)$ & $119.9(3)$ \\
\hline$C(7)-P(1)-C(1)$ & $102.32(15)$ & $C(17)-C(18)-C(19)$ & $120.0(3)$ \\
\hline $\mathrm{C}(7)-\mathrm{P}(1)-\mathrm{C}(13)$ & $102.59(14)$ & $\mathrm{C}(20)-\mathrm{C}(19)-\mathrm{C}(18)$ & $119.5(4)$ \\
\hline $\mathrm{C}(1)-\mathrm{P}(1)-\mathrm{C}(13)$ & $102.94(14)$ & $C(19)-C(20)-C(15)$ & $121.1(3)$ \\
\hline $\mathrm{C}(7)-\mathrm{P}(1)-\mathrm{Rh}(1)$ & $120.35(10)$ & $C(22)-C(21)-C(26)$ & $118.0(3)$ \\
\hline $\mathrm{C}(1)-\mathrm{P}(1)-\mathrm{Rh}(1)$ & $117.51(11)$ & $\mathrm{C}(22)-\mathrm{C}(21)-\mathrm{P}(2)$ & $122.8(2)$ \\
\hline $\mathrm{C}(13)-\mathrm{P}(1)-\mathrm{Rh}(1)$ & $108.88(10)$ & $\mathrm{C}(26)-\mathrm{C}(21)-\mathrm{P}(2)$ & $119.1(2)$ \\
\hline $\mathrm{C}(21)-\mathrm{P}(2)-\mathrm{C}(15)$ & $105.19(14)$ & $\mathrm{C}(21)-\mathrm{C}(22)-\mathrm{C}(23)$ & $121.1(3)$ \\
\hline $\mathrm{C}(21)-\mathrm{P}(2)-\mathrm{C}(14)$ & $104.05(14)$ & $\mathrm{C}(24)-\mathrm{C}(23)-\mathrm{C}(22)$ & $119.9(3)$ \\
\hline$C(15)-P(2)-C(14)$ & $102.27(14)$ & $C(25)-C(24)-C(23)$ & $119.7(3)$ \\
\hline $\mathrm{C}(21)-\mathrm{P}(2)-\mathrm{Rh}(1)$ & $114.32(10)$ & $C(26)-C(25)-C(24)$ & $120.6(3)$ \\
\hline $\mathrm{C}(15)-\mathrm{P}(2)-\mathrm{Rh}(1)$ & $122.06(10)$ & $C(25)-C(26)-C(21)$ & $120.7(3)$ \\
\hline $\mathrm{C}(14)-\mathrm{P}(2)-\mathrm{Rh}(1)$ & 106.94(10) & $\mathrm{C}(28)-\mathrm{C}(27)-\mathrm{C}(32)$ & $120.7(3)$ \\
\hline $\mathrm{C}(33)-\mathrm{O}(1)-\mathrm{Rh}(1)$ & $71.36(15)$ & $\mathrm{C}(29)-\mathrm{C}(28)-\mathrm{C}(27)$ & $120.8(4)$ \\
\hline$C(6)-C(1)-C(2)$ & 119.3(3) & $\mathrm{C}(28)-\mathrm{C}(29)-\mathrm{C}(30)$ & $119.0(3)$ \\
\hline $\mathrm{C}(6)-\mathrm{C}(1)-\mathrm{P}(1)$ & $121.0(3)$ & $\mathrm{C}(31)-\mathrm{C}(30)-\mathrm{C}(29)$ & $120.6(4)$ \\
\hline $\mathrm{C}(2)-\mathrm{C}(1)-\mathrm{P}(1)$ & $119.7(2)$ & $\mathrm{C}(30)-\mathrm{C}(31)-\mathrm{C}(32)$ & $120.7(4)$ \\
\hline$C(3)-C(2)-C(1)$ & $119.6(3)$ & $\mathrm{C}(27)-\mathrm{C}(32)-\mathrm{C}(31)$ & $118.2(3)$ \\
\hline
\end{tabular}




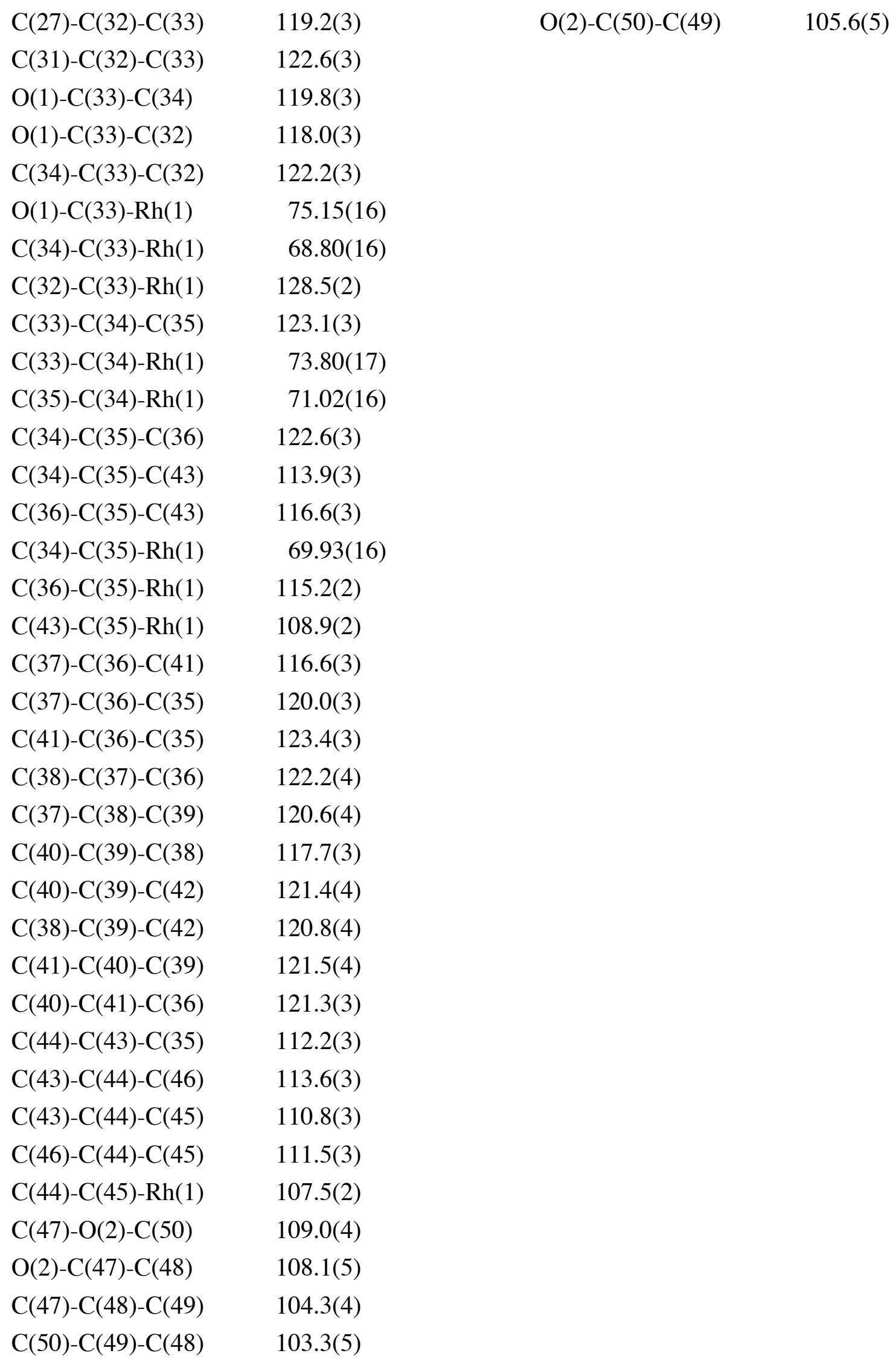


Table S25. Anisotropic displacement parameters $\left(\AA^{2} \times 10^{3}\right)$ for 26. The anisotropic displacement factor exponent takes the form: $-2 \pi^{2}\left[h^{2} a^{* 2} U^{11}+\ldots+2 h k a^{*} b^{*} U^{12}\right]$.

$$
\begin{array}{llllll}
\mathrm{U}^{11} & \mathrm{U}^{22} & \mathrm{U}^{33} & \mathrm{U}^{23} & \mathrm{U}^{13} & \mathrm{U}^{12}
\end{array}
$$

\begin{tabular}{|c|c|c|c|c|c|c|}
\hline $\mathrm{Rh}(1)$ & $24(1)$ & $22(1)$ & $31(1)$ & $0(1)$ & $5(1)$ & 1(1) \\
\hline $\mathrm{P}(1)$ & $24(1)$ & $26(1)$ & $36(1)$ & $-1(1)$ & $7(1)$ & $0(1)$ \\
\hline $\mathrm{P}(2)$ & $26(1)$ & $22(1)$ & $34(1)$ & $1(1)$ & $6(1)$ & $-1(1)$ \\
\hline $\mathrm{C}(1)$ & $30(2)$ & $29(2)$ & $38(2)$ & $-3(1)$ & $7(1)$ & $-5(1)$ \\
\hline $\mathrm{C}(2)$ & $34(2)$ & $31(2)$ & $37(2)$ & $-3(1)$ & $6(1)$ & $-1(1)$ \\
\hline $\mathrm{C}(3)$ & $50(2)$ & $38(2)$ & $38(2)$ & $4(2)$ & $2(2)$ & $-2(2)$ \\
\hline $\mathrm{C}(4)$ & $54(2)$ & $46(2)$ & $35(2)$ & $4(2)$ & $9(2)$ & $-4(2)$ \\
\hline$C(5)$ & $49(2)$ & $50(2)$ & $44(2)$ & $-12(2)$ & $19(2)$ & $-8(2)$ \\
\hline $\mathrm{C}(6)$ & $37(2)$ & $36(2)$ & $46(2)$ & $-1(2)$ & $10(2)$ & 1(2) \\
\hline $\mathrm{C}(7)$ & $25(2)$ & $26(2)$ & $41(2)$ & $-7(1)$ & $10(1)$ & $3(1)$ \\
\hline $\mathrm{C}(8)$ & $35(2)$ & $30(2)$ & $52(2)$ & $-8(2)$ & $12(2)$ & $-3(2)$ \\
\hline $\mathrm{C}(9)$ & $37(2)$ & $45(2)$ & $65(3)$ & $-18(2)$ & $9(2)$ & $-8(2)$ \\
\hline$C(10)$ & $29(2)$ & $63(3)$ & $66(3)$ & $-25(2)$ & $2(2)$ & $-6(2)$ \\
\hline $\mathrm{C}(11)$ & $36(2)$ & $58(3)$ & $50(2)$ & $-9(2)$ & $1(2)$ & $14(2)$ \\
\hline $\mathrm{C}(12)$ & $30(2)$ & $35(2)$ & $46(2)$ & $-2(2)$ & $7(2)$ & $5(2)$ \\
\hline $\mathrm{C}(13)$ & $28(2)$ & $28(2)$ & $43(2)$ & $-4(1)$ & $7(1)$ & $0(1)$ \\
\hline $\mathrm{C}(14)$ & $29(2)$ & $23(2)$ & $45(2)$ & $2(1)$ & $7(1)$ & $3(1)$ \\
\hline$C(15)$ & $26(2)$ & $30(2)$ & $34(2)$ & 1(1) & $3(1)$ & $-3(1)$ \\
\hline$C(16)$ & $42(2)$ & $34(2)$ & $47(2)$ & $5(2)$ & $9(2)$ & 1(2) \\
\hline $\mathrm{C}(17)$ & $57(2)$ & $41(2)$ & $53(2)$ & $16(2)$ & $10(2)$ & $-2(2)$ \\
\hline $\mathrm{C}(18)$ & $65(3)$ & $59(3)$ & $40(2)$ & $14(2)$ & $8(2)$ & $-14(2)$ \\
\hline $\mathrm{C}(19)$ & 73(3) & $50(2)$ & $47(2)$ & $-4(2)$ & $26(2)$ & $-12(2)$ \\
\hline$C(20)$ & $52(2)$ & $36(2)$ & $43(2)$ & $1(2)$ & $17(2)$ & $-1(2)$ \\
\hline $\mathrm{C}(21)$ & $27(2)$ & $24(2)$ & $38(2)$ & $-2(1)$ & $6(1)$ & $2(1)$ \\
\hline$C(22)$ & $32(2)$ & $37(2)$ & $40(2)$ & $4(2)$ & $6(1)$ & $-4(2)$ \\
\hline$C(23)$ & $35(2)$ & $43(2)$ & $50(2)$ & $0(2)$ & $3(2)$ & $-12(2)$ \\
\hline$C(24)$ & $37(2)$ & $56(2)$ & $42(2)$ & $-2(2)$ & $-3(2)$ & $-3(2)$ \\
\hline$C(25)$ & $41(2)$ & $48(2)$ & $32(2)$ & $0(2)$ & $4(2)$ & $-2(2)$ \\
\hline$C(26)$ & $35(2)$ & $31(2)$ & $39(2)$ & $1(2)$ & $7(2)$ & $-2(1)$ \\
\hline $\mathrm{C}(27)$ & $29(2)$ & $38(2)$ & $52(2)$ & $2(2)$ & $7(2)$ & $5(1)$ \\
\hline$C(28)$ & $33(2)$ & $46(2)$ & 77(3) & $-4(2)$ & $4(2)$ & $0(2)$ \\
\hline
\end{tabular}




\begin{tabular}{|c|c|c|c|c|c|c|}
\hline$C(29)$ & $31(2)$ & $54(3)$ & $81(3)$ & $5(2)$ & $20(2)$ & $-3(2)$ \\
\hline$C(30)$ & $40(2)$ & $59(3)$ & $58(2)$ & $9(2)$ & $19(2)$ & $4(2)$ \\
\hline $\mathrm{C}(31)$ & $34(2)$ & $49(2)$ & $41(2)$ & $6(2)$ & $6(2)$ & $1(2)$ \\
\hline$C(32)$ & $25(2)$ & $32(2)$ & $41(2)$ & $5(1)$ & $2(1)$ & $6(1)$ \\
\hline$C(33)$ & $25(2)$ & $24(2)$ & $38(2)$ & $4(1)$ & $4(1)$ & $6(1)$ \\
\hline$C(34)$ & $31(2)$ & $24(2)$ & $36(2)$ & $0(1)$ & $7(1)$ & $9(1)$ \\
\hline$C(35)$ & $33(2)$ & $19(2)$ & $41(2)$ & $-5(1)$ & $3(1)$ & $2(1)$ \\
\hline$C(36)$ & $37(2)$ & $20(2)$ & $42(2)$ & $-6(1)$ & $7(2)$ & $2(1)$ \\
\hline$C(37)$ & $39(2)$ & $22(2)$ & $57(2)$ & $-2(2)$ & $9(2)$ & $-1(1)$ \\
\hline $\mathrm{C}(38)$ & $62(3)$ & $31(2)$ & $58(2)$ & $-9(2)$ & $27(2)$ & $-8(2)$ \\
\hline$C(39)$ & $85(3)$ & $25(2)$ & $41(2)$ & $-6(2)$ & $15(2)$ & $-10(2)$ \\
\hline $\mathrm{C}(40)$ & $65(3)$ & $26(2)$ & $42(2)$ & $-1(2)$ & $-6(2)$ & $1(2)$ \\
\hline $\mathrm{C}(41)$ & $41(2)$ & $24(2)$ & $48(2)$ & $-3(2)$ & $3(2)$ & $2(1)$ \\
\hline $\mathrm{C}(42)$ & $138(5)$ & $54(3)$ & $43(3)$ & $-5(2)$ & $24(3)$ & $-19(3)$ \\
\hline$C(43)$ & $38(2)$ & $28(2)$ & $41(2)$ & $-7(1)$ & $-3(2)$ & $-2(1)$ \\
\hline $\mathrm{C}(44)$ & $46(2)$ & $41(2)$ & $49(2)$ & $-5(2)$ & $-4(2)$ & $-1(2)$ \\
\hline$C(45)$ & $29(2)$ & $33(2)$ & $32(2)$ & $3(1)$ & $3(1)$ & $1(1)$ \\
\hline$C(46)$ & $43(2)$ & $44(2)$ & $40(2)$ & $-4(2)$ & $-3(2)$ & $2(2)$ \\
\hline $\mathrm{O}(2)$ & $72(2)$ & $124(3)$ & $70(2)$ & $29(2)$ & $8(2)$ & $-18(2)$ \\
\hline$C(47)$ & $92(4)$ & $93(4)$ & $73(3)$ & $1(3)$ & $17(3)$ & $-14(3)$ \\
\hline $\mathrm{C}(48)$ & $98(4)$ & $85(4)$ & $87(4)$ & $-14(3)$ & $33(3)$ & $-30(3)$ \\
\hline$C(49)$ & $115(5)$ & $98(5)$ & $105(5)$ & $18(4)$ & $37(4)$ & $-11(4)$ \\
\hline$C(50)$ & $73(4)$ & $141(6)$ & $81(4)$ & $22(4)$ & $-4(3)$ & $-18(4)$ \\
\hline
\end{tabular}


Table S26. Hydrogen coordinates $\left(\mathrm{x} 10^{4}\right)$ and isotropic displacement parameters $\left(\AA^{2} \times 10^{3}\right)$ for 26.

$\begin{array}{lrrrr} & \mathrm{x} & \mathrm{y} & \mathrm{z} & \mathrm{U}(\mathrm{eq}) \\ \mathrm{H}(2 \mathrm{~A}) & & & & \\ \mathrm{H}(3 \mathrm{~A}) & 2719 & 5994 & 1709 & 40 \\ \mathrm{H}(4 \mathrm{~A}) & 2726 & 5213 & 2256 & 51 \\ \mathrm{H}(5 \mathrm{~A}) & 1978 & 6004 & 2593 & 53 \\ \mathrm{H}(6 \mathrm{~A}) & 1225 & 7573 & 2388 & 56 \\ \mathrm{H}(8 \mathrm{~A}) & 1199 & 8344 & 1840 & 47 \\ \mathrm{H}(9 \mathrm{~A}) & 962 & 5916 & 1396 & 46 \\ \mathrm{H}(10 \mathrm{~A}) & -71 & 5423 & 1144 & 59 \\ \mathrm{H}(11 \mathrm{~A}) & -556 & 6733 & 708 & 64 \\ \mathrm{H}(12 \mathrm{~A}) & -27 & 8609 & 538 & 58 \\ \mathrm{H}(13 \mathrm{~A}) & 1009 & 9110 & 797 & 44 \\ \mathrm{H}(13 \mathrm{~B}) & 1542 & 9995 & 1336 & 40 \\ \mathrm{H}(14 \mathrm{~A}) & 2235 & 9856 & 1551 & 40 \\ \mathrm{H}(14 \mathrm{~B}) & 2413 & 11215 & 1113 & 39 \\ \mathrm{H}(16 \mathrm{~A}) & 1986 & 10307 & 844 & 39 \\ \mathrm{H}(17 \mathrm{~A}) & 2943 & 11995 & 679 & 49 \\ \mathrm{H}(18 \mathrm{~A}) & 3245 & 12912 & 194 & 60 \\ \mathrm{H}(19 \mathrm{~A}) & 3751 & 11606 & -175 & 65 \\ \mathrm{H}(20 \mathrm{~A}) & 3969 & 9380 & -50 & 66 \\ \mathrm{H}(22 \mathrm{~A}) & 3645 & 8457 & 433 & 51 \\ \mathrm{H}(23 \mathrm{~A}) & 4126 & 11141 & 1069 & 43 \\ \mathrm{H}(24 \mathrm{~A}) & 4917 & 11650 & 1510 & 51 \\ \mathrm{H}(25 \mathrm{~A}) & 4874 & 10718 & 2040 & 55 \\ \mathrm{H}(26 \mathrm{~A}) & 4072 & 9201 & 2118 & 49 \\ \mathrm{H}(27 \mathrm{~A}) & 3293 & 8654 & 1679 & 42 \\ \mathrm{H}(28 \mathrm{~A}) & 4564 & 7749 & 1407 & 47 \\ \mathrm{H}(29 \mathrm{~A}) & 5546 & 8603 & 1294 & 62 \\ \mathrm{H}(30 \mathrm{~A}) & 5928 & 8175 & 784 & 65 \\ \mathrm{H}(31 \mathrm{~A}) & 5318 & 6845 & 386 & 61 \\ \mathrm{H}(34 \mathrm{~A}) & 4335 & 5994 & 494 & 49 \\ \mathrm{H}(37 \mathrm{~A}) & 3378 & 5533 & 574 & 36 \\ & 1627 & 4184 & 1128 & 47\end{array}$




$\begin{array}{lrrrr}\mathrm{H}(38 \mathrm{~A}) & 1481 & 2942 & 1598 & 58 \\ \mathrm{H}(40 \mathrm{~A}) & 3406 & 2506 & 1798 & 55 \\ \mathrm{H}(41 \mathrm{~A}) & 3551 & 3755 & 1330 & 45 \\ \mathrm{H}(42 \mathrm{~A}) & 1875 & 1760 & 2086 & 116 \\ \mathrm{H}(42 \mathrm{~B}) & 2556 & 2274 & 2264 & 116 \\ \mathrm{H}(42 \mathrm{C}) & 2517 & 940 & 2047 & 116 \\ \mathrm{H}(43 \mathrm{~A}) & 2420 & 4606 & 380 & 44 \\ \mathrm{H}(43 \mathrm{~B}) & 1917 & 4016 & 611 & 44 \\ \mathrm{H}(44 \mathrm{~A}) & 1444 & 5991 & 665 & 55 \\ \mathrm{H}(45 \mathrm{~A}) & 1853 & 8037 & 546 & 37 \\ \mathrm{H}(45 \mathrm{~B}) & 2405 & 7392 & 353 & 37 \\ \mathrm{H}(46 \mathrm{~A}) & 1119 & 5083 & 132 & 65 \\ \mathrm{H}(46 \mathrm{~B}) & 1651 & 5953 & -22 & 65 \\ \mathrm{H}(46 \mathrm{C}) & 1063 & 6663 & 126 & 65 \\ \mathrm{H}(47 \mathrm{~A}) & 246 & 2476 & 2097 & 102 \\ \mathrm{H}(47 \mathrm{~B}) & 629 & 3299 & 2400 & 102 \\ \mathrm{H}(48 \mathrm{~A}) & 320 & 4111 & 1746 & 106 \\ \mathrm{H}(48 \mathrm{~B}) & 806 & 4817 & 2034 & 106 \\ \mathrm{H}(49 \mathrm{~A}) & 29 & 6108 & 2198 & 125 \\ \mathrm{H}(49 B) & -309 & 5857 & 1820 & 125 \\ \mathrm{H}(50 \mathrm{~A}) & -888 & 5148 & 2313 & 119 \\ \mathrm{H}(50 \mathrm{~B}) & -949 & 4254 & 1979 & 119 \\ & & & & \end{array}$

